ROGER DAVID CASTILLO ARTEAGA

\title{
CARACTERIZAÇÃO DOS MECANISMOS DE RESISTÊNCIA AO ANTIBIÓTICO ANTITUMORAL COSMOMICINA D
}

Dissertação apresentada ao Programa de Pós-Graduação em Microbiologia do Instituto de Ciências Biomédicas da Universidade de São Paulo, para a obtenção do título de Mestre em Ciências.

São Paulo

2015 
ROGER DAVID CASTILLO ARTEAGA

\section{CARACTERIZAÇÃO DOS MECANISMOS DE RESISTÊNCIA AO ANTIBIÓTICO ANTITUMORAL COSMOMICINA D}

Dissertação apresentada ao Programa de PósGraduação em Microbiologia do Instituto de Ciências Biomédicas da Universidade de São Paulo, para a obtenção do título de Mestre em Ciências.

Área de concentração: Microbiologia

Orientador: Prof. Dr. Gabriel Padilla Maldonado

Versão corrigida. A versão original eletrônica encontra-se disponível tanto na biblioteca do ICB quanto na Biblioteca Digital de Teses e Dissertações da USP (BDTD)

São Paulo

2015 
DADOS DE CATALOGAÇÃO NA PUBLICAÇÃO (CIP)

Serviço de Biblioteca e Informação Biomédica do

Instituto de Ciências Biomédicas da Universidade de São Paulo

reprodução não autorizada pelo autor

Arteaga, Roger David Castillo.

Caracterização dos mecanismos de resistência ao antibiótico antitumoral cosmomicina D / Roger David Castillo Arteaga. -- São Paulo, 2015.

Orientador: Prof. Dr. Gabriel Padilla Maldonado.

Dissertação (Mestrado) - Universidade de São Paulo. Instituto de Ciências Biomédicas. Departamento de Microbiologia. Área de concentração: Microbiologia. Linha de pesquisa: Genética de microrganismos.

Versão do título para o inglês: Characterization of self-resistance mechanisms to the antitumoral cosmomycin $D$.

$\begin{array}{llll}\text { 1. Streptomyces } & \text { 2. Resistência } & \text { 3. Cosmomicina D 4. Doxorubicina }\end{array}$ 5. Clonagem 6. Expressão heteróloga I. Maldonado, Prof. Dr.

Gabriel Padilla II. Universidade de São Paulo. Instituto de Ciências Biomédicas. Programa de Pós-Graduação em Microbiologia III. Título. 
Candidato(a):

Título da Dissertação:

Orientador(a):
Roger David Castillo Arteaga.

Caracterização dos mecanismos de resistência ao antibiótico antitumoral cosmomicina D.

A Comissão Julgadora dos trabalhos de Defesa da Dissertação de Mestrado, em sessão pública realizada a considerou

\section{( ) Aprovado(a)}

( ) Reprovado(a)

Examinador(a): Assinatura:

Nome:

Instituição:

Examinador(a): Assinatura:

Nome:

Instituição:

Presidente: Assinatura:

Nome:

Instituição: 


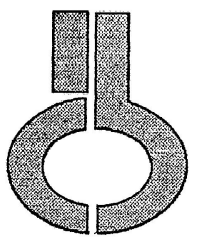
INSTITUTO DE CIÊNCIAS BIOMÉDICAS

Cidade Universitária "Armando de Salles Oliveira"

Av. Prof. Lineu Prestes, 2415 - CEP. 05508-000 São Paulo, SP - Brasil

Telefone :(55) (11) 3091-7733 - telefax : (55) (11) $3091-8405$

e-mail: cep@icb.usp.br

\section{CERTIFICADO DE ISENÇÃO}

Certificamos que o Protocolo CEP-ICB N 642/14 referente ao projeto intitulado: "Caracterização dos genes de resistência ao antibiótico antitumoral cosmomicina D" sob a responsabilidade de Roger David Castillo Arteaga, foi analisado na presente data pela CEUA - COMISSÃO DE ÉTICA NO USO DE ANIMAIS e pela CEPSH- COMISSÃo DE ÉTICA EM PESQUiSA COM SERES HUMANOS, tendo sido deliberado que o referido projeto não utilizará animais que estejam sob a égide da lei 11.794 de 8 de outubro de 2008, nem envolverá procedimentos regulados pela Resolução CONEP nº 466 de 2012.

São Paulo, 26 de fevereiro de 2014.

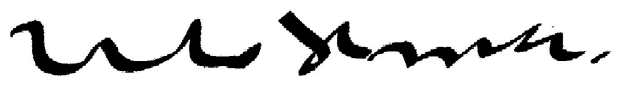

PROF. DR. WOTHAN TAVARES DE LIMA Coordenador da CEUA - ICB/USP

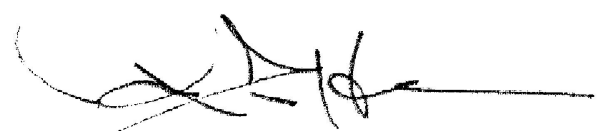

Prof. Dr. PaOlo M.A ZanotTo Coordenador da CEPsh - ICB/USP

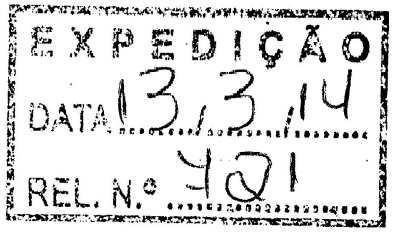


Dedicado a:

mis Padres y mi hermanita Adalberto, Aura y Anabel

Mi gratitud es tan absoluta que las palabras sobran 


\section{AGRADECIMIENTOS}

Quiero agradecer a todas las personas que de alguna forma me permitieron crecer profesionalmente y como persona.

A quien mantiene en mi la confianza, la esperanza, la calma, y la fuerza necesaria para continuar mi camino.

A la familia Castillo y la familia Arteaga, que con su apoyo incondicional, me impulsaron a alcanzar mis objetivos.

Al Prof. Dr. Gabriel Padilla Maldonado, por su amistad, innumerables orientaciones, recomendaciones, motivación y por brindarme un lugar en el laboratorio de bioprodutos.

Al Dr. Leandro Maza Garrido por su tiempo y consejos que permitieron guiar de la mejor forma este proyecto.

Al Prof. Dr. Welington Luiz de Araújo y a la Dra. Manuella Nóbrega Dourado por ser una parte fundamental en el trabajo conjunto con el laboratorio 136 LABMEN.

Al Prof. Dr. Rui Curi y el Dr. Gilson Murata por la asistencia en la parte de proteínas y actividad enzimática.

A la agencia de fomento CAPES, CNPq, y al Instituto de Ciências Biomédicas da Universidade de São Paulo, por la asistencia durante el desarrollo de las actividades realizadas y por brindarme un espacio para la investigación.

A mis compañeros y amigos de los laboratorios 164, 136 e ICB II: Fernanda, Aline, Simone, Mariana, Renata, Mapa, Ruth, Aleja, Mauricio, Leandro, Manu, Eliane, Daiene, Lina, Jennifer, Nadia, Priscila, Roberta, Almir, Felipe, Mabel, Emy, Raíssa, Nicolas, Gerardo, Mireia, Ciça, Tais, Enyd y todos sus integrantes por la colaboración y disposición para ayudar.

A mi familia en SP "el combo alpinito" María Paula, Ruth, Alejandra, Lizeth, Maira, Juan C, y León por compartir una gran amistad, buenos momentos, aventuras, por crecer y aprender juntos.

A Lina, Cata, Yasmin, Marcela Pérez, Diana T, Jennifer, Esteban, Camilo, Danny, Santiago, Juan CM, Dra. Mariela Burbano y a mis amigos de todos los puntos cardinales. 
"The only symbol of superiority that $\mathcal{I}$ know is goodness."

Ludwig van Beethoven

"Um dia de cada vez, que é pra não perder as boas surpresas da vida" Clarice Lispector

"La creación intelectual es el más misterioso y solitario de los oficios humanos".

Gabriel García Márquez 


\section{RESUMO}

ARTEAGA R. D. C. Caracterização dos mecanismos de resistência ao antibiótico antitumoral cosmomicina D. 2015. 116 f. Dissertação (Mestrado em Microbiologia) Instituto de Ciências Biomédicas, Universidade de São Paulo, São Paulo, 2015.

O gênero Streptomyces tem sido estudado nas últimas décadas, pela sua capacidade de produzir vários produtos naturais bioativos. Os microrganismos produtores de antibióticos exigem um ou mais mecanismos de resistência durante a produção desses antibióticos. Os efetores desses mecanismos são proteínas que inativam o antibiótico, facilitam a sua exportação, ou modificam o alvo de ação para torná-lo insensível à molécula. Streptomyces olindensis DAUFPE 5622 produz o antitumoral cosmomicina D que faz parte da família das antraciclinas. Alguns estudos da molécula incluem a produção, toxicidade, análise estrutural, propriedades químicas, interação DNAantraciclina, e biossíntese. Neste estudo, apresenta-se um modelo de resistência que é expresso conjuntamente com a biossíntese do antibiótico. Os três mecanismos incluem uma bomba de efluxo dependente de ATP, um mecanismo enzimático envolvido na resposta a espécies reativas de oxigênio (ROS), e um mecanismo de resistência envolvido no reparo do DNA, pela ação da proteína homóloga UvrA. Os genes de resistência de $S$. olindensis foram clonados e expressos em Streptomyces albus hospedeiro naturalmente sensível às antraciclinas, contendo o plasmídeo de expressão PEM4A com o promotor constitutivo ermE* $\mathrm{p}$. Avaliou-se a capacidade de resistência à diferentes concentrações das antraciclinas cosmomicina $D$ e doxorubicina. A expressão de cada um dos mecanismos de resistência incrementou a resposta às antraciclinas. Finalmente, foram discutidas as diferentes estratégias de resistência para este antibiótico em Streptomyces olindensis. A introdução de genes de resistência ou sobreexpressão dos mesmos pode agir positivamente na produção de antibióticos em futuros estudos de clusters sintéticos contendo sistemas de desintoxicação mais eficientes. Além disso, estes mecanismos ajudam na compreensão da resistência aos medicamentos em bactérias patogênicas.

Palavras-chave: Streptomyces. Resistência. Cosmomicina D. Doxorubicina. Clonagem. Expressão heteróloga. 


\begin{abstract}
ARTEAGA R. D. C. Characterization of self-resistance mechanisms to the antitumoral cosmomycin D. 2015. 116 p. Master thesis (Microbiology) - Instituto de Ciências Biomédicas, Universidade de São Paulo, São Paulo, 2015.
\end{abstract}

Streptomyces produce various bioactive natural products and possess resistance systems for these metabolites, which are co-regulated with antibiotic biosynthesis genes. Antibiotic producer microorganisms require one or more self-resistance determinants to survival during antibiotic production. The effectors of these mechanisms are proteins that inactivate the antibiotic, facilitate its export, or modify the host to render it insensitive to the molecule. Streptomyces olindensis DAUFPE 5622 produces the antitumoral Cosmomycin D part of the anthracycline family, widely studied such as production, toxicity, structural analysis, chemical proprieties, interaction DNAanthracycline, biosynthesis and genome sequencing. In this study we show resistance genes in Cosmomycin D biosynthetic cluster provide self-resistance, including an ATPdependent efflux pump for transporting drug, resistance to DNA damage through UvrA class lla protein, and response to reactive oxygen species (ROS) by the enzyme Glutathione peroxidase. We cloned and expressed the resistance genes from Streptomyces olindensis in Streptomyces albus anthracycline sensitive host, containing expression plasmid PEM4A with constitutive promoter ermE* ${ }^{*}$. We evaluated the capacity of resistance with different concentrations of anthracyclines Cosmomycin D and commercial Doxorubicin widely used for the treatment of human cancers. The expression of each resistance components increment the response to anthracyclines. Finally, we could be assisted and discuss different active self-resistance strategies for this drugs in Streptomyces olindensis. Indeed, introduction of multicopies of resistance genes probably act positively into the production of antibiotics containing efficient efflux pumps and detoxification systems for secondary metabolites. In addition helps to understand future strategies to drug resistance in pathogenic bacteria.

Keywords: Streptomyces. Self-resistance. Cosmomycin D. Doxorubicin. Cloning. Expression host. 


\section{LISTA DE ILUSTRAÇÕES}

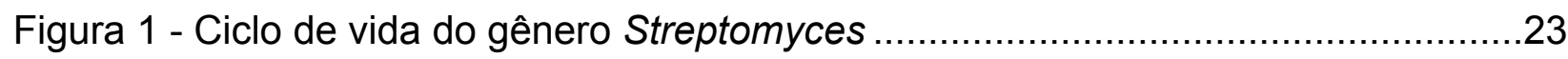

Figura 2 - Exemplos de policetídeos com atividade biológica.....................................25

Figura 3 - Mecanismo de base envolvido na síntese de a) ácidos graxos b) policetídeos

Figura 4 - Exemplo da biossíntese da Doxorubicina (PKS II) …...............................28

Figura 5 - Estrutura química da Doxorubicina (DOX) e Daunorubicina (DNR) ...............29

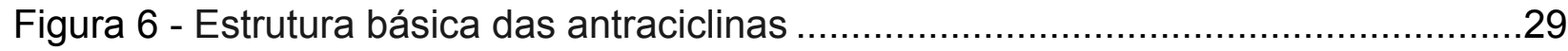

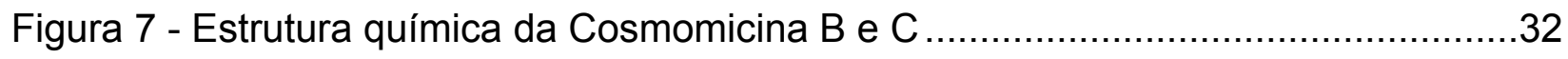

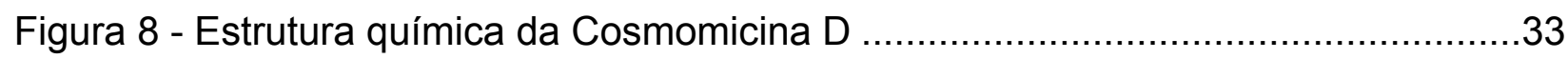

Figura 9 - Organização gênica do cluster da Cosmomicina D....................................34

Figura 10 - Esquema da organização estrutural dos componentes formadores de um

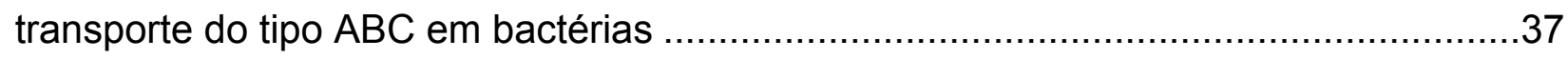

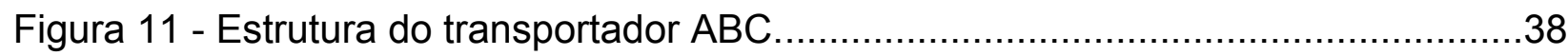

Figura 12 - Dímero sanduiche de ligação ao ATP (NBD) ……....................................39

Figura 13 - Estrutura e organização dos diferentes tipos de transportadores $A B C$ em

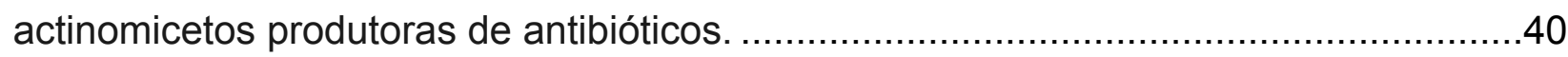

Figura 14 - Efluxo da doxorrubicina (DOX) e daunorubicina (DNR) com ação do transportador abc codificado pelos genes (drra e drrb). .............................................

Figura 15 - Modelo para a topologia da proteína Drrb na membrana de S. peucetius. ..43

Figura 16 - Classificação de proteínas homólogas às UvrA ......................................47

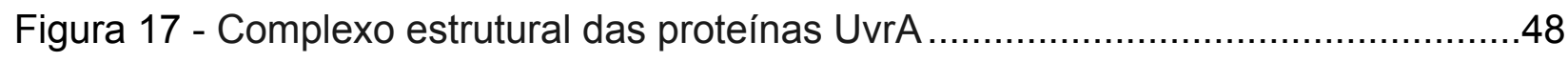

Figura 18 - Estrutura da PTM e PTN e ciclo das FAS...................................................50

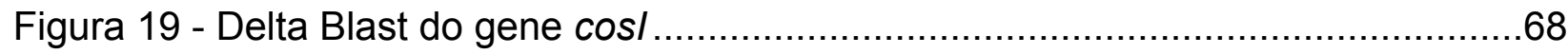

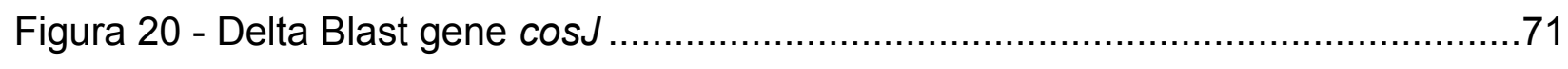

Figura 21 - Distribuição das hélices transmembranares ............................................72

Figura 22 - Probabilidade de hélices transmembranares...........................................72

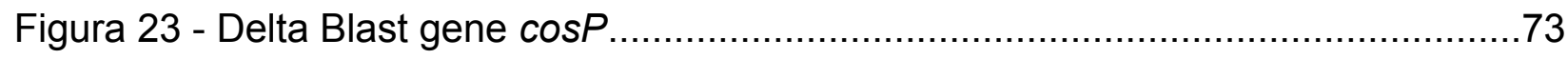

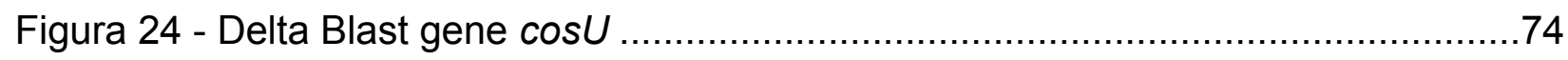

Figura 25 - Mapa físico dos genes de resistência e posição dos iniciadores desenhados 
Figura 26 - Amplificação por PCR dos genes $\cos / J, \cos P, \cos U, \cos I J P U$ .75

Figura 27 - Mapa físico do plasmídeo PEM4A utilizado para realizar as construções contendo os genes de resistência. .76

Figura 28 - Restrição dos plasmídeos recombinantes PRD8001,8002, 8003, 8004

(Hindlll e Ecorl).

Figura 29 - Concentração mínima inibitória de doxorubicina em Streptomyces albus

selvagem (WT) 79

Figura 30 - PCR quantitativa- real time dos genes cosJ, cosP e cosU.

Figura 31 - Peroxidação lipídica (a e b) e quantificação de $\mathrm{H}_{2} \mathrm{O}_{2}$ (c e d). .83

Figura 32 - RNA total extraído apos $48 \mathrm{~h}$ de crescimento das linhagens $S$. olindensis wt e S. olindensis $\triangle \mathrm{PKS}$ (antes do tratamento com DNase). .87

Figura 33 - Eletroforese RT-PCR .88

Figura 34 - PCR quantitativa- real time dos genes cosJ, $\cos \mathrm{P}$ e $\cos \mathrm{U}$ durante a produção e não produção do antibiótico na linhagem selvagem S. olindensis .88

Figura 35 - Western blot e quantificação da enzima glutationa peroxidase com o anticorpo GPx1 na linhagem recombinante $S$. albus 8000 e 8002 .90

Figura 36 - Atividade da enzima glutationa peroxidase .92

Figura 37 - Geração de espécies reativas de oxigênio (ROS), por antraciclinas. .96

Figura 38 - Modelo proposto para resistência (self-resistance) à cosmomicina D em Streptomyces olindensis 102 


\section{LISTA DE TABELAS}

Tabela 1 - Características dos transportadores ABC de actinomicetos produtores de antibióticos 41

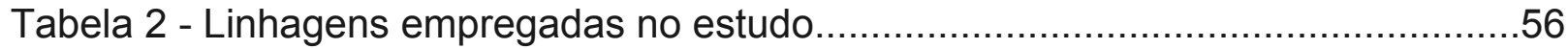

Tabela 3 - Plasmídeos e construções utilizadas neste trabalho.................................57

Tabela 4 - Primers usados para amplificar por PCR e qPCR .........................57

Tabela 5 - Condições de amplificação por PCR .......................................57

Tabela 6 - Predição da função dos genes de resistência...........................................68

Tabela 7 - Concentração mínima inibitória (MIC). Susceptibilidade à doxorubicina e

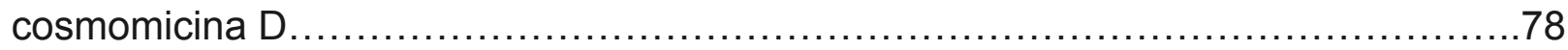




\section{LISTA DE ABREVIATURAS}

aa

Aminoácido

ACP Proteína transportadora de grupos acilo

ARO Aromatase

AT Aciltransferase

ATP Adenosina 5' -trifosfato

CoA Coenzima A

DNA Ácido desoxirribonucleico

$\mathrm{DH} \quad$ Desidratase

DMSO Dimetil-sulfóxido

DOX Doxorubicina

DNR Daunorubicina

EDTA Ácido etilendiamino tetracético

EGTA Ácido Etileno glicol tetracético

FAS Sintase de ácidos graxos

GPx Glutationa peroxidase

IPTG Isopropil tio $\beta$-D-galactosídeo

kB Kilobase

kDa Kilodalton

KR $\quad$ Cetoredutase 


\begin{tabular}{|c|c|}
\hline KS & Cetosintase \\
\hline $\mathrm{Mb}$ & Megabase \\
\hline $\mathrm{mM}$ & Milimolar \\
\hline MDA & Malondialdeído \\
\hline $\mathrm{nm}$ & Nanômetros \\
\hline NBD & Domínio de ligação a nucleotídeo \\
\hline NP40 & Nonil fenoxi polietoxi etanol \\
\hline $\mathrm{pb}$ & Pares de bases \\
\hline PBS & solução salina tamponada com fosfato \\
\hline PCR & Reação em cadeia da polimerase \\
\hline qPCR & Reação quantitativa em cadeia da polimerase \\
\hline PKS & Policetídeo sintase \\
\hline rpm & Revoluções por minuto \\
\hline ROS & Espécies reativas do oxigênio \\
\hline RNA & Ácido ribonucleico \\
\hline RT & Retrotranscriptase \\
\hline SDS & Dodecil sulfato de sódio \\
\hline SDS-PAGE & SDS-Eletroforese gel de poliacrilamida \\
\hline TAE & Tris-acetato-EDTA \\
\hline TBA & Ácido tiobarbitúrico \\
\hline
\end{tabular}


TBS Solução salina tamponada com Tris

TBST Solução salina tamponada com Tris acrescida de Tween 20

TMD Domínio transmembranar

TE Tioesterase

TRIS Tris-2-amino-2 (hidroximetil)-1,3-propanodiol

UV Luz ultravioleta

X-Gal 5-bromo-4-cloro-3-indolil-ß-D-galactopiranosídeo 


\section{SUMARIO}

1 INTRODUÇÃO

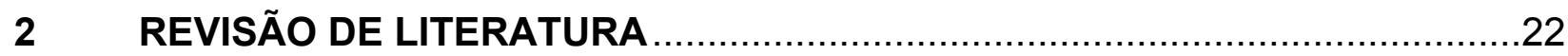

2.1 Características gerais do gênero Streptomyces spp................................23

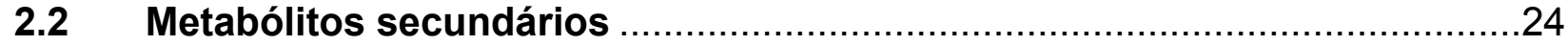

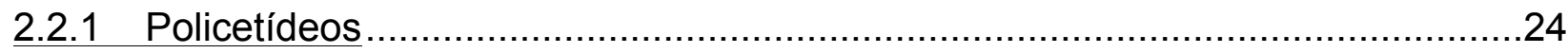

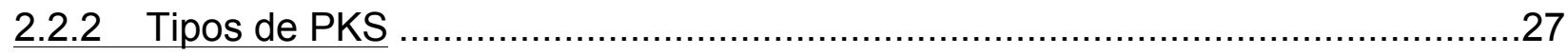

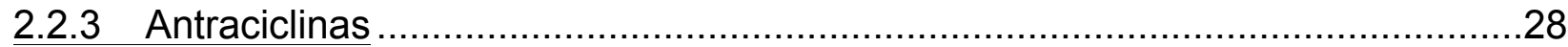

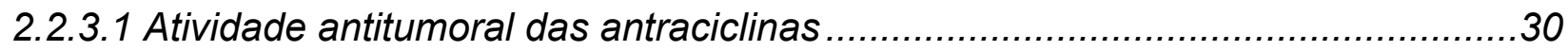

2.2.3.2 Principal mecanismo de ação das antraciclinas..............................................30

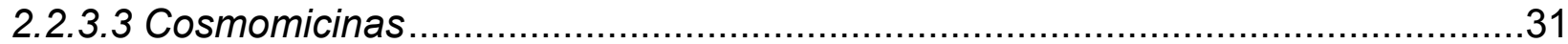

2.3 Mecanismos de resistência a antibióticos (Self-resistance) ..........................35

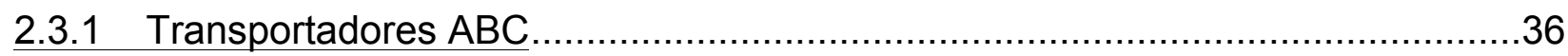

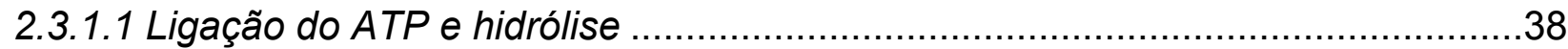

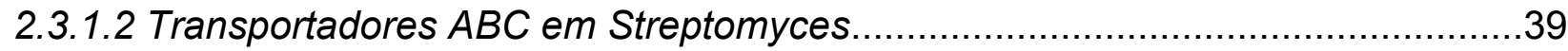

2.3.2 Mecanismos de resistência associados à interação com DNA ............................44

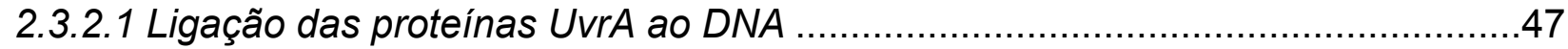

2.3.2.2 Proteínas UvrA homólogas em Streptomyces ...............................................

2.3.3 Outros mecanismos de resistência no gênero Streptomyces ..............................49

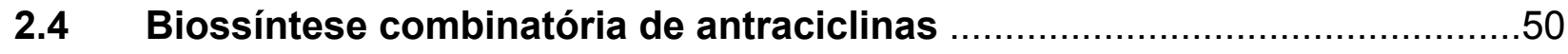

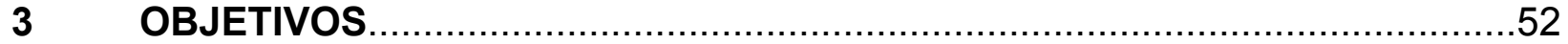

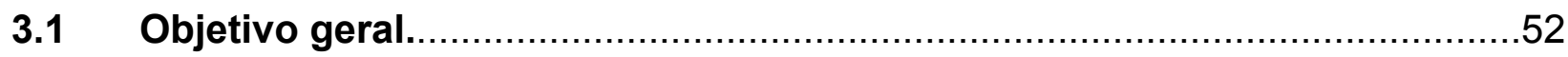

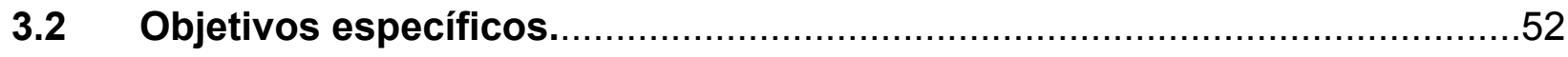

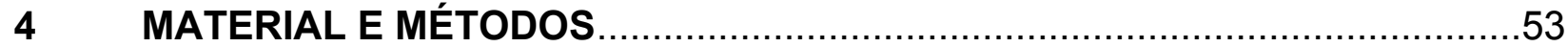

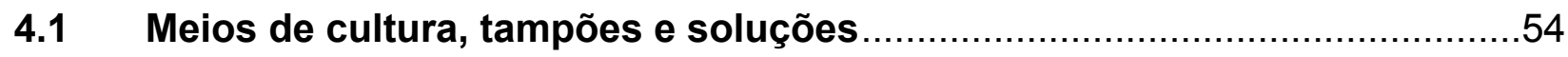

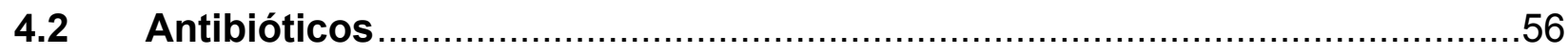

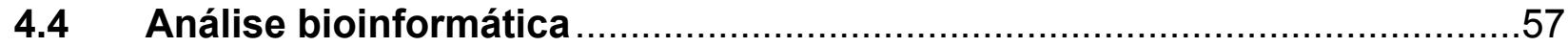

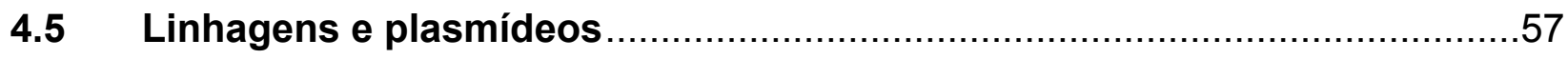

4.6 Condições de cultivo e preservação de linhagens …................................59

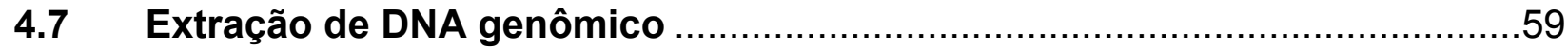

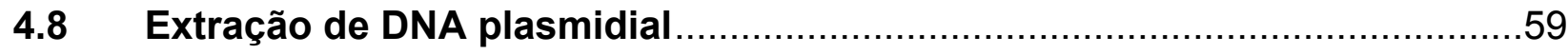




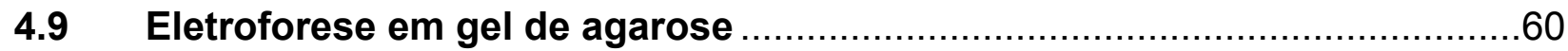

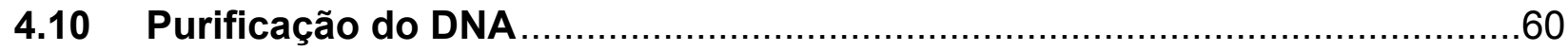

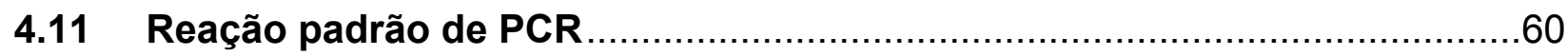

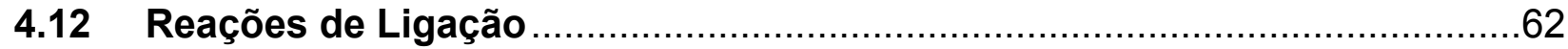

4.13 Preparação e transformação de células eletrocompetentes .......................62

4.14 Preparação e transformação de protoplastos de Streptomyces ..................62

4.15 Replicação das construções em Streptomyces ..........................................63

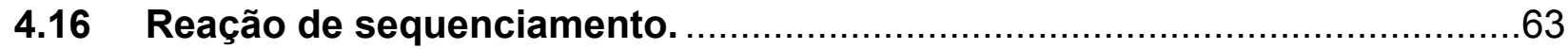

4.17 Teste de atividade de resistência em $S$. albus transformantes $\cos / J$, $\cos P$,

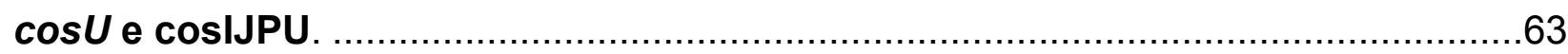

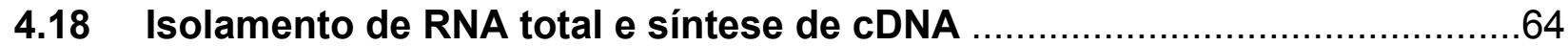

4.19 Análise de qPCR

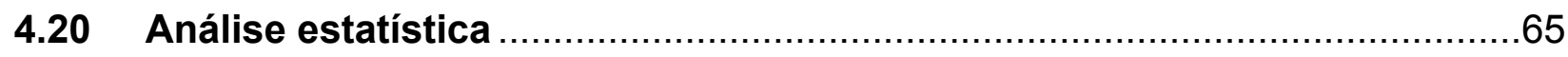

4.21 Peroxidação lipídica e quantificação de peróxido de hidrogênio .................65

4.23 Atividade enzimática da Glutationa Peroxidase GPx ...............................66

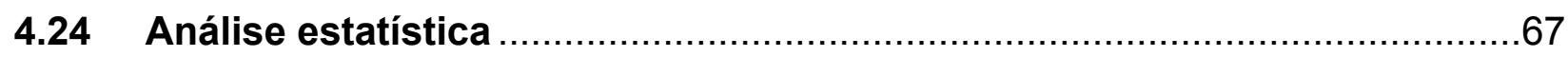

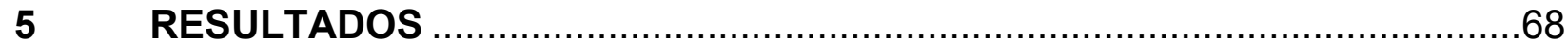

5.1 Analise bioinformática e predição da função dos genes de resistência .....68

5.1.1 Mecanismo de efluxo codificado pelos genes cosl e cosJ................................69

5.1.2 Novo mecanismo hipotético com função peroxidase codificado pelo gene cos $P$ 73

5.1.3 Mecanismo de reparo de DNA pela proteína do tipo UvrA like codificada pelo gene $\cos U$.

5.2 Amplificação e clonagem dos genes $\cos I J, \cos P, \cos U$ e $\cos I J P U$ no vetor PEM4A.

5.3 Análise de resistência em transformantes de $S$. albus $(\cos I J, \cos P, \cos U$, cos(JPU)

5.4 Níveis de expressão dos genes de resistência em S. albus $8001,8002,8003,8004$ por qPCR.

5.5 Resposta da enzima Glutationa peroxidase à peroxidação lipídica causada por estresse com cosmomicina $D$. 
5.6 Níveis de expressão dos genes de resistência por RT-PCR e qPCR em S.

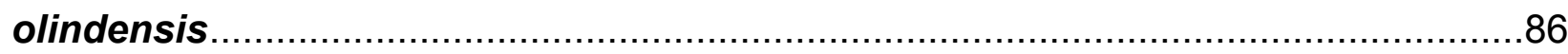

5.7 Western Blotting da linhagem recombinante S. albus $8002 \ldots \ldots \ldots \ldots \ldots \ldots \ldots . . .90$

5.8 Atividade enzimática da Glutationa peroxidase como resposta ao estresse por Doxorubicina e Cosmomicina D..................................................................

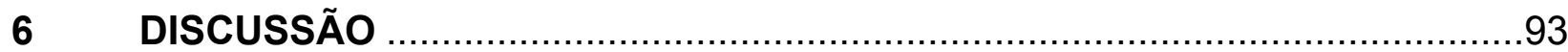

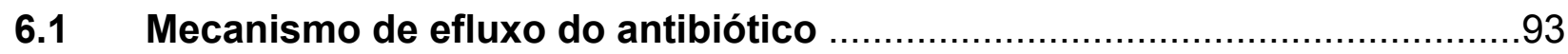

6.2 Mecanismo de detoxificação de espécies reativas de oxigênio (ROS)

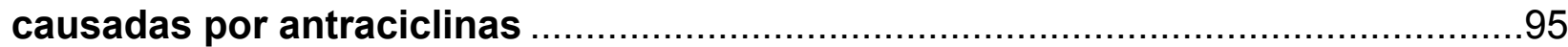

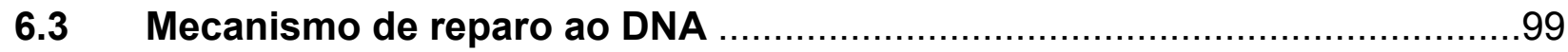

7 CONCLUSÃO

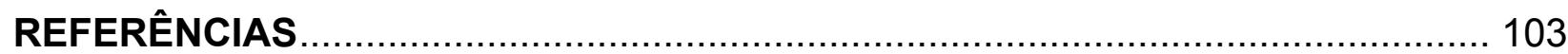
ANEXO

A - Mapa Físico das construções geradas a partir do plasmídeo PEM4A contendo os genes de resistência 


\section{INTRODUÇÃO}

A produção e pesquisa de novos medicamentos têm sido extensivamente exploradas nos microrganismos de solo, tais como os actinomicetos. Uma das características neste grupo é a diversidade do metabolismo secundário, que permite o estudo de valiosas moléculas bioativas com potencial antibiótico, antifúngico, antitumoral e imunossupressor. Entre as biomoléculas utilizadas na indústria farmacêutica produzidas por actinobactérias, destacam-se as cefalosporinas, tetraciclinas, rifamicinas, eritromicinas, diferentes $\beta$ lactâmicos e antraciclinas (GILLESPIE et al., 2002; HOPWOOD, 2004).

As antraciclinas são um grupo de produtos naturais que fazem parte da família dos policétideos tipo II. A estrutura base contém um esqueleto aglicônico e desoxihexoses derivadas biossintéticamente da glucose-1-fosfato (Figura 6). As primeiras antraciclinas foram isoladas do pigmento produzido por Streptomyces peucetius e são quimicamente conhecidas como doxorrubicina (DXR) e daunorubicina (DNR). Estas moléculas são clinicamente utilizadas no tratamento de diversos tipos de câncer, como o câncer de mama, linfomas, leucemias agudas, neuroblastomas, e sarcomas (BINASCHI et al., 2001; LORUSSO; MANZIONE; SILVESTRIS, 2007; MINOTTI et al., 2004).

Os microrganismos produtores de moléculas bioativas apresentam diferentes estratégias para se proteger do efeito letal do seu próprio produto. Esta capacidade inerente é chamada de auto-resistência (self-resistance). O conhecimento destes mecanismos é muito importante e significativo no desenvolvimento de medicamentos terapêuticos para doenças infecciosas, permitindo gerar estratégias contra bactérias patogénicas que adquiriram diferentes genes tornado as resistentes (HOPWOOD, 2007; SUGIYAMA, 2015). Outra vantagem de conhecer estes mecanismos é a possibilidade de melhorar a produção de biomoléculas já conhecidas por meio da sobre-expressão e inclusão de novos mecanismos de resistência nos clusters biossintéticos. 
A expressão dos genes de resistência é regulada pelo sistema de transcrição do cluster de biossíntese. Para que os genes possam atuar de forma eficaz, deve ocorrer a proteção do alvo onde age o antibiótico, como por exemplo, proteção por modificação enzimática, reparo do DNA, resposta a espécies reativas de oxigênio (ROS) ou sistemas de efluxo do antibiótico (LOMOVSKAYA et al., 1996; SUGIYAMA; NIMI, 1990; SUGIYAMA, 2015).

$\mathrm{Na}$ região nordeste do Brasil foi isolada a bactéria Streptomyces olindensis DAUFPE 5622; que produz um pigmento roxo, originalmente descrito como uma antraciclina com atividade antimicrobiana e antitumoral (LIMA et al., 1969). Estudos estruturais determinaram que a molécula é um complexo aromático com duas cadeias trissacarídicas no carbono 7 e 10 chamado cosmomicina D (Figura 8 )(GARRIDO et al., 2006; FURLAN et al., 2004;). As cosmomicinas são um grupo de compostos interessantes porque apresentam um dos padrões de glicosilação mais complexos encontrados nas antraciclinas (MIYAMOTO et al., 2002).

Com o sequenciamento do genoma de $S$. olindensis foi possível determinar a sequência completa do cluster biossintético da cosmomicina D (ROJAS et al., 2014). Este cluster é considerado um dos maiores descrito até hoje dentro do grupo das antraciclinas, com um tamanho aproximado de $45 \mathrm{~Kb}$, maior do que o cluster da DNR com $40 \mathrm{~Kb}$ (VASANTHAKUMAR; KATTUSAMY; PRASAD, 2013). Uma das características da cosmomicina $D$ produzida por $S$. olindensis, é a elevada toxicidade quando comparada com outras antraciclinas, tais como a doxorrubicina (CARVALHO et al., 2010), levando à hipótese de que esta bactéria possui diferentes estratégias de resistência como resposta à toxicidade.

No presente estudo, foram demostrados três mecanismos de resistência (selfresistance). O primeiro mecanismo, codificado pelos genes cosl e cosJ, consiste em um complexo de efluxo, pertencente à família de proteínas transportadoras $A B C$. $O$ segundo mecanismo, codificado pelo gene cosP, é uma enzima glutationa peroxidase que provavelmente está envolvida na desintoxicação de espécies reativas de oxigênio (ROS), causadas por antraciclinas. Finalmente, o terceiro mecanismo, codificado pelo gene cosU, consiste em uma proteína homóloga à UvrA, encarregada do reparo do 
DNA danificado pela antraciclina. Estes resultados ajudam a compreender melhor o gênero Streptomyces como um grupo de microrganismos que oferece diferentes estratégias de resistência dependendo da funcionalidade e alvos da molécula produzida. 


\section{REVISÃO DE LITERATURA}

\subsection{Características gerais do gênero Streptomyces spp.}

O gênero Streptomyces, é um grupo de bactérias Gram-positivas, que pertencem ao filo Actinobacteria. Os membros deste gênero são aeróbios estritos, têm cadeias que formam esporos individuais numa estrutura fibrosa. Os conídios de cada cadeia são frequentemente pigmentados e podem ser de textura variável. Normalmente, há mais do que três conídios por cadeia (MURRAY; HOLT, 1989). Em muitos aspectos, são muito semelhantes aos fungos filamentosos: ambos têm crescimento como hifas, formação do micélio vegetativo, mecanismo de reprodução através de esporos que se formam numa estrutura especializada chamada hifa aérea, que emergem da superfície da colônia para o ar (Figura 1). Estas semelhanças provavelmente são resultado de adaptações a nichos ecológicos semelhantes, embora os mecanismos subjacentes tenham diferentes origens evolutivas. Como os fungos, a maioria dos estreptomicetos vive como saprófitos no solo. No entanto, as espécies do gênero Streptomyces também habitam com sucesso uma ampla gama de outros nichos, tanto terrestres quanto aquáticos, e algumas cepas são patógenos animais. A riqueza insuperável e diversidade do metabolismo secundário do gênero, tornou estes organismos importantes na produção de valiosos antibióticos e outras moléculas bioativas. A produção destes compostos é coordenado com o desenvolvimento de inovações na biossíntese dos metabólitos (HOPWOOD, 2004). 
Figura 1- Ciclo de vida do gênero Streptomyces

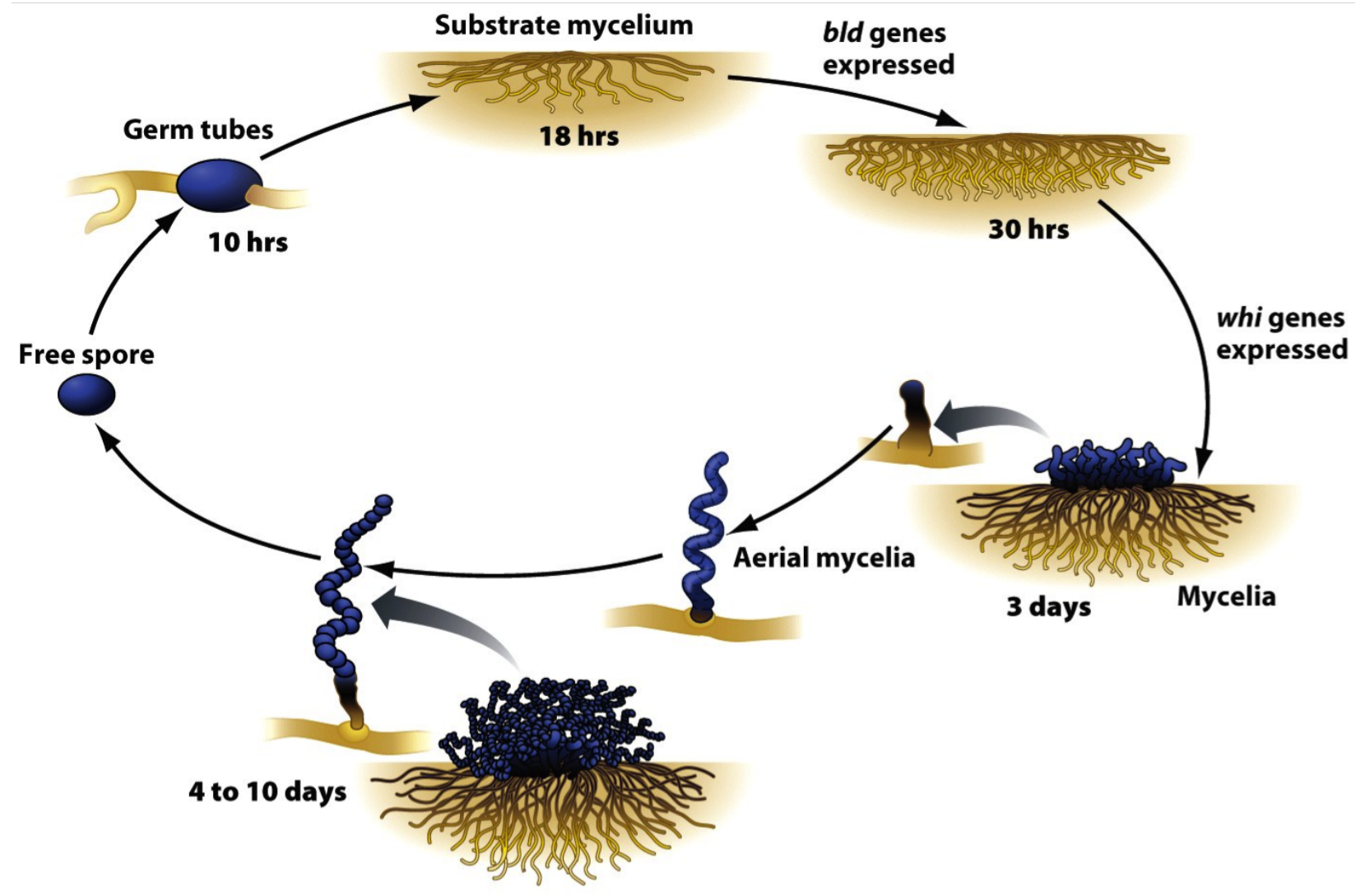

Fonte: (SLONCZEWSKI; FOSTER, 2009)

As espécies do gênero Streptomyces têm sido caracterizadas por meio de características morfológicas e fisiológicas, incluindo: a cor do micélio aéreo e substrato, disposição dos esporos, a utilização de diferentes fontes de carbono, a produção de antibióticos, a síntese de melanina, a redução de nitrato e de hidrólise de ureia e ácido hipúrico (FOSTER, 2009; MURRAY; HOLT, 1989; SLONCZEWSKI).

O gênero Streptomyces é muito importante, tanto do ponto de vista ecológico como médico. O habitat natural da maioria dos estreptomicetos é o solo, onde constituem entre $1 \%$ e $20 \%$ dos microrganismos cultiváveis. Estes microrganismos são flexíveis do ponto de vista nutricional e podem degradar substâncias como a pectina, lignina, queratina, quitina, e compostos aromáticos. Também são conhecidos pela síntese de uma grande variedade de antibióticos, alguns dos quais são úteis na investigação médica e biológica (HOPWOOD, 2004; MURRAY; HOLT, 1989). 


\subsection{Metabólitos secundários}

O crescimento das células é determinado pela atividade metabólica primária, e tem como resultado a produção de enzimas, ácidos orgânicos, etanol, entre outros. Os metabólitos secundários, por outro lado, não são essenciais e unicamente acompanham a síntese em algumas fases do crescimento celular (KLEINKAUF; VON DÖHREN, 1996). O metabolismo secundário é interessante devido à produção de uma variedade de compostos que são de grande utilidade como: antibióticos, antifúngicos, agentes imunossupressores, antitumoral, inibidores de enzimas, toxinas e pigmentos. A maioria são moléculas orgânicas complexas produzidas por uma cadeia de reações enzimáticas (DEMAIN, 1992; KLEINKAUF; VON DÖHREN, 1996; MASSINI, 2009).

\subsubsection{Policetídeos}

Entre os metabólitos secundários encontram-se os policetídeos, que são uma família estruturalmente ampla de compostos com um espectro de atividade diversa (Figura 2). Aproximadamente um terço dos bioprodutos aprovados como fármacos são compostos policetídicos. Apesar da sua diversidade, todos compartilham o mesmo padrão de biossíntese, onde a chave para as macromoléculas de biossíntese são enzimas chamadas policetídeo sintases (HOPWOOD, 2004). 
Figura 2- Exemplos de policetídeos com atividade biológica

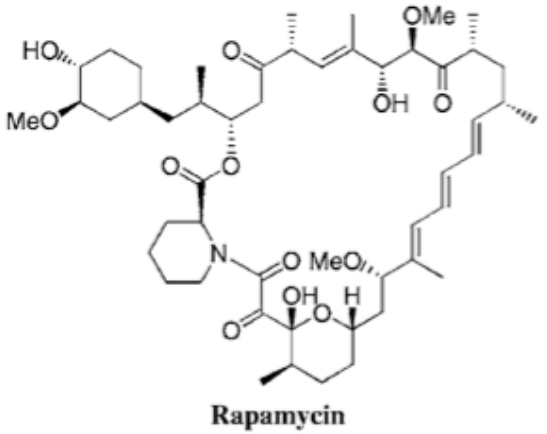

(polieno- Inmunosupresor)

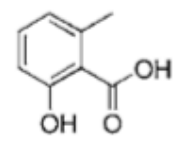

6-Methylsalicylic acid Antibiotico aromatico<smiles>C[C@H]1O[C@H](CC(=O)O)CC2=C1C(=O)c1c(O)c(O)cc(O)c1C2=O</smiles>

Actinorhodin Antibiotico aromatico

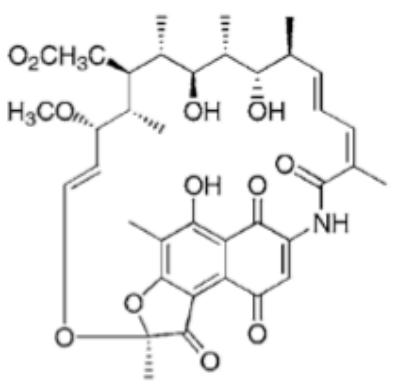

Rifamycin S Antibiotico ansamicinico

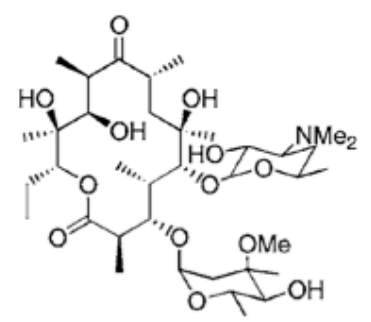

Erythromycin A Antibiotico (Macrolido)

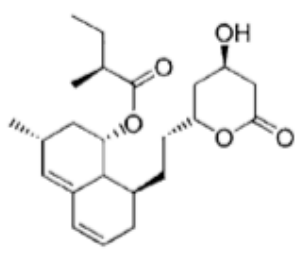

Lovastatin Anticolesterol
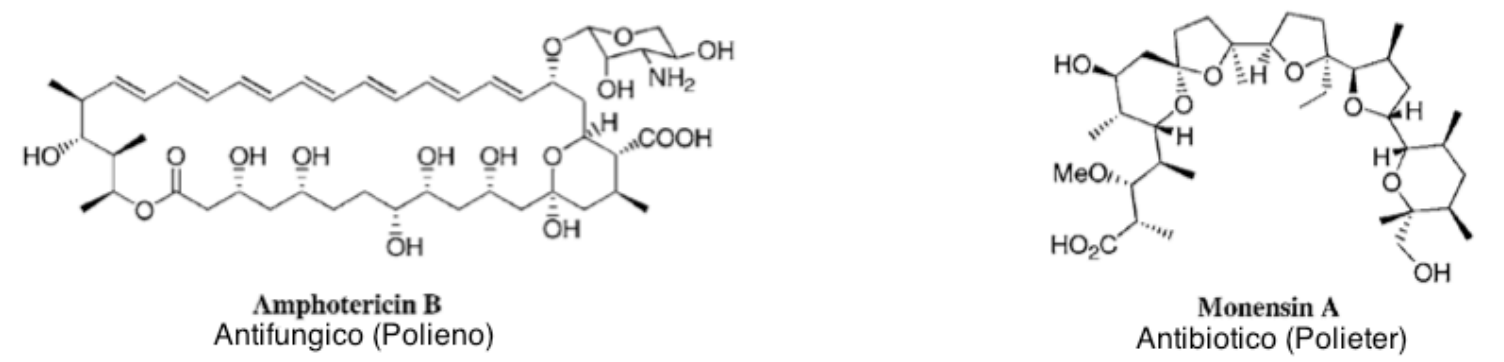

Fonte: adaptado e modificado de (HERTWECK, 2009).

As vias de síntese de policetídeos têm maior similaridade com os mecanismos de síntese de ácidos graxos, sendo que as duas vias compartilham enzimas sintases (HUTCHINSON; FUJII, 1995). O sistema enzimático que catalisa a síntese de ácidos graxos é chamado (FAS) e está envolvido na síntese de policetídeos (PKS); tanto o FAS quanto a PKS precisam dos grupos acetilo e malonil na condensação das cadeias finais. A essência da síntese de ácidos graxos e policetídeos é uma condensação descarboxilativa, que liga os ácidos carboxílicos simples para produzir uma cadeia de 6 
a 50 átomos de carbono, na qual cada unidade contribui com dois carbonos da estrutura cadeia (HOPWOOD, 2004).

A síntese de compostos policetídicos inicia-se com a ligação de moléculas de unidades de acetil-CoA ou malonil-CoA, pela enzima cetosintase (KS), conhecida como a iniciadora. Em seguida, uma unidade Acil-transferase (AT) transfere moléculas acilas para a proteína carreadora de acil (ACP). A unidade KS continua com as condensações descarboxilativas para gerar $\beta$-ceto-acil-ACP. Através deste processo, múltiplas redes originam grupos ceto na sua estrutura (Figura 3) (HOPWOOD, 2004; STAUNTON; WEISSMAN, 2001). A síntese de compostos policetídicos, é acompanhada por outros grupos que exercem processamento final da molécula, como Cetoredutasas (KR), que catalisa a redução do grupo-ceto $\beta$; desidratase (DH) unidade que transforma álcool ($\mathrm{OH}$ ) em $\mathrm{C}=\mathrm{C}$, e a unidade redutase $(\mathrm{ER})$ reduzindo o $\mathrm{C}=\mathrm{C}$ a $\mathrm{C}-\mathrm{C}$ (HERTWECK, 2009; REEVES, 2003).

Figura 3- Mecanismo de base envolvido na síntese de A) ácidos graxos B) policetídeos
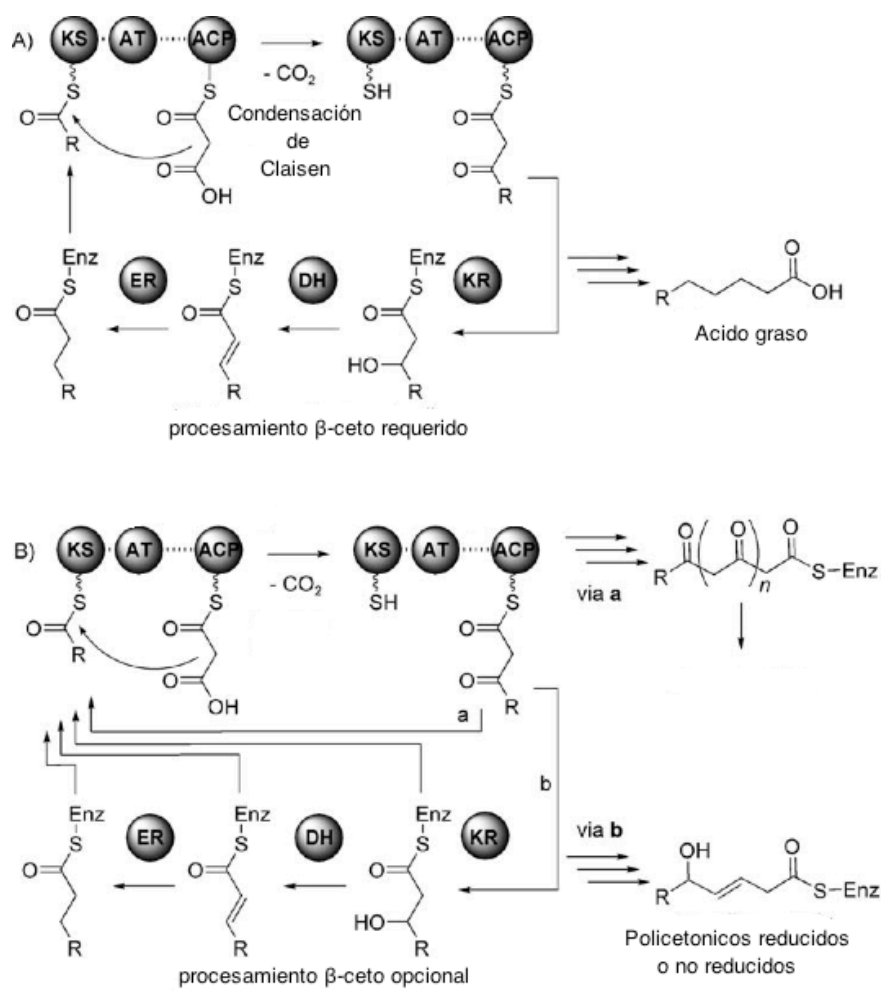

Fonte: (HERTWECK, 2009). 


\subsubsection{Tipos de PKS}

Os policetídeos são divididos em 3 grupos (AUSTIN; NOEL, 2003):

PKS tipo I: São moléculas complexas que podem ser grandes ou pequenas, são sintetizados pelas sintases tipo I; neste grupo encontram-se estatinas e eritromicinas.

PKS tipo II: Estas são moléculas aromáticas principalmente, sintetizadas pelas sintases II, e são enzimas multifuncionais, neste grupo encontram-se as antraciclinas (antitumorais).

PKS tipo III: Estes policetídeos são produzidos principalmente por plantas superiores, neste grupo encontram-se os flavonoides.

As enzimas PKS II são um grupo de proteínas monofuncionais que catalisam a formação de compostos aromáticos cíclicos e não exigem a redução ou ciclos de desidratação (HERTWECK et al., 2007; HUTCHINSON; FUJII, 1995). O complexo enzimático é chamada PKS mínimo (Figura 4), e tem três subunidades KSa, KS $\beta$ e ACP. A subunidade KS $\alpha$ está envolvida na condensação, a subunidade KS $\beta$ determina o comprimento da cadeia e a unidade ACP é responsável pelo transporte dos grupos acil. No entanto, a ação das enzimas codificadas pelos PKS mínima não determina a formação do composto final, de modo que, enzimas tais como ciclases, aromatases e reductases dão a formação final dos policetídeos tipo II, neste grupo encontram-se as antraciclinas que possuem atividade antitumoral (KEATINGE-CLAY et al., 2004; METSÄ-KETELÄ et al., 1999). 
Figura 4- Exemplo da biossíntese da doxorubicina (PKS II)

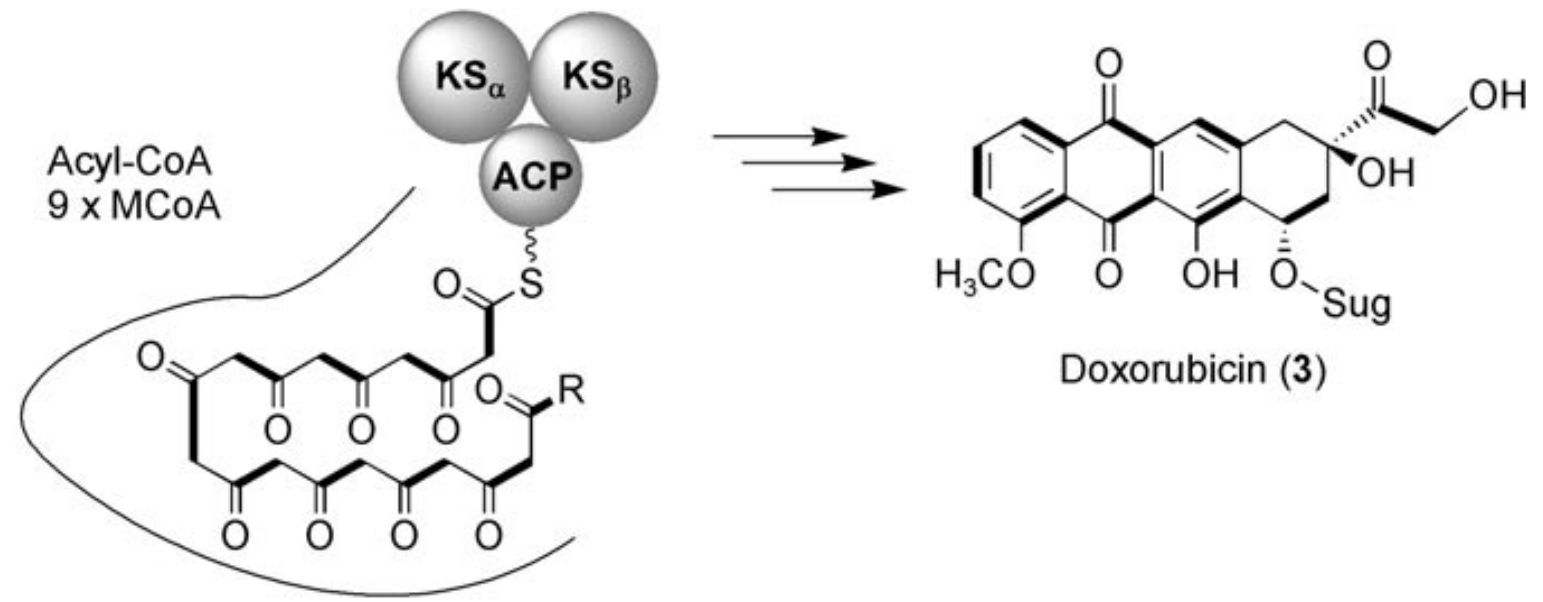

Fonte: (HERTWECK, 2009).

\subsubsection{Antraciclinas}

As antraciclinas estão entre os medicamentos mais eficazes contra o câncer já desenvolvidos (leucemias agudas, linfomas e outros tumores sólidos) (PÉREZ; AGUSTÍ; TORNOS, 2009; WEISS, 1992). As primeiras antraciclinas foram isoladas a partir do pigmento produzido por Streptomyces peucetius no início da década de 1960 e foram nomeadas doxorrubicina (DOX) e a daunorubicina (DNR). Como mostrado na Figura 5, DOX e DNR compartilham a porção aglicônica. 
Figura 5- Estrutura química da Doxorubicina (DOX) e Daunorubicina (DNR)
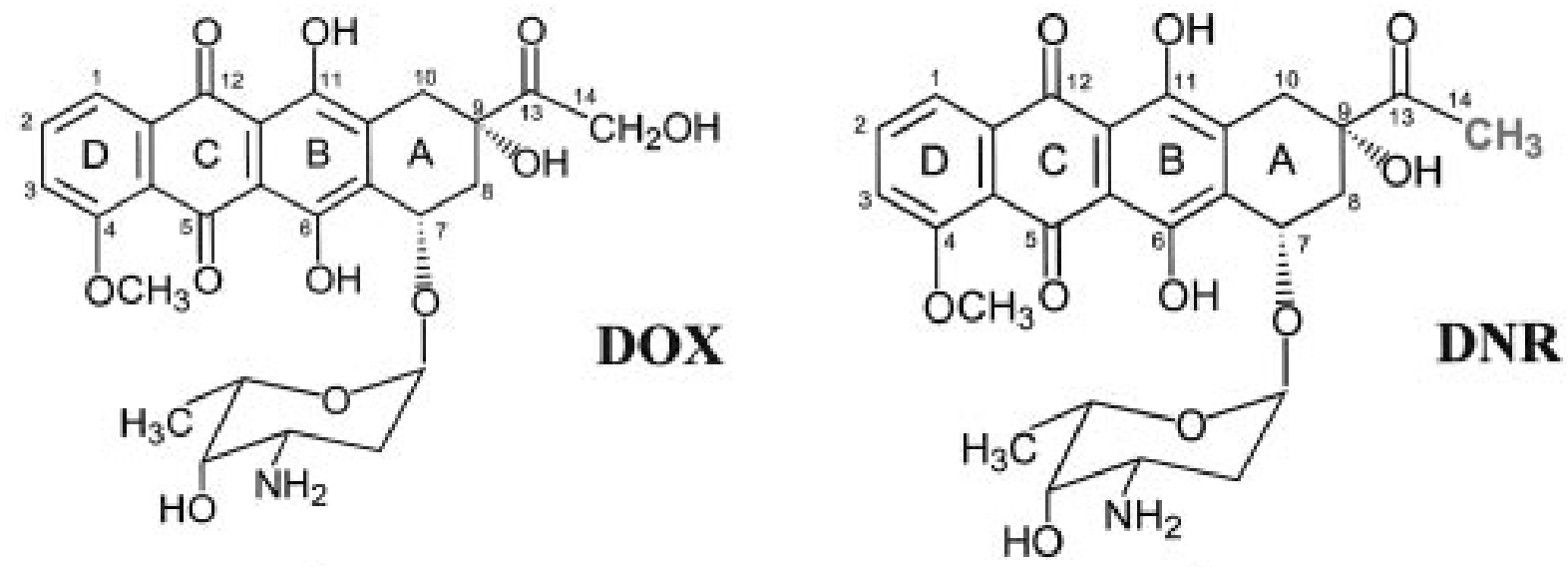

Fonte: (MINOTTI et al., 2004).

A aglicona é constituída por um anel tetracíclico com grupos de quinonahidroquinona em anéis adjacentes $C$ e $B$, um substituinte metoxi na posição $C-4$ no anel D, e uma cadeia lateral curta na posição C-9 (Figura 6).

Figura 6- Estrutura básica das antraciclinas<smiles>[R2]c1cc([R2])c2c(c1[R])C(=O)c1c([R6])c3c(c([R6])c1C2=O)C([R7])CC([R9])(O)C3[R7]</smiles>

Fonte: (SULTANA, 2006)

Os compostos antracíclicos incluindo a nogalamicina e outras como a idarubicina, epirubicina, zorubicina, aclacinomicina A e B usadas na prática clínica, apresentam uma elevada toxicidade, e podem causar problemas como o desenvolvimento de resistência nas células tumorais ou de toxicidade nos tecidos saudáveis, principalmente na forma de cardiomiopatia crônica e insuficiência cardíaca (MINOTTI et al., 2004). 


\subsubsection{Atividade antitumoral das antraciclinas}

Apesar da extensa utilização clínica, os mecanismos de ação das antraciclinas em células cancerosas continuam a ser uma questão de controvérsia. Têm sido considerados os seguintes mecanismos: 1) intercalação no DNA, levando à inibição da síntese de macromoléculas, 2) Geração de radicais livres, o que leva a danos no DNA ou a peroxidação lipídica, 3) Ligação ao DNA e de alquilação, 4) interferência com DNA no desenrolamento ou a separação das cadeias de DNA e a atividade da helicase, 5) Efeitos diretos na membrana, 6) Iniciação de dano de DNA através da inibição da topoisomerase II, e 7) Indução de apoptose em resposta à inibição topoisomerase II (GEWIRTZ, 1999).

\subsubsection{Principal mecanismo de ação das antraciclinas}

As topoisomerases modificam a topologia do DNA, sem alterar a estrutura desoxinucleotídeo e sua sequência. Elas podem desenovelar cadeias simples (topoisomerase I) ou cadeias duplas (topoisomerase II). Inicialmente o DNA é relaxado depois de mudar o status de dupla hélice. Essa atividade confere um papel importante nas topoisomerases como o super-enovelamento da dupla hélice do DNA, e é modulado de acordo com a fase do ciclo celular e atividade transcricional (BINASCHI et al., 2001).

As antraciclinas atuam sobre as cadeias de DNA e ligam-se de forma covalente a resíduos de tirosina da topoisomerase II, eventualmente impedindo a sua separação do DNA. A formação e estabilidade de um complexo ternário de antraciclina - DNA topoisomerase II, depende de determinantes estruturais definidas. O sistema de anéis é importante para intercalação no DNA, como os anéis B e C de sobreposição com os pares de bases adjacentes e $O$ anel $D$ passa através do local de intercalação. As porções externas da molécula na antraciclina (o resíduo do açúcar e o anel A) parecem desempenhar um papel importante na formação e estabilização do complexo ternário. 
Em particular, a molécula de açúcar, localizada no sulco menor, é um determinante crítico da atividade das antraciclinas na inibição da topoisomerase II. (BINASCHI et al., 1997, 2001).

Os danos na topoisomerase II influem diretamente no crescimento celular das fases G1 e G2, resultando na morte celular programada (PEREGO et al., 2001; ZUNINO; PRATESI; PEREGO, 2001). Pode-se concluir que as células tumorais podem tornar-se resistentes a antraciclinas por causa da alteração da expressão do gene da topoisomerase II ou de sua atividade (LAGE et al., 2000). Em situações clínicas, o grau de indução de apoptose se correlaciona com a resposta do tumor e os resultados do paciente (OAKES et al., 2012).

A pesquisa de novas antraciclinas foi influenciada pela avaliação do papel do açúcar aminado na estabilização de drogas e na intercalação do DNA. Análogos de nova geração foram, portanto, projetados durante o curso de estudos que visam elucidar o impacto desta porção crítica sobre as propriedades farmacológicas e toxicológicas das antraciclinas. Agentes promissores obtidos por esta estratégia são as antraciclinas com morfolinilo ou alquilo na posição do grupo amino no C-3. Outra classe de antraciclinas tem sido obtida através da combinação de modificações no C-14 com as modificações do açúcar aminado. Esta última estratégia tem produzido congêneres que não têm como alvo o DNA, mas potenciam eventos apoptóticos modulada pela proteína quinase C (PKC) (BINASCHI et al., 1997, 2001).

\subsubsection{Cosmomicinas}

As cosmomicinas pertencem ao grupo das antraciclinas. São moléculas interessantes que apresentam um dos mais complexos padrões de glicosilação presentes na aglicona que compõe a molécula; com duas cadeias trissacarídicas localizadas no carbono 7 e no carbono 10 da aglicona y-rodomicinona (FURLAN et al., 2004). 
A partir de estudos feitos em alguns isolados do gênero Streptomyces foi determinada a produção de quatro tipos de cosmomicinas: cosmomicina A, cosmomicina B, cosmomicina C e cosmomicina D (Figura 7), os quais diferem no número de açúcares incorporados na aglicona (KIM et al., 2011). Estudos feitos por Garrido (2006) com o uso de espectroscopia de massa, elucidaram diferenças entre as Cosmomicinas C, D e Citorrodina $\mathrm{N}$, nas frações de trissacarídeos destas moléculas, variando na posição dos açúcares: L-rodosamina, 2-desoxi-L-fucose e L-rodinose na aglicona (Figura 8).

Figura 7- Estrutura química da Cosmomicina B e C

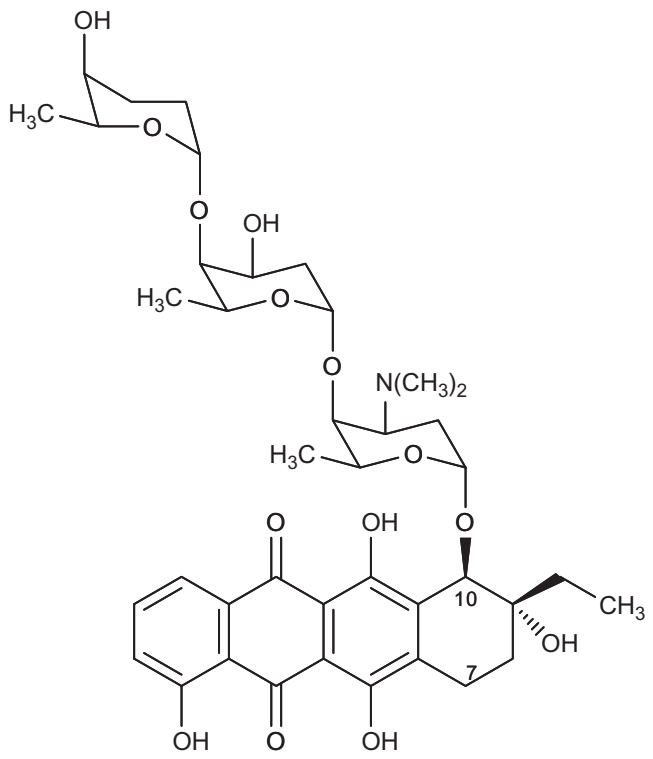

Cosmomicina B

Fonte: (KIM et al., 2011)

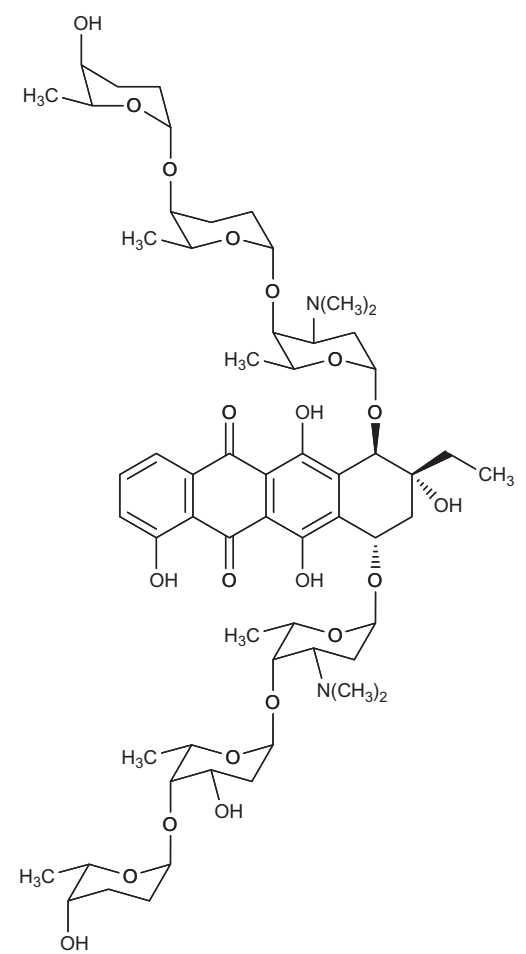

Cosmomicina C 
Figura 8- Estrutura química da cosmomicina D

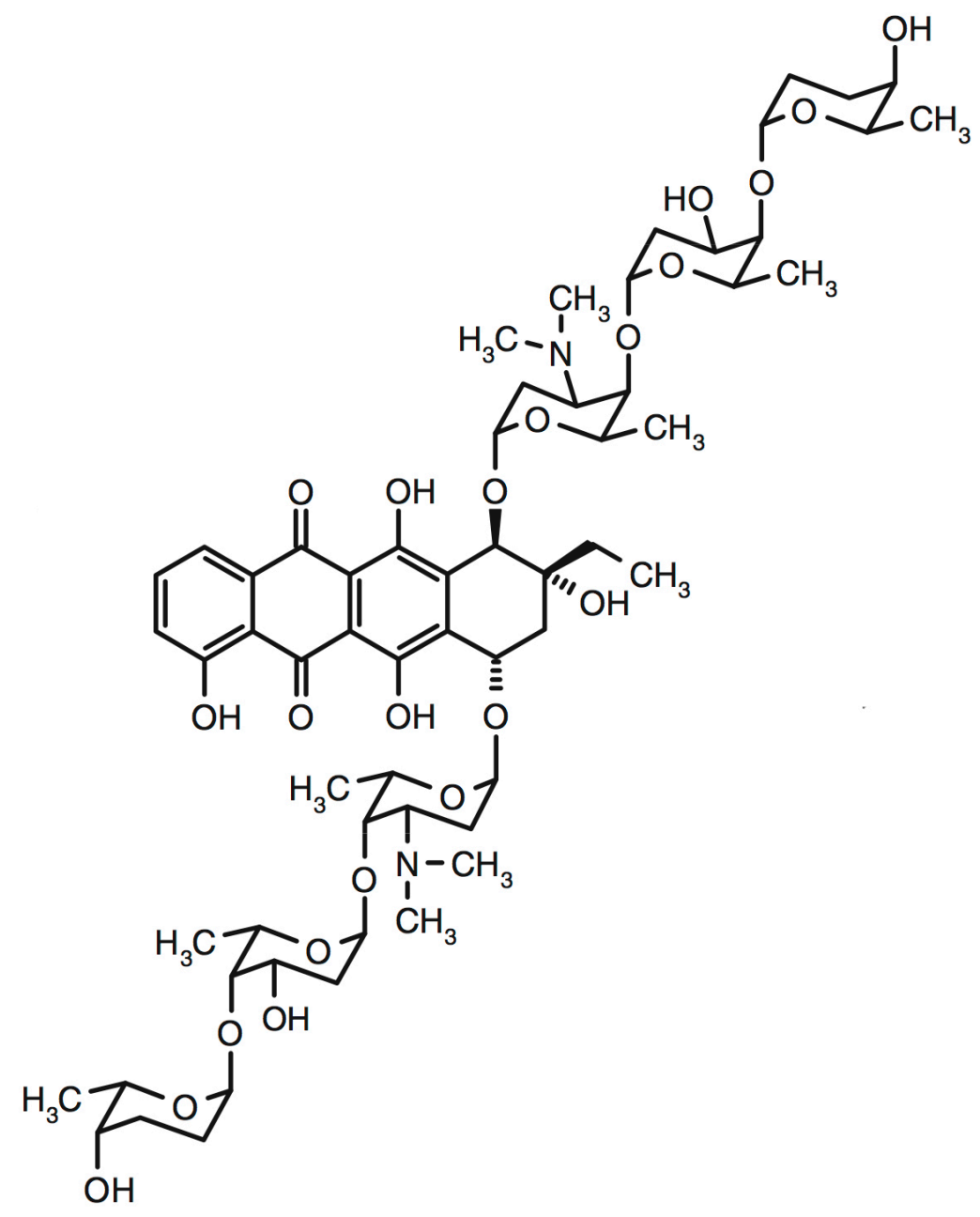

Fonte: (GARRIDO et al., 2006)

A linhagem Streptomyces olindensis DAUFPE 5622, isolada pelo Departamento de Antibióticos da Universidade Federal de Pernambuco na década de 1960 apresentou a produção do complexo retamicina, o qual revelou possuir atividade antimicrobiana e antineoplásica, mostrando resultado positivo no tratamento contra leucemias (LIMA et al., 1969). Na época, este complexo policetídeo foi denominado de retamicina, molécula que possuía 3 açúcares no carbono 10 da aglicona, evento inédito nas antraciclinas. Estudos posteriores determinaram que a molécula possui 3 açúcares no carbono 7 e 3 açúcares no carbono 10 (FURLAN et al., 2004). Esta molécula foi denominada cosmomicina D. 
Estudos de sequenciamento feitos por Garrido (2005) encontraram parte de uma região (14kb) responsável da biossíntese desta antraciclina. Entre os genes identificados se destacam os genes da síntese de açúcares, glicosiltransferases, genes reguladores, genes de resistência e outros com função ainda desconhecida. Com a disponibilização da sequencia do genoma de S. olindensis (ROJAS et al., 2014), foi possível identificar o cluster biossintético da cosmomicina $D$, através do alinhamento da sequência descrita por GARRIDO et al. (2006) com os contigs gerados. Observou-se uma correspondência total dos $14 \mathrm{~kb}$. Análises com os algoritmos e ferramentas de bioinformática permitiram identificar uma região de 43129 bp, contendo o "cluster" da cosmomicina D (Figura 9); a qual apresenta um conteúdo de GC de 72,2\%. Este cluster é considerado um dos maiores até hoje descritos dentro do grupo das antraciclinas atingindo um tamanho semelhante ao descrito à daunomicina de $40 \mathrm{~kb}$ (VASANTHAKUMAR; KATTUSAMY; PRASAD, 2013).

Figura 9- Organização gênica do cluster da Cosmomicina D.

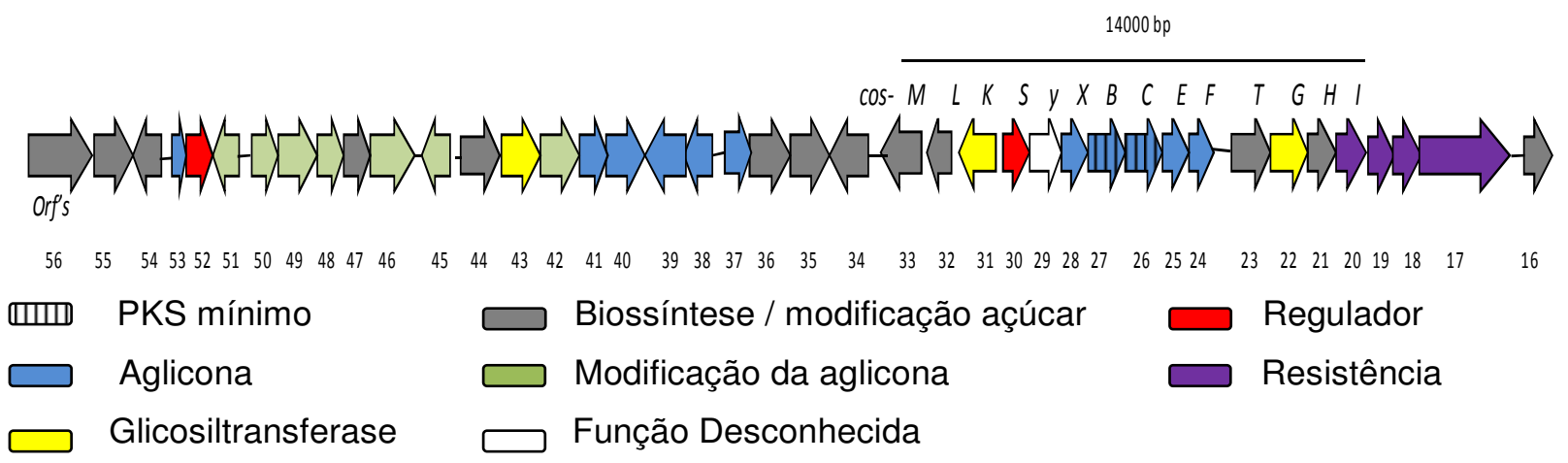

Fonte: (CONTRERAS, 2013). 
Contreras (2013) estabeleceu as principais funções gênicas do cluster da cosmomicina $D$ baseado nas comparações com as bases de dados do NCBI e PFAM, o que permitiu agrupar os genes em várias categorias, permitindo complementar a via biossintética proposta por Garrido et al, 2006. A anotação do conjunto de genes responsáveis na formação da molécula, permitiria a obtenção de novas estruturas com propriedades bioativas usando técnicas de engenharia genética. No entanto, ainda precisam ser feitos estudos de confirmação das funções atribuídas aos genes, especialmente para os genes de resistência.

\subsection{Mecanismos de resistência a antibióticos (Self-resistance)}

Os antibióticos são metabólitos secundários, ou seja, metabólitos não essenciais para o crescimento, mas que podem inibir o crescimento ou matar microrganismos diferentes ao produtor. Para agentes antimicrobianos, a resistência é normalmente quantificada como a concentração mínima necessária para a inibição do crescimento numa população de células (KÜMMERER, 2004). Os antibióticos têm como alvo um grande número de processos essenciais para a célula, incluindo a síntese da parede e membrana celular, o metabolismo do ácido fólico, a duplicação do DNA, a transcrição, e a síntese de proteínas (MADIGAN et al., 2008).

A resistência aos antibióticos é inata nos microrganismos produtores, mas pode se desenvolver em outros organismos através de três mecanismos principais: a aquisição de genes de resistência ou complexos de genes através de plasmídeos e outros elementos transponíveis, a recombinação de DNA a partir de outras bactérias para dentro do cromossomo, por transformação ou por meio de mutações espontâneas no genoma (LEWIS, 2008; POPE et al., 2008). Os mecanismos principais que podem proporcionar resistência a antibióticos são: 

A) Mecanismos de transporte ligados à membrana citoplasmática.
B) Mecanismos enzimáticos através da alteração do agente antimicrobiano ou modificação do alvo de ação.
C) Mecanismos de reparo do DNA.

\subsubsection{Transportadores ABC}

A superfamília de proteínas do grupo $A B C$ é um dos maiores grupos de proteínas e encontra-se nos 3 domínios (Arqueas, Bactérias, Eucariotos) e são sistemas encarregados da importação e exportação de diversas substâncias em processos celulares, como também em processos de regulação (BOUIGE et al., 2002). Algumas das substâncias incluem açúcares, aminoácidos, antibióticos, toxinas, lipídeos, esteróis, sais biliares, peptídeos, nucleotídeos, metabólitos endógenos e íons.

As proteínas $A B C$ em sua forma funcional são compostas por quatro domínios fundamentais, dois domínios de membrana ligados que formam a via de penetração para o transporte de substratos e dois domínios de ligação de nucleotídeos (NBD) que hidrolisam ATP para alimentar este processo (SHAROM, 2008) (Figura 10). 
Figura 10- Esquema da organização estrutural dos componentes formadores de um transporte do tipo $A B C$ em bactérias

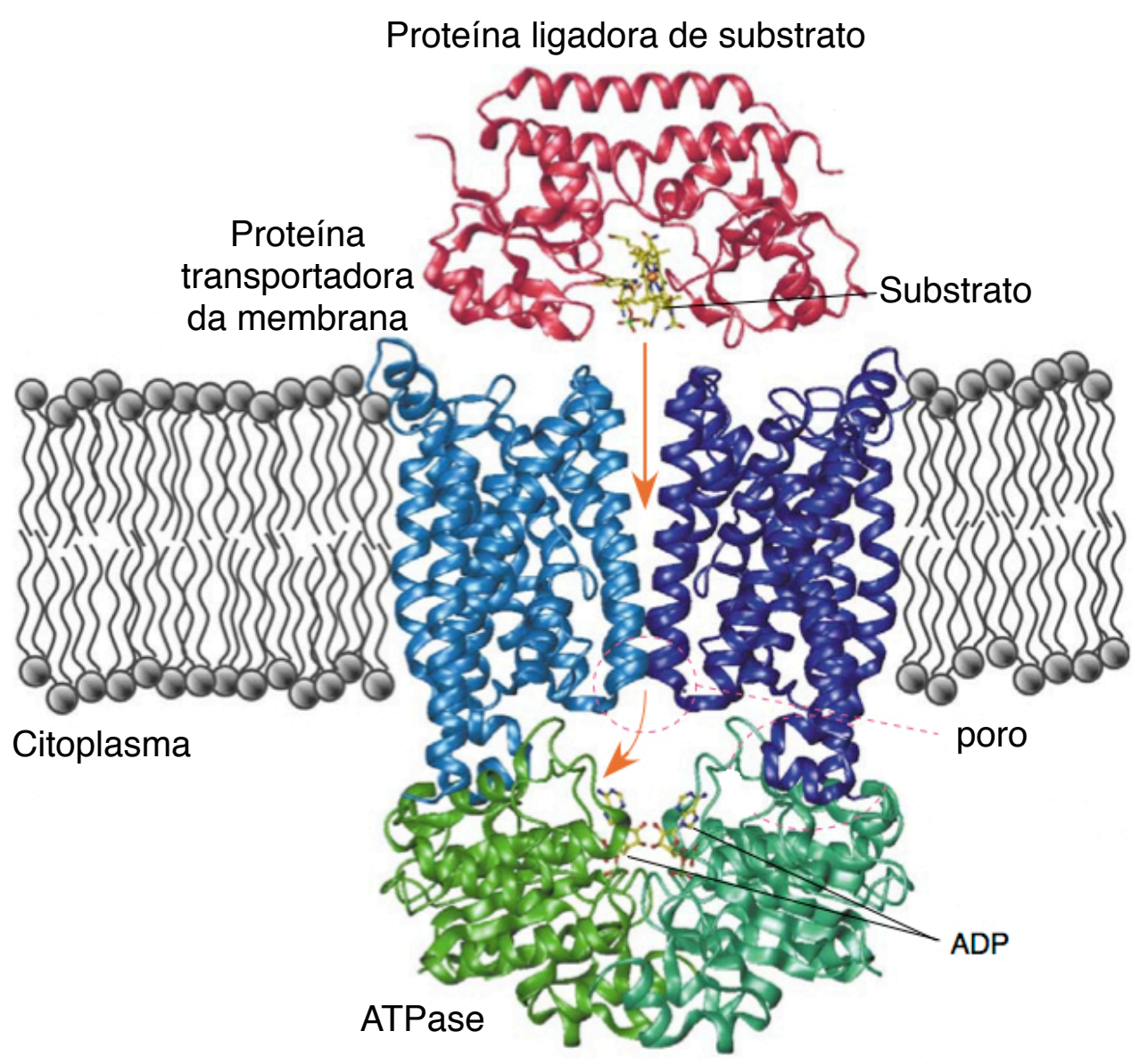

Fonte: Adaptado e modificado de (LOCHER, 2004).

Um dos componentes associados à membrana é responsável pela formação do poro pelo qual a substância será transportada. Esse componente é, em geral, formado por duas proteínas hidrofóbicas que atravessam a membrana citoplasmática, formando o domínio integral de membrana (TM ou permease). As TM são formadas por proteínas que apresentam de quatro a oito estruturas em forma de hélices-alfa (usualmente seis) que se organizam como homodímeros (HOLLAND, 2011) (Figura 11). 
Figura 11- Estrutura do transportador ABC.

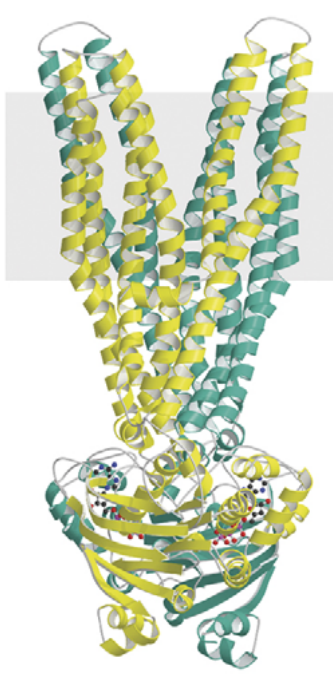

S. aureus Sav1866 Multidrug exporter

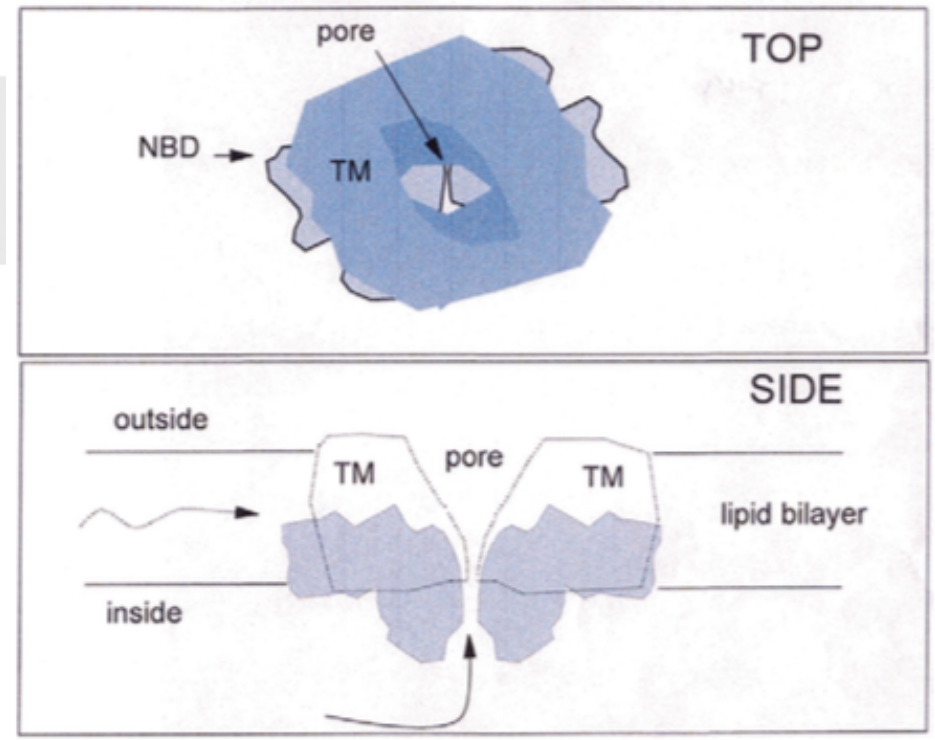

A proteína é composta por um poro aquoso, formada pela TMD, com uma grande abertura na face extracelular da membrana. O NBD encontra-se na face citoplasmática da membrana em estreita justaposição com as TMD.

Fonte: (HOLLENSTEIN; DAWSON; LOCHER, 2007)

O segundo componente dos sistemas $A B C$ de transporte de bactérias é chamado de domínio de ligação de nucleotídeos (NBD ou ATPase). É representado por proteínas associadas à face interna da membrana citoplasmática com dois domínios geradores de energia, que ligam ATP e o hidrolisam alterando a conformação protéica da NBD permitindo a passagem do substrato (HOLLAND, 2011).

\subsubsection{Ligação do ATP e hidrólise}

Os NBDs das proteínas $A B C$ tem três motivos altamente conservados que desempenham um papel crítico na ligação do ATP, os motivos Walker A e Walker B, encontrados em muitas proteínas que se ligam a ATP ou GTP, e uma assinatura C LSGGQ única para a superfamília $A B C$. Abordagens de mutagênese dirigida têm 
revelado a importância destas três regiões na função catalítica (FRELET; KLEIN, 2006). Os estudos estruturais das subunidades NBD isoladas a partir de muitas proteínas ABC produziram informações úteis sobre o ciclo catalítico. Nas estruturas de BtuCD e Rad50cd (domínios catalíticos de uma enzima de reparação do DNA), a dois NBD estão em estreito contato, para formar uma estrutura dupla. Cada local de ligação do ATP é formado a partir dos motivos Walker A e B de uma subunidade de NBD e a assinatura CLSGGQ motivo da subunidade NBD (Figura 12). Duas moléculas de ATP estão ligados nestes locais na interface do dímero. Esta estrutura sanduíche foi observada para a subunidade NBD das proteínas ABC bacterianas MJ0796 e HlyB (HANEKOP et al., 2006).

Figura 12- Dímero sanduiche de ligação ao ATP (NBD) subunidade HlyB (45)

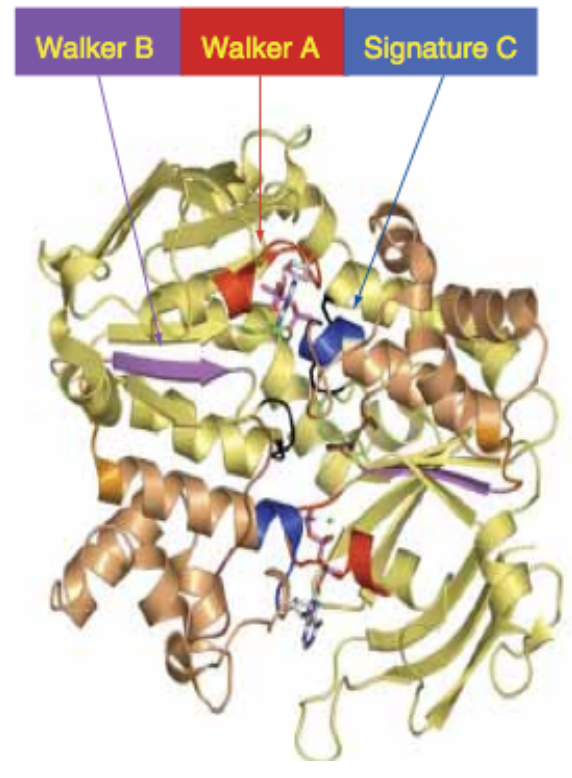

Fonte: (HANEKOP et al., 2006)

\subsubsection{Transportadores $A B C$ em Streptomyces}

Actinomicetos (em particular Streptomyces) são produtores de cerca de três quartos de todos os antibióticos conhecidos. Este grupo de bactérias Gram-positivas tem desenvolvido, através da evolução, mecanismos de resistência específicos para facilitar sua sobrevivência durante a produção dos compostos potencialmente tóxicos 
(CUNDLIFFE; DEMAIN, 2010). Curiosamente, muitos dos mecanismos de resistência encontrados em organismos produtores têm homólogos em bactérias isoladas clinicamente e isso levantou uma questão sobre a origem da resistência aos antibióticos encontrados em bactérias. Têm sido descrito que os organismos que produzem antibióticos podem representar a fonte de pelo menos algumas das determinantes de resistência encontrados em isolados clínicos (BENVENISTE; DAVIES, 1973).

Certo número de sistemas transportadores, provavelmente envolvidos na secreção e resistência, foi descrito em organismos produtores de antibióticos. Os primeiros transportadores $A B C$ identificados foram uma consequência da clonagem de determinantes de resistência a antibióticos. O sequenciamento de DNA mostrou que os genes de resistência codificam para sistemas típicos de transportadores $A B C$. Os diferentes transportadores $A B C$, até agora descritos são de três tipos, designados como tipo I, II e III (Figura 13) (MÉNDEZ; SALAS, 1998).

Figura 13- Estrutura e organização dos diferentes tipos de transportadores $A B C$ em actinomicetos produtoras de antibióticos.

\section{OUT}

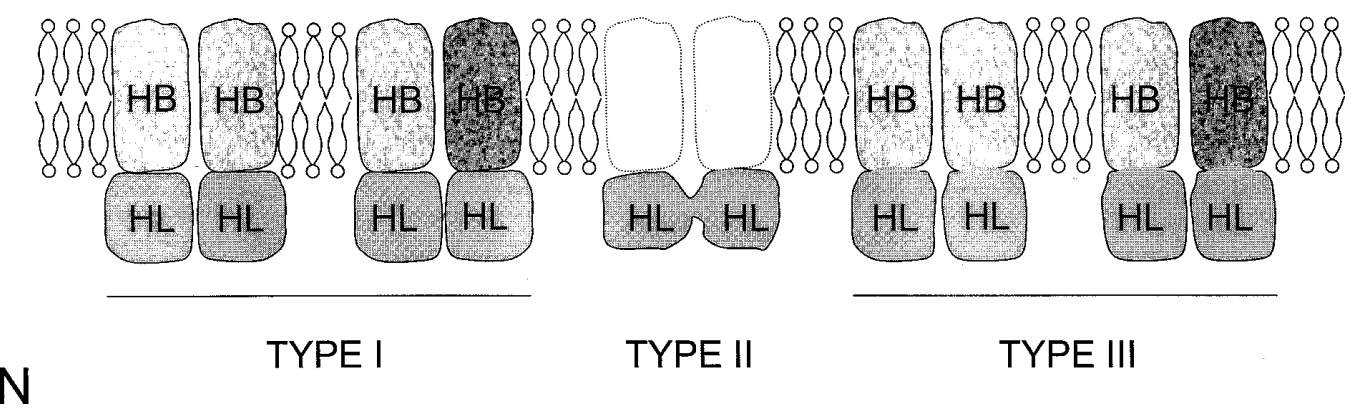

HB (Hidrofóbico) HL (Hidrofílico). No caso dos transportadores do tipo II, não há domínios HB identificadas.

Fonte: (MÉNDEZ; SALAS, 2001). 
Esta classificação baseia-se no número e organização dos domínios de ligação dos nucleotídeos (NBDs), e a composição do sistema transportador (Tabela 1). No tipo I, o sistema de transporte é formado por duas proteínas codificadas por genes independentes: uma proteína de ligação do ATP, com um único domínio de ligação de nucleotídeos (um motivo Walker A e B) e um (ou dois) de proteínas de membrana hidrofóbica contendo seis domínios transmembranares. Transportadores de tipo II são formados por dois domínios hidrofílicos da proteína contendo nucleotídeos de ligação (cada um contendo motivos Walker A e B) e codificada por um único gene.

Tabela 1- Características dos transportadores $A B C$ de actinomicetos produtores de antibióticos.

\begin{tabular}{cccccc}
\hline $\begin{array}{c}\text { Transportador } \\
\text { ABC }\end{array}$ & $\begin{array}{c}\text { Numero de } \\
\text { genes } \\
\text { envolvidos }\end{array}$ & $\begin{array}{c}\text { Gene } \\
\text { codificante } \\
\text { de ATPase }\end{array}$ & $\begin{array}{c}\text { Gene } \\
\text { codificante } \\
\text { de proteína } \\
\text { de membrana }\end{array}$ & $\begin{array}{c}\text { Domínio de } \\
\text { ligação ao } \\
\text { ATP (NBD) }\end{array}$ & $\begin{array}{c}\text { Fusão de } \\
\text { proteínas }\end{array}$ \\
\hline Tipo I & $\begin{array}{c}\text { Dois/Três } \\
\text { Um }\end{array}$ & $\begin{array}{c}\text { Presente } \\
\text { Presente }\end{array}$ & $\begin{array}{c}\text { Presente } \\
\text { Não } \\
\text { identificado } \\
\text { Presente }\end{array}$ & Dois & Naño \\
Tipo III & Um/Dois & Presente & Dois & Sim \\
\hline
\end{tabular}

Fonte: Adaptado e modificado de (MÉNDEZ; SALAS, 2001)

Os transportadores Tipo I e tipo III formam um cluster mais relacionado, enquanto transportadores do tipo II parecem formar uma classe claramente separada. Esta análise sugere que os transportadores do tipo II podem ter evoluído a partir de um único ancestral de dois domínios, em vez de ter evoluído individualmente como consequência da duplicação de genes independentes. Outra conclusão dessa análise é que os transportadores macrolídeos apresentam algum grau de agrupamento dentro do grupo de tipo II (MÉNDEZ; SALAS, 2001).

Todos os transportadores de antibióticos contêm os domínios de ligação ao ATP típicos com os motivos característicos Walker $\mathrm{A}$ e $\mathrm{B}$ separados por um número diferente de aminoácidos, dependendo do tipo do transportador. No tipo I, os resíduos de aminoácidos entre a lisina conservada é de cerca de 115, enquanto que no tipo III é de 
120, em média. No entanto, no tipo II (transportadores contendo dois domínios de ligação a ATP), têm aproximadamente 137 aminoácidos. Curiosamente, todos os transportadores de macrolídeos até agora identificados têm exatamente uma distância de 100 aminoácidos no domínio-C (MÉNDEZ; SALAS, 2001).

Têm sido descritos alguns genes que cumprem a função de transporte, como por exemplo, para daunorubicina, uma droga do grupo das antraciclinas produzida por Streptomyces peucetius. Dois genes (drrA e drrB) (Figura 14) que formam parte do sistema de transportador tipo I, tem sido clonados e verificou-se a resistência à daunorrubicina/doxorrubicina (GUILFOILE; HUTCHINSON, 1991).

Figura 14- Efluxo da doxorrubicina (DXR) e daunorubicina (DNR) com ação do transportador $\mathrm{ABC}$ codificado pelos genes (drrA e drrB).

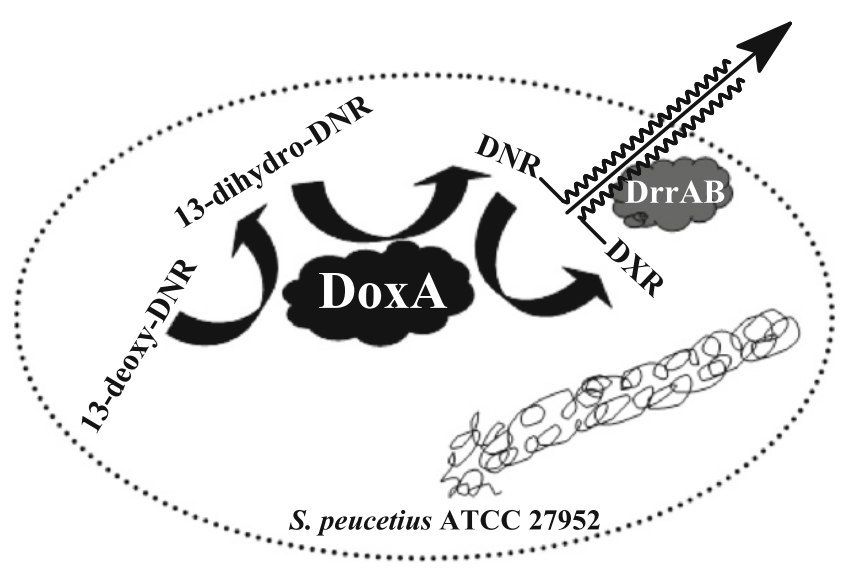

As setas abertas indicam os passos entre o precursor e o produto indicado com a ação dos genes drraAB.

Fonte: (MALLA et al., 2010)

O componente hidrofílico DrrA mostrou ligar-se ao ATP e GTP numa reação dependente de $\mathrm{Mg}^{2+}$, com ligação melhorada pela adição de doxorrubicina ou daunorrubicina. O componente DrrB foi encontrado na membrana (Figura 15), esta 
proteína foi apenas mantida estavelmente na célula, se o componente hidrofílico DrrA também estava presente. Além disso, o componente catalítico DrrA estava numa conformação ativa apenas quando foi complexado com DrrB (GANDLUR et al., 2004; KAUR, 1998).

Figura 15- Modelo para a topologia da proteína DrrB na membrana de S. peucetius.

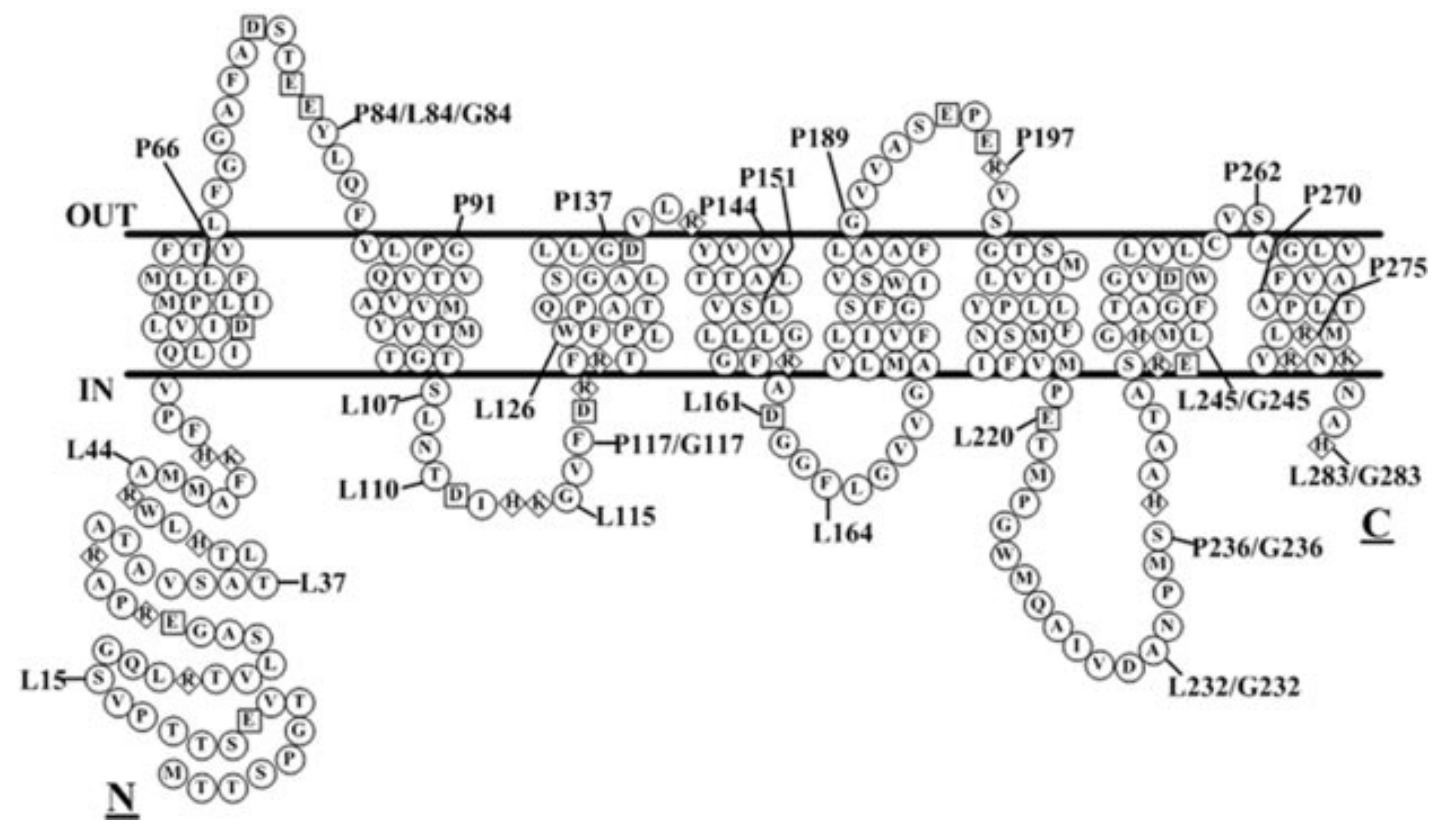

A proteína DrrB contém oito a hélices transmembrana. Tanto o terminal $\mathrm{N}$ e o terminal $\mathrm{C}$ de DrrB são dirigidas no citoplasma. A proteína tem uma cauda citoplasmática $\mathrm{N}$-terminal longa de cerca de 50 aminoácidos. Resíduos são indicados: ácidas (quadrados) e básicas (diamantes)

Fonte: (GANDLUR et al., 2004).

A mitramicina é um fármaco antitumoral do grupo do ácido aureólico. Um determinante de resistência a mitramicina de Streptomyces argillaceus, foi clonado e expresso num hospedeiro sensível e confere resistência a mitramicina, mas não para as cromomicinas e olivomicinas estruturalmente relacionados (FERNÁNDEZ-MORENO; VALLÍN; MALPARTIDA, 1997). Os genes (mtrA e mtrB) são envolvidos nos transportadores de tipo I que conferem a resistência à mitramicina. Curiosamente, um mutante deste transportador não pode ser obtido quando se utiliza a cepa selvagem, 
sugerindo assim um papel importante para este transportador na sobrevivência do organismo produtor (FERNÁNDEZ-MORENO; VALLÍN; MALPARTIDA, 1997).

A tetronasina e macrotetrolida são antibióticos do grupo dos poliéteres produzidos por Streptomyces longisporoflavus e Streptomyces griseus, respectivamente. Eles são antibióticos que atuam na despolarização da membrana das bactérias sensíveis a estes medicamentos. Dois determinantes de resistência para tetronasina são conhecidos (tnrA e tnrB); e codificam para a proteína de ligação do ATP e a proteína de membrana, respectivamente, formando um transportador ABC tipo I (LINTON et al., 1994).

A rapamicina é um policetídeo macrocíclico produzido por Streptomyces hygroscopicus, o composto tem atividade antifúngica e antitumoral, além disso, é um composto imunossupressor. O cluster dos genes biossintéticos da rapamicina foi clonado e sequenciado. Foi localizado um gene (orfX) com função de transporte, seu envolvimento na resistência à rapamicina não foi provado. A proteína orfX tem um domínio de ligação a o ATP com motivos Walker A e B, portanto, pode ser incluído dentro dos transportadores tipo I (SCHWECKE et al., 1995).

\subsubsection{Mecanismos de resistência associados à interação com DNA}

A reparação por excisão de nucleotídeos (NER) é um sistema que se encontra ao longo do genoma nos procariotas, e sua principal função é retirar uma grande variedade de lesões, causadas por fatores ambientais físicos ou químicos. 0 reconhecimento dos danos é realizado pela proteína UvrA que pertence à superfamília das ATPases. As proteínas do tipo UvrA nas bactérias são diméricas, e únicas entre as enzimas de reparação do DNA o que permite que as UvrA usem um mecanismo de leitura indireta (JACIUK et al., 2011). Em conjunto com outras proteínas, conhecidas como UvrB, UvrC, e UvrD, complementam a função da proteína UvrA, formando um sistema essencial para a sobrevivência de quase todos os procariotas (TRUGLIO et al., 2006). 
A análise de alguns homólogos das proteínas UvrA revelou que podem ser divididas em cinco classes diferentes. Proteínas da classe I são proteínas UvrA de comprimento completo, que estão presentes na maioria das espécies bacterianas, incluindo E. coli. Proteínas de Classe II e III contêm grandes deleções, cada uma delas numa região diferente. Proteínas da Classe IV contem duplicações da proteína UvrA e apresentam comprimento total; e as proteínas da classe $V$ são duplicações com uma deleção na metade da região C-terminal. Levando em conta as informações dos diferentes homólogos das proteínas UvrA, foi criada uma nova classificação baseada na análise de 2400 genomas (MARSZAŁKOWSKA et al., 2013).

A nova divisão consiste em quatro classes principais de proteínas UvrA e cinco subclasses (Figura 16):

Classe I (900-1050 aa): está presente na maioria das bactérias; sequências deste tipo de UvrA contém dois locais de ligação ao ATP, um domínio de ligação da proteína UvrB e três motivos de zinco.

Classe Ila (740-880 aa): Esta classe de UvrA não contém o domínio de ligação à proteína UvrB e o primeiro motivo de zinco. Em outras palavras, não existem entre 120140 resíduos de aminoácidos. Esta classe de proteínas está presente em diferentes espécies de Actinobacterias, Firmicutes, Bacteroidetes e Proteobacterias.

Classe Ilb (800-900 aa): Este tipo de UvrA contém a supressão do primeiro motivo de zinco; e todos os outros domínios, incluindo o domínio de ligação à proteína UvrB, e estão presentes em todas as espécies do gênero Chlorobi e em algumas espécies de Firmicutes e Proteobacterias.

Classe III (1750-2012 aa): Este tipo de proteínas compreende homólogos que foram duplicados para formar uma proteína de mais de 200 kDa; todos os sitios ATPase estão presentes, assim como os três motivos dedo de zinco e dois domínios de ligação 
UvrB. Estes tipos de proteínas estão presentes em Proteobacteria, particularmente em muitas espécies de Betaproteoabacteria e Planctomycetes.

Classe IV- a (1800-1950 aa): Semelhante à classe III, as sequências deste tipo de proteínas UvrA foram duplicadas, mas falta-Ihes o primeiro motivo dedo de zinco; este tipo de homólogos pode ser encontrado em várias espécies de Betaproteobacteria e Chlamydiae.

Classe IV-B (1900-2000 aa): Estes homólogos diferem das classes III e IVa pois contêm deleções no primeiro motivo de zinco e na primeira cisteína do quarto motivo de zinco. Estão presentes em muitas espécies de Betaproteobacteria.

Classe IVc (1780-1900 AA): como todos os outros subtipos de proteínas da classe IV, a sequência da classe de IV foi duplicada, mas é caracterizada pela falta do primeiro e do quarto motivo de zinco; estes homólogos podem ser encontrados em várias espécies de Verrucomicrobia e Proteobacteria. 
Figura 16- Classificação de proteínas homólogas às UvrA

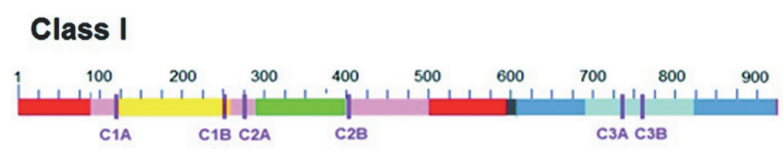

Class Ila

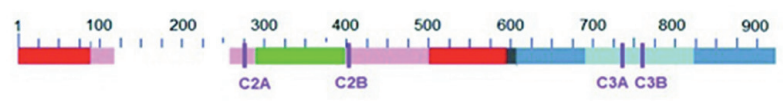

\section{Class IIb}

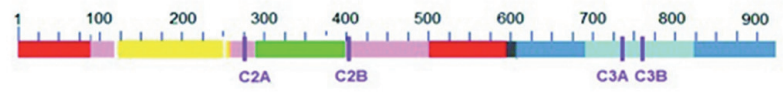

Class III

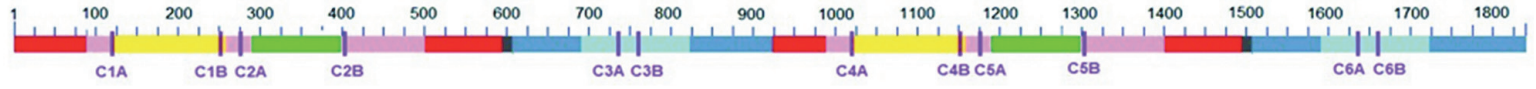

Class IVa

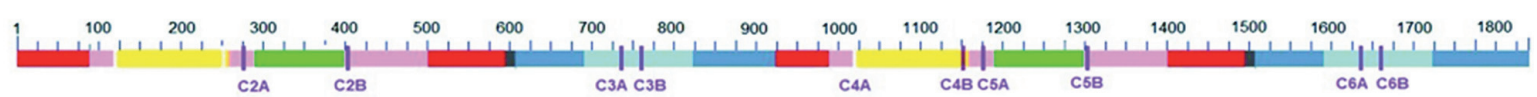

Class IVb

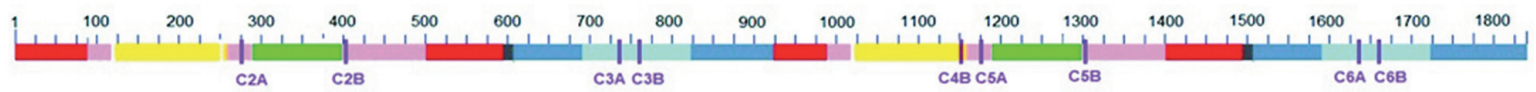

\section{Class IVc}

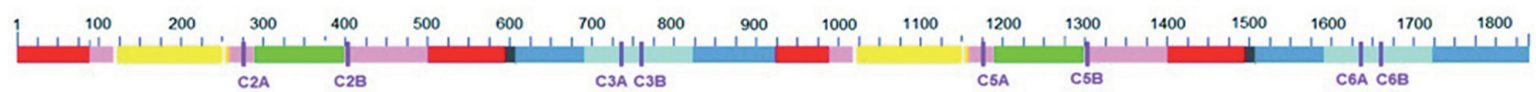

As sequências são coloridas de acordo com o domínio: domínio de ligação ao ATP I e III, vermelho; assinatura motivo I e III, rosa; domínio de ligação ao ATP II e IV, azul; assinatura motivo II e IV, ciano; domínio I e II de ligação à proteína UvrB, amarelo; inserção de sequências I e II, verde; clusters de cisteína (C1A - C6B), roxo; falta do domínio de ligação à proteína UvrB, branco.

Fonte: (MARSZAŁKOWSKA et al., 2013).

\subsubsection{Ligação das proteínas UvrA ao DNA}

As proteínas UvrA contém dois domínios de ligação ao ATP, I e II. A assinatura do domínio I e II é inserida nos domínios de ligação ao ATP correspondente. O primeiro domínio assinatura contém uma região responsável pela ligação à proteína UvrB e uma região responsável pela ligação ao DNA. Três elementos de ligação de zinco estruturais estão presentes na estrutura (JACIUK et al., 2011). 
Figura 17- Complexo estrutural das proteínas UvrA
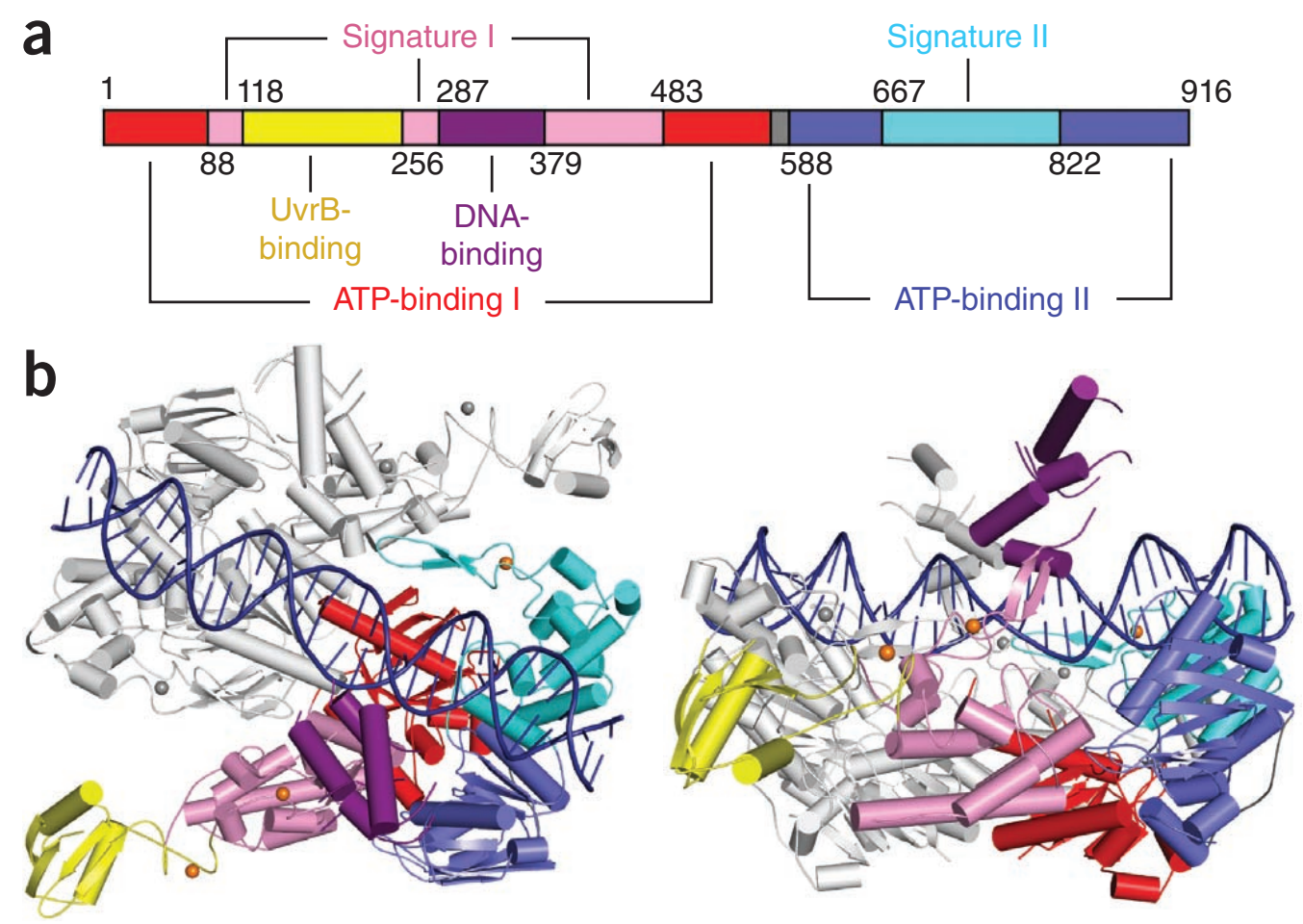

(a) organização dos domínios de ligação e assinaturas da proteína UvrA. (b) Dois modelos estruturais do complexo UvrA-DNA. Os domínios da proteína são coloridos. DNA mostra-se em azul; íons de zinco estruturais, laranja e cinza.

Fonte: (JACIUK et al., 2011).

\subsubsection{Proteínas UvrA homólogas em Streptomyces}

O sistema de transporte DrrAB não é o único mecanismo de resistência a daunorubicina em $S$. peucetius. Outro gene $(d r r C)$ tem sido relatado que apresenta uma forte semelhança com a proteína UvrA de E. coli, envolvida na reparação do DNA. drrC também contém um domínio $A B C$, mas foi mostrado que sua função está ligada com a interação com o DNA, numa reação dependente de ATP (FURUYA; HUTCHINSON, 1998). 
Outro gene $(m t r X)$ também tem sido descrito como necessário na resistência ao antibiótico mitramicina, que codifica para o sistema da classe $A B C$ e de ligação ao DNA que também é semelhante ao $d r r C$. A expressão de $m$ trX num hospedeiro sensível confere um baixo nível de resistência a mitramicina, e portanto pode representar um mecanismo de defesa secundária (GARCIA-BERNARDO et al., 2000). No mesmo sentido o gene $\mathrm{cmrX}$ foi confirmado como necessário na resistência a Cromomicina em S. griseus subsp. griseus (MENÉNDEZ et al., 2007).

\subsubsection{Outros mecanismos de resistência no gênero Streptomyces}

Streptomyces verticillus ATCC15003 produz um potente anticancerígeno conhecido como bleomicina $(\mathrm{Bm})$. O mecanismo de resistência à $(\mathrm{Bm})$ é uma enzima que acetila o grupo primário de aminoácidos do motivo $\beta$-aminoalanina da bleimicina, levando a concluir que a enzima é Bleomicina $\mathrm{N}$-acetiltransferase (BAT) (HE; SHELDON; SHERMAN, 2001; MARTIN et al., 2002; MASANORI et al., 1994; SHELDON et al., 1997; ODA et al., 2010). Streptomyces platensis produtora dos antibióticos platensimicina (PTM) e platencina (PTN) (Figura 18a), dois potentes inibidores das sintases de ácidos graxos bacterianos (FAS). PTM inibe seletivamente proteína carregadora do grupo acila (ACP), as sintases (KAS) I / II, ou FabB/F; enquanto a PTN é um inibidor duplo de ambos FabF e KAS III, ou FabH (PETERSON et al., 2014; WANG et al., 2006, 2007;). Os mecanismos de resistência são altamente eficientes e representam um aparente "híbrido " KAS II /III capaz de complementar tanto FabF nativa (KAS II) e FabH (KAS III). Estas enzimas em Streptomyces platensis representam um mecanismo de resistência (Figura 18b) desenvolvido pelo produtor para neutralizar um inibidor (FAS) de dois objetivos separados (PETERSON et al., 2014). 
Figura 18- Estrutura da PTM e PTN e ciclo das FAS

A<smiles>O=C(CCCCC1CC2C=CC(=O)C1C2)Nc1c(O)ccc(O)c1O</smiles>

Platensimycin (PTM)

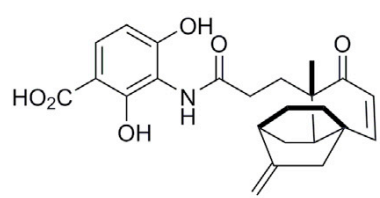

Platencin (PTN)
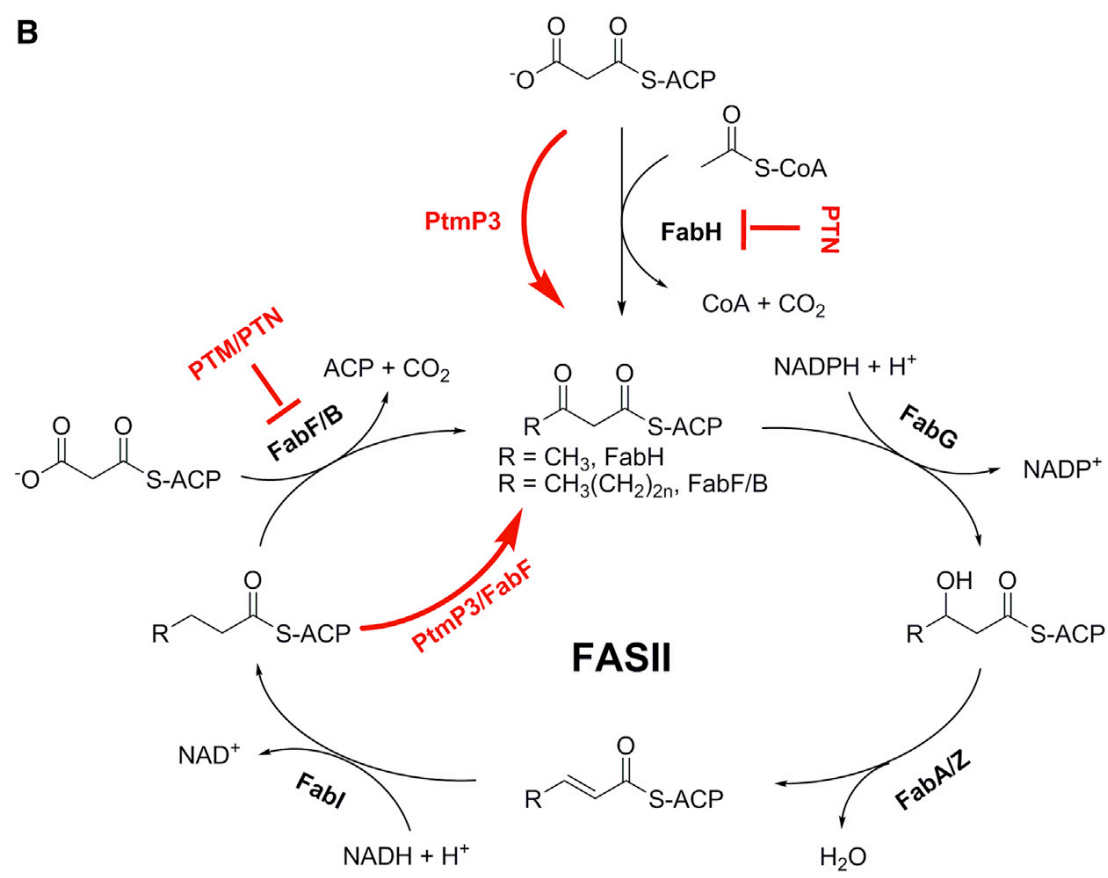

Estruturas de PTM e PTN (A) e sintases de ácidos graxos (FASII; B). Destacadas em vermelho são: (1) inibição da PTM FabF/ B, a etapa de alongamento da FASII, e PTN duplamente inibe FabF e FabH, a etapa de iniciação da FASII; e (2) os dois mecanismos complementares da resistência a PTM e PTN em S. platensis por substituição alvo (ou seja, FabF e FabH por PtmP3) e modificação alvo (ou seja, por uma variante FabF PTM-insensível).

Fonte: (PETERSON et al., 2014)

\subsection{Biossíntese combinatória de antraciclinas}

Outra vantagem de conhecer estes mecanismos é a possibilidade de melhorar a produção de biomoléculas já conhecidas por meio da sobre-expressão e inclusão de novos mecanismos de resistência nos clusters biossintéticos. Várias abordagens químicas e genéticas têm sido utilizadas de forma a produzir novas antraciclinas, que partilham da mesma atividade que o composto original a um nível mais eficiente, com menos toxicidade, ausência de resistência cruzada ou atividade contra células tumorais insensíveis aos fármacos originais (ALBERTS et al., 2004). 
As vias de biossíntese levaram à investigação da biossíntese combinatória, um método que utiliza a engenharia genética de vias metabólicas para fornecer produtos naturais modificados para a descoberta de medicamentos (HUTCHINSON, 1998; KHOSLA; ZAWADA, 1996). As primeiras investigações levaram à identificação de um conjunto de padrões (MCDANIEL et al., 1995), que podem ser utilizados para gerar novos policetídeos aromáticos de uma maneira previsível. A biossíntese combinatória de antraciclinas foi estudada durante as duas últimas décadas (HOPWOOD, 1993; OMURA et al., 1986; STROHL; CONNORS, 1992;). Em esforços para produzir metabólitos híbridos, os primeiros genes da biossíntese de actinorodina biossíntese foram clonados em diferentes isolados de Streptomyces produtores de antraciclinas que resultou na produção de um novo composto aloesaponarina II (STROHL; CONNORS, 1992).

Em outra tentativa para produzir compostos híbridos, os primeiros genes da biossíntese de Streptomyces nogalater foram introduzidos na estirpe hospedeira de $S$. lividans TK24 e os produtos resultantes apresentavam as características estruturais que podem ser associados com as culturas originais (YLIHONKO et al., 1996). Um exemplo bem sucedido da abordagem de híbrido foi a transformação do $S$. galilaeus ATCC31133, com um plasmídeo contendo o gene aklavinone-11-hidroxilase $(d n r F)$ de S. peucetius que resultou em um derivado da aclacinomicina com grupo hidroxila na posição do C11 (HWANG, et al., 1995; KIM, et al., 1996). 


\section{OBJETIVOS}

\subsection{Objetivo geral}

Caracterizar os mecanismos de resistência ao antibiótico antitumoral Cosmomicina D proveniente de Streptomyces olindensis.

\subsection{Objetivos específicos}
A). Avaliar a função dos genes de resistência a Cosmomicina D.
B). Clonar os genes de resistência, num hospedeiro naturalmente sensível às antraciclinas (Streptomyces albus).
C). Confirmar experimentalmente a função predita dos genes de resistência
D). Avaliar o grau de expressão e resistência conferido pelos genes. 


\section{MATERIAL E MÉTODOS}

\section{Desenho Experimental}
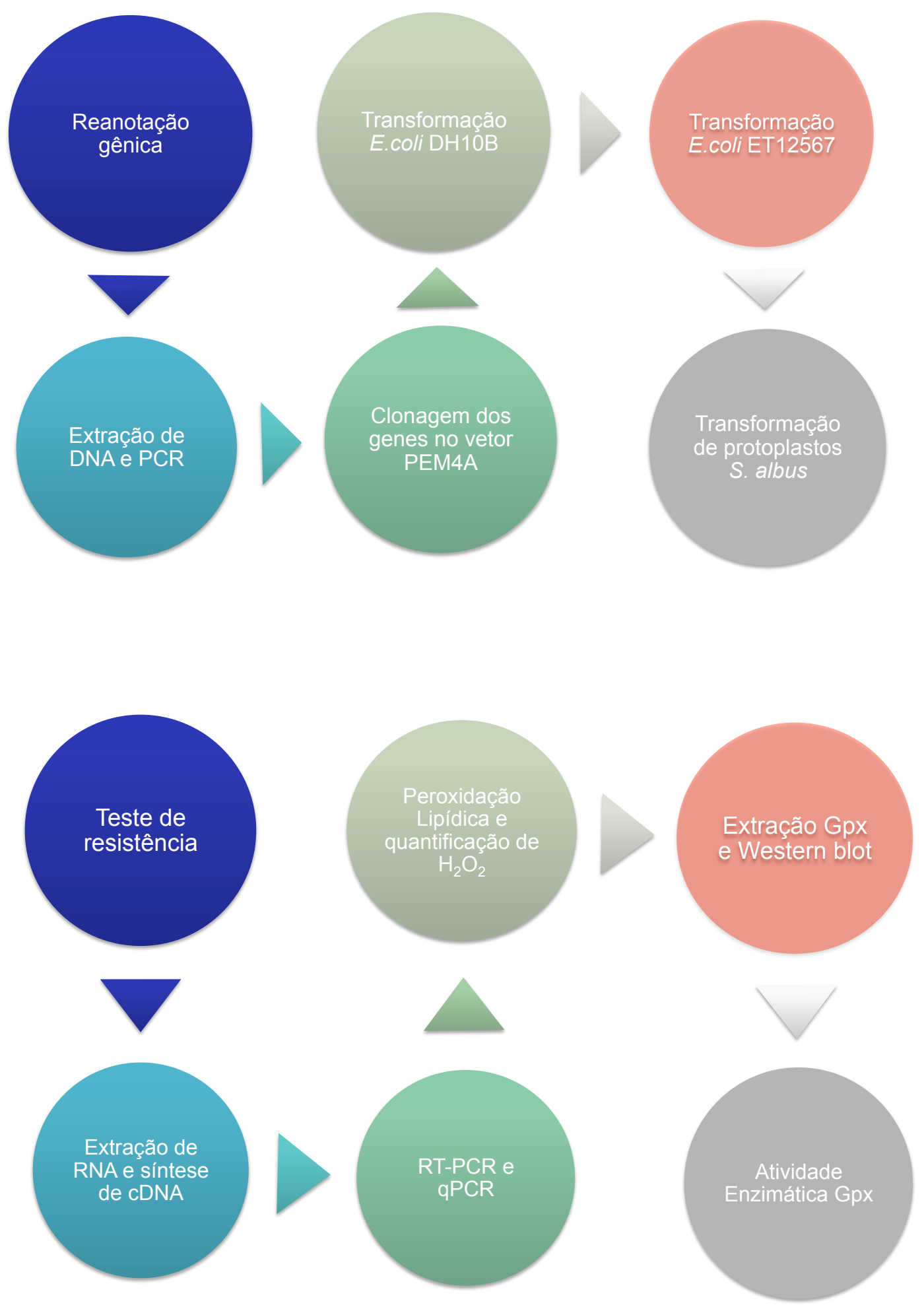


\subsection{Meios de cultura, tampões e soluções}

Todos os meios de cultura, tampões e soluções foram feitos com água destilada, e autoclavados a $121^{\circ} \mathrm{C}$ durante $15 \mathrm{~min}$.

\section{Meio LB}

Meio líquido ou sólido utilizado para obter massa celular de $E$. coli e isolar colônias. Composição: triptona $(5 \mathrm{~g} / \mathrm{l})$, extrato de levedura $(5 \mathrm{~g} / \mathrm{l}), \mathrm{NaCl}(5 \mathrm{~g} / \mathrm{l})$, e ágar $(15 \mathrm{~g} / \mathrm{l})$ quando necessário.

Meio R5M modificado a partir do meio R5 (KIESER et al., 2000).

Meio usado para produção de antibiótico cosmomicina D. Composição: glicose (10 $\mathrm{g} / \mathrm{L})$, extrato de levedura (5 $\mathrm{g} / \mathrm{L})$, casaminoácidos $(0.1 \mathrm{~g} / \mathrm{l}), \mathrm{MgCl}_{2} \cdot 6 \mathrm{H}_{2} \mathrm{O}(10,12 \mathrm{~g} / \mathrm{L}), 2 \mathrm{ml}$ de elementos traços. Após autoclavar adicionam-se $2,5 \mathrm{~mL}$ de $\mathrm{KH}_{2} \mathrm{PO}_{4}$ em concentração $0,5 \%$ e $1 \mathrm{~mL}$ de solução de $\mathrm{CaCl}_{2} \cdot 2 \mathrm{H}_{2} \mathrm{O}$ em concentração de $5 \mathrm{M}$.

Meio R2YE (KIESER et al., 2000):

Meio usado para regeneração de protoplastos e antagonismo de Streptomyces. Composição: Sucrose (103 g/L), glicose (10 g/L), extrato de levedura (5 g/L), $\mathrm{K}_{2} \mathrm{SO}_{4}$ $(0,25 \mathrm{~g} / \mathrm{L}), \mathrm{MgCl}_{2} \cdot 6 \mathrm{H}_{2} \mathrm{O}(10,12 \mathrm{~g} / \mathrm{L})$, casaminoácidos $(0.1 \mathrm{~g} / \mathrm{L}), 2 \mathrm{~mL}$ de elementos traços. Após autoclavar adicionam-se tampão TES $\left(5.73 \%\right.$, w/v): $100 \mathrm{~mL}, \mathrm{KH}_{2} \mathrm{PO}_{4}$ (0.5\%, w/v): $10 \mathrm{~mL}, \mathrm{CaCl}_{2} .2 \mathrm{H}_{2} \mathrm{O}(3.68 \%$, w/v): $80 \mathrm{~mL}$, L-proline, $(20 \%, \mathrm{w} / \mathrm{v}): 15 \mathrm{~mL}, 1 \mathrm{M}$ $\mathrm{NaOH}: 5 \mathrm{~mL}$, completar até o volume de $1 \mathrm{~L}$.

Meio A (KIESER et al., 2000).

Meio sólido utilizado para esporulação de Streptomyces. Composição: MOPS (21 $\mathrm{g} / \mathrm{l})$, glicose $(5 \mathrm{~g} / \mathrm{L})$, extrato de levedura $(0.5 \mathrm{~g} / \mathrm{L})$, extrato de carne $(0.5 \mathrm{~g} / \mathrm{L})$, casaminoácidos $(1 \mathrm{~g} / \mathrm{L})$, ágar $(22 \mathrm{~g} / \mathrm{L})$. Ajustado com $\mathrm{KOH}$ para $\mathrm{pH} 7,2$ antes de autoclavar. 
Meio MS (KIESER et al., 2000).

Meio sólido utilizado para esporulação de Streptomyces. Composição: Farinha de soja (20 g/L), Manitol (20 g/L), Ágar (20 g/L).

Solução de elementos traços.

$40 \mathrm{mg} / \mathrm{L}$ de $\mathrm{ZnCl}_{2}, 200 \mathrm{mg} / \mathrm{L}$ de $\mathrm{FeCl}_{3} \cdot 6 \mathrm{H}_{2} \mathrm{O}, 10 \mathrm{mg} / \mathrm{L} \mathrm{CuCl} \mathrm{Cu}_{2} \cdot 2 \mathrm{H}_{2} \mathrm{O}, 10 \mathrm{mg} / \mathrm{L}$ $\mathrm{MnCl}_{2} \cdot 4 \mathrm{H}_{2} \mathrm{O}, 10 \mathrm{mg} / \mathrm{L} \mathrm{Na}{ }_{2} \mathrm{~B}_{4} \mathrm{O}_{7} \cdot 10 \mathrm{H}_{2} \mathrm{O}, 10 \mathrm{mg} / \mathrm{L}$ de $\left(\mathrm{NH}_{4}\right) \mathrm{Mo}_{24} \cdot 4 \mathrm{H}_{2} \mathrm{O}$.

Tampão TAE:

Tris $0,04 \mathrm{M}$, ácido acético glacial $0,12 \%$ e $\mathrm{Na}_{2}$-EDTA $1 \mathrm{mM}(\mathrm{pH} 8)$.

Tampão de corrida para SDS-PAGE

Trizma (25 mmol/L), glicina (0,2 mol/L) e SDS $(0,1 \%)$,

Tampão de amostra para SDS-PAGE 10x:

Tris-HCl 1 mol.L-1 pH 6,8, SDS 10\% (m/V), Azul de bromofenol 0,5\% (m/V), glicerol 50\% (V/V) e $\beta$-mercaptoetanol 14,3 mol.L-1.

Tampão de lise

NP40 (1\%), deoxicolato de sódio (0,5\%), SDS (1\%), EDTA ( $1 \mathrm{mmol} / \mathrm{L})$, EGTA $(1 \mathrm{mmol} / \mathrm{L})$ e coquetel inibidor de proteases (Sigma- Aldrich, 1\%) em PBS $(\mathrm{pH} 7,4)$.

Tampão de transferência

Trizma $(25 \mathrm{mmol} / \mathrm{L})$, glicina $(0,2 \mathrm{~mol} / \mathrm{L})$ e metanol $(10 \%) 4{ }^{\circ} \mathrm{C}$

Solução corante de SDS-PAGE:

"Comassie Blue Brillant" 0,25\% (m/ $/$ ), etanol 40\% (V/N) e ácido acético 10\% $(\mathrm{V} / \mathrm{N})$.

Solução descorante de SDS-PAGE:

Etanol 30\% (V/V) e ácido acético 10\% (V/V). 
Solução secante de SDS-PAGE:

Etanol 50\% (V/V) e ácido acético 10\% (V/V).

Solução de bloqueio

(tampão TBS pH 7,5 + Tween 20 0,3\% + Leite Desnatado 5\%).

PBS (Solução tampão fosfato):

$\mathrm{NaCl}$ 1,37 mol.L-1, KCl 27 mmol.L-1, Na2HPO4 100 mmol.L-1, KH2PO4 14 mmol.L-1 ajustado para $\mathrm{pH} 7,4$.

PBS-T:

PBS e Tween ${ }^{\circledR} 20$ 0,05\% (V/V).

Soluções extração DNA plasmidial (SAMBROOK; FRITSCH; MANIATIS, 1989)

Solução I:

$50 \mathrm{mM}$ glucose, $25 \mathrm{mM}$ Tris-Hcl, pH 8.0, $10 \mathrm{mM} \mathrm{Na}_{2}$.EDTA

Solução II

$0,2 \mathrm{M} \mathrm{NaOH}, 1,0 \%$ SDS

Solução III:

3 M KOAc, pH 5,5 TE: 10 mM Tris-Hcl, pH 8.0, 1 mM Na 2 -EDTA, pH 8,0 Adicionado RNAse A na concentração final de $50 \mu \mathrm{g} / \mathrm{mL}$ antes do uso.

\subsection{Antibióticos}

A cosmomicina $D$ foi isolada e purificada a partir de fermentações de $S$. olindensis utilizando meio R5M, segundo a metodologia de GARRIDO et al., (2006). Os antibióticos cloranfenicol, kanamicina, apramicina e doxorubicina foram obtidos da (Sigma Aldrich, St Louis, USA). 


\subsection{Anticorpos}

Anti Glutathione peroxidase (GPx 1) (Cell Signaling Technology, Inc. Massachusetts, USA)

\subsection{Análise bioinformática}

A análise dos genes de resistência no cluster da Cosmomicina $D$ foi realizada através da ferramenta DELTA-BLAST do NCBI, e a base de dados HMMER (http://hmmer.janelia.org/) e o servidor TMHMM server $\vee 2.0$ para proteínas transmembranares. (http://www.cbs.dtu.dk/services/TMHMM).

\subsection{Linhagens e plasmídeos}

Tabela 2- Linhagens empregadas no estudo

\begin{tabular}{cc}
\hline Linhagens & Referência \\
\hline Streptomyces olindensis & DAUFPE 5622 \\
ICB/USP \\
cosB-PKS não produtor do antibiótico) & Universidad de Oviedo, Espanha \\
Streptomyces albus & University of Cambridge \\
Streptomyces lividans TK24 & University of Cambridge \\
Streptomyces coelicolor CH999 & Invitrogen Brasil Ltda \\
E.coli DH10B & Kieser et al, 2000 \\
E. coli ET12567/pUZ8002 S. albus 8000 & Este trabalho \\
S. albus 8001 & Este trabalho \\
S. albus 8002 & Este trabalho \\
S. albus 8003 & Este trabalho \\
S. albus 8004 & Este trabalho
\end{tabular}

Tabela 3- Plasmídeos e construções utilizadas neste trabalho

\begin{tabular}{cccc}
\hline Vetor & Resistência & Tipo de vetor & Referência \\
\hline PEM4A & Apramicina & Plasmídeo de expressão & Eugenio Patallo (U.de Oviedo) \\
pRD8001 & Apramicina & PEM4A+coslJ & Este trabalho \\
pRD8002 & Apramicina & PEM4A+cosP & Este trabalho \\
pRD8003 & Apramicina & PEM4A+cosU & Este trabalho \\
pRD8004 & Apramicina & PEM4A+cosIJPU & Este trabalho \\
\hline
\end{tabular}


Tabela 4- Primers usados para amplificar por PCR e qPCR.

\begin{tabular}{|c|c|}
\hline Nome & *Oligonucleotídeo \\
\hline coslJ Forward & ATCCATCTAGACAAATTTGAGCACCCGAAAG \\
\hline coslJ Reverse & TGTATGAATTCAGGCTGAGGGGGTGTGAG \\
\hline cosP Forward & ATCCATCTAGACAAGTACCGGGCCCTGAG \\
\hline cosP Reverse & TGTATGAATTCGTCGGGTGAGTCGTCGAG \\
\hline cosU Forward & ATCCA TCTAGAACCGCCTCGACGACTCAC \\
\hline cosU Reverse & TGTAT GAATTCGTCTGTCCAAGGCATTTGGT \\
\hline qcosJ Forward & ATCCTGATGGTGCTGCTGTT \\
\hline qcosJ Reverse & AGCATGTTGACGATGCTCTG \\
\hline$q \cos P$ Forward & CCTGCTCATCGTCAACGTC \\
\hline qcosP Reverse & GTGAGGGGGAACGTGATCT \\
\hline qcosU Forward & CCAGACCTGGCTCTACTCCTT \\
\hline qcosU Reverse & TAGTCCGCGAGCTTCTTCTC \\
\hline qdnaJ S.albus Forward & GACCTGGATGTCCTTGGTGG \\
\hline qdnaJ S. albus Reverse & TCGGCAACTTCTCCGACATC \\
\hline qdnaJ S.olindensis Forward & TCCCAGGACGAGATCAAGAAG \\
\hline qdnaJ S. olindensis Reverse & CGTCCATGATGTCGGAGAAGT \\
\hline
\end{tabular}


*Sítios de restrição adicionados aos oligonucleotídeos para auxiliar o processo de clonagem:

$$
\begin{aligned}
\text { TCTAGA } & =\text { Xbal } \\
\text { GAATTC } & =\text { EcoRI }
\end{aligned}
$$

\subsection{Condições de cultivo e preservação de linhagens}

O cultivo de $E$. coli foi mantido a $37{ }^{\circ} \mathrm{C}$ em estufa por 18 horas a $150 \mathrm{rpm}$ em meio líquido LB, adicionando antibiótico quando for necessário. Os cultivos de Streptomyces foram mantidos a $28{ }^{\circ} \mathrm{C}$ em agitador orbital a $200 \mathrm{rpm}$ por um período de 3 a 5 dias tanto para crescimento como para produção de cosmomicina D.

A preservação das linhagens de E. coli foi realizada a partir de $1,5 \mathrm{ml}$ de uma cultura crescida durante $18 \mathrm{~h}$. Após centrifugar a 3000 rpm por 10 minutos o sedimento foi resuspendido em glicerol $20 \%$ e posteriormente armazenadas a $-80{ }^{\circ} \mathrm{C}$ e $-20{ }^{\circ} \mathrm{C}$. As linhagens de Streptomyces foram preservadas através da suspensão de esporos em glicerol $30 \%$, recolhidos de cultivos crescidos durante cinco dias em meio A e MS com ajuda de lâminas de bisturi estéril e armazenados a $-20^{\circ} \mathrm{C}$.

\subsection{Extração de DNA genômico}

O DNA genômico foi extraído utilizando o método clássico de extração segundo o protocolo descrito em KIESER et al (2000). Além disso, foi utilizado o kit comercial Wizard $\circledast$ Genomic DNA Purification Kit (Promega Corporation, Fitchburg, USA) seguindo as recomendações para Gram-positivas ou Gram-negativas segundo o caso.

\subsection{Extração de DNA plasmidial}

A obtenção do DNA plasmidial de $E$. coli em pequena escala foi feito pelo método de lise alcalina descrito por (SAMBROOK; FRITSCH; MANIATIS, 1989) e pelo Kit comercial Wizard® Plus SV Minipreps DNA Purification System (Promega Corporation, Fitchburg, USA). Para Streptomyces a extração de DNA plasmidial foi feito de acordo com os protocolos descritos por Kieser et al (2000). 
A pureza e concentração do DNA genômico e plasmidial foi avaliada por espectrofotometria (260 nm/280 nm) (SAMBROOK; FRITSCH; MANIATIS, 1989) no espectrofotómetro Nanodrop ND 2000 (Thermo Fisher Scientific, Waltham, USA).

\subsection{Eletroforese em gel de agarose}

A eletroforese foi feita em gel de agarose com concentração de $0.8 \%$ suplementado com SYBR® Safe (Thermo Fisher Scientific, Waltham, USA) contendo tampão TAE, a corrida foi feita aplicando $5 \mathrm{~V} / \mathrm{cm}^{2}$ durante $45 \mathrm{~min}$.

\subsection{Purificação do DNA}

O DNA foi purificado de reações enzimáticas empregando o KIT comercial GFX MicroSpin Column (General Electric, Buckinghamshire, UK) seguindo as recomendações do mesmo.

\subsection{Reação padrão de PCR}

As reações de PCR foram padronizadas em volume de $50 \mu \mathrm{L}$ contendo tampão Pfu $\left(200 \mathrm{mM}\right.$ Tris- $\mathrm{HCl}\left(\mathrm{pH} 8.8\right.$ a $\left.25^{\circ} \mathrm{C}\right), 100 \mathrm{mM}\left(\mathrm{NH}_{4}\right)_{2} \mathrm{SO}_{4}, 100 \mathrm{M} \mathrm{KCl}, 1 \%(\mathrm{v} / \mathrm{v})$ Triton X100, $1 \mathrm{mg} / \mathrm{mL} \mathrm{BSA}$ ), $\mathrm{MgSO}_{4}$, solução de dNTPs (Thermo Fisher Scientific); cada iniciador (senso e antisenso); Pfu (Pyrococcus furiosus) DNA polimerase de (Thermo Fisher Scientific, Waltham, USA) (Tabela 5) e corridas em termociclador Veriti® (Life Technologies Thermo Fisher Scientific, Waltham, USA). 
Tabela 5- Condições de amplificação por PCR.

\section{Reagentes}

\begin{tabular}{|c|c|}
\hline (Concentração Inicial) & (Concentração Final) \\
\hline DNTP's (Thermo Scientific $25 \mathrm{mM}$ ) & 1 mM de dNTP's (Thermo scientific) \\
\hline Primers (Invitrogen-100 mM) & $1 \mu \mathrm{M}$ de cada primer \\
\hline pfu DNA Polimerase $5 \mathrm{U} / \mu \mathrm{L}$ (Thermo & 2,5 U de pfu DNA polimerase (Thermo \\
\hline Scientific) & scientific) \\
\hline Buffer pfu $+\mathrm{MgSO}_{4}($ Thermo Scientific 10X) & 1X Buffer pfu \\
\hline DMSO $100 \%$ & DMSO $10 \%$ \\
\hline DNA & $100 \mathrm{ng}$ \\
\hline \multicolumn{2}{|c|}{$\cos \mid \mathbf{J}$} \\
\hline Programa Termociclado & Temperatura e tempo \\
\hline Desnaturação inicial & $95^{\circ} \mathrm{C} 3 \mathrm{~min}$. \\
\hline Desnaturação Cíclica & $95^{\circ} \mathrm{C} 40 \mathrm{seg}$. \\
\hline Anelamento inicial & $59^{\circ} \mathrm{C} 30$ seg. \\
\hline Extensão Cíclica & $72^{\circ} \mathrm{C} 5 \mathrm{~min}$. \\
\hline Extensão Final & $72^{\circ} \mathrm{C} 5 \mathrm{~min}$. \\
\hline Ciclos de Repetição & 30 \\
\hline \multicolumn{2}{|c|}{$\cos \mathrm{P}$} \\
\hline Programa Termociclado & Temperatura e tempo \\
\hline Desnaturação inicial & $95^{\circ} \mathrm{C} 3 \mathrm{~min}$. \\
\hline Desnaturação Cíclica & $95^{\circ} \mathrm{C} 40$ seg. \\
\hline Anelamento inicial & $59^{\circ} \mathrm{C} 30 \mathrm{seg}$. \\
\hline Extensão Cíclica & $72^{\circ} \mathrm{C} 1 \mathrm{~min} 20 \mathrm{seg}$. \\
\hline Extensão Final & $72^{\circ} \mathrm{C} 8 \min 40$ seg. \\
\hline Ciclos de Repetição & 30 \\
\hline \multicolumn{2}{|c|}{$\cos U$} \\
\hline Programa Termociclado & Temperatura e tempo \\
\hline Desnaturação inicial & $95^{\circ} \mathrm{C} 3 \mathrm{~min}$. \\
\hline Desnaturação Cíclica & $95^{\circ} \mathrm{C} 40 \mathrm{seg}$. \\
\hline Anelamento inicial & $59^{\circ} \mathrm{C} 30 \mathrm{seg}$. \\
\hline Extensão Cíclica & $72^{\circ} \mathrm{C} 5 \mathrm{~min}$. \\
\hline Extensão Final & $72^{\circ} \mathrm{C} 5 \mathrm{~min}$. \\
\hline Ciclos de Repetição & 30 \\
\hline \multicolumn{2}{|c|}{ cosIJPU } \\
\hline Programa Termociclado & Temperatura e tempo \\
\hline Desnaturação inicial & $95^{\circ} \mathrm{C} 3 \mathrm{~min}$. \\
\hline Desnaturação Cíclica & $95^{\circ} \mathrm{C} 40 \mathrm{seg}$. \\
\hline Anelamento inicial & $59^{\circ} \mathrm{C} 30$ seg. \\
\hline Extensão Cíclica & $72^{\circ} \mathrm{C} 10 \mathrm{~min}$. \\
\hline Extensão Final & $72^{\circ} \mathrm{C} 1 \mathrm{~min}$. \\
\hline Ciclos de Repetição & 30 \\
\hline
\end{tabular}




\subsection{Reações de Ligação}

As ligações foram realizadas empregando a enzima T4 DNA ligase (New England BioLabs Inc, Ipswich, USA) com relação de 3:1 Inserto plasmídeo. As reações foram incubadas a $18^{\circ} \mathrm{C}$ overnight.

\subsection{Preparação e transformação de células eletrocompetentes}

As linhagens E. coli DH10B, e E. coli ET12567/pUZ8002 foram crescidas até atingir fase exponencial (densidade óptica entre 0.4-0.6), centrifugadas e posteriormente submetidas a lavagens com glicerol $10 \%$ gelado, estocadas e congeladas a $-80{ }^{\circ} \mathrm{C}$, segundo o protocolo descrito por (SAMBROOK; FRITSCH; MANIATIS, 1989).

A transformação foi realizada colocando $1 \mu \mathrm{L}$ da reação de ligação adicionada a 50 $\mu \mathrm{L}$ de células eletrocompetentes. As reações foram realizadas em cubetas de $0,2 \mathrm{~cm}$ (Bio-Rad Inc), usando um eletroporador Gene Pulser Xcell ${ }^{\text {TM }}$ (Bio-Rad Inc) com pulso de $12.500 \mathrm{~V} / \mathrm{cm}$, resistência paralela de $200 \Omega$ e capacitância de $25 \mu \mathrm{F}$. A seleção dos transformantes foi realizada através da marca de resistência correspondente aos vetores empregados: PEM4A (apramicina). Adicionalmente foi utilizada seleção de transformantes pela adição de $40 \mu \mathrm{g} / \mathrm{mL}$ de IPTG (isopropil tio $\beta$-D-galactósido) e 40 $\mu \mathrm{g} / \mathrm{mL}$ de X-gal (5-bromo-4-cloro-3-indolil- $\beta$-D-galactopiranósido) nas placas de meio de cultura. Desta forma, foi possível eliminar transformantes que só possuíam o vetor sem inserto.

\subsection{Preparação e transformação de protoplastos de Streptomyces}

A preparação de protoplastos foi realizada como descrito por Kieser et al., (2000). A transformação foi realizada descongelando $200 \mu \mathrm{L}$ de protoplastos, seguido de centrifugação por 7 minutos a $3000 \mathrm{rpm}$. O sobrenadante foi descartado, deixando um volume de aproximadamente $50 \mu \mathrm{L}$ para ressuspender as células. Foram adicionados $20 \mu \mathrm{L}$ de solução de DNA com os protoplastos e $200 \mu \mathrm{L}$ da solução P suplementada 
com 25\% de polietileno glicol (PEG) 1500. Posteriormente, o volume total foi semeado em placas de meio R5 sólido de forma massiva. As placas foram incubadas a $30{ }^{\circ} \mathrm{C}$ durante 20 horas, em seguida foram adicionados $2 \mathrm{~mL}$ de solução do antibiótico na concentração adequada cobrindo a placa totalmente. Este método é conhecido como Flooding e permite selecionar as colônias transformantes depois de incubar as placas entre 5 e 7 dias a $30^{\circ} \mathrm{C}$. As colônias emergentes foram repicadas em placas de meio R5 (KIESER et al., 2000).

\subsection{Replicação das construções em Streptomyces}

As construções inseridas em Streptomyces, devem ser mantidas de forma estável. Neste caso, foram inseridas em protoplastos de $S$. albus, as colônias transformantes foram replicadas em meio R5. O vetor PEM4A usado neste estudo contém um forte promotor constitutivo (ermE* $\mathrm{p}$ ) que é amplamente utilizado para a expressão heteróloga em Streptomyces (MALPARTIDA; HOPWOOD, 1986; OLANO et al., 2014).

\subsection{Reação de sequenciamento.}

Os amplicons e os plasmídeos gerados foram sequenciados no centro de Estudos do Genoma Humano da Universidade de São Paulo, com um sequenciador ABI 3730 DNA Analyser (Applied Biosystems 4849USA). As reações de sequenciamento foram realizadas utilizando BigDye ${ }^{\circledR}$ Terminator Cycle Sequencing Kit v3.1.

\subsection{Teste de atividade de resistência em $S$. albus transformantes $\cos I J, \cos P$, $\cos U$ e cosIJPU.}

Foram testadas as linhagens recombinantes S. albus 8000 S. albus 8001 , S. albus 8002 , S. albus 8003 , S. albus 8004 . Foram inoculados $10^{7}$ esporos em placas de polipropileno de 24 poços contendo $1 \mathrm{~mL}$ de meio R2YE solido e concentrações de 0 a $200 \mu \mathrm{g} / \mathrm{mL}$ do antibiótico Doxorubicina e Cosmomicina D. As culturas foram incubadas durante $48 \mathrm{~h}$ e documentadas para análise de inibição de crescimento. 


\subsection{Isolamento de RNA total e síntese de cDNA}

O RNA total de $S$. olindensis WT e $S$. olindensis $\triangle$ PKS foi extraído usando o reagente Trizol de acordo com o manual (Invitrogen, Carlsbad, Califórnia). As linhagens recombinantes de $S$. albus 8000, 8001, 8002, 8003,8004 foi extraída com o kit PureLink ${ }^{\circledR}$ RNA Mini Kit (Life technologies, Carlsbad, Calif) de acordo com as instruções do fabricante. Todas as cepas foram coletadas às $48 \mathrm{~h}$ após o crescimento. As amostras congeladas foram trituradas em nitrogênio líquido. O DNA residual foi removido por tratamento com DNase I de acordo com as instruções do fabricante (Life Technologies). Uma alíquota de $2 \mu \mathrm{g}$ de RNA tratada com DNAse foi-transcrito em cDNA utilizando o kit SuperScript $₫$ III Reverse Transcriptase e random hexamers (Life Technologies, Carlsbad, Calif).

\subsection{Análise de qPCR}

Todas as reações de amplificação por qPCR foram corridas no termociclador StepOne (Applied Biosystems, Foster City, USA), programado para uma desnaturação inicial de $5 \mathrm{~min}$ a $94{ }^{\circ} \mathrm{C}$, seguido de 40 ciclos de $15 \mathrm{~s}$ a $94{ }^{\circ} \mathrm{C}$ e 1 min a $60{ }^{\circ} \mathrm{C}$. A especificidade dos conjuntos de iniciadores de qPCR foi avaliado pela curva de melting com gradiente de 60 para $96{ }^{\circ} \mathrm{C}$ variando de $1{ }^{\circ} \mathrm{C}$ a cada $30 \mathrm{~s}$. Cada reação de

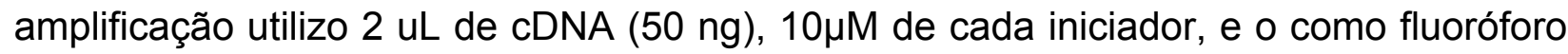
foi utilizado o reagente Ambion SYBR Green qPCR.

Foi utilizado o software StepOne Plus v2.2.2 para determinar a quantificação relativa dos genes alvo em comparação com o gene de referência.

A seleção do gene enógeno a ser usado como um normalizador foi feita por meio de testes dos valores de Ct para os genes de referência já descritos. Desse modo, o dnaJ que codifica uma proteína chaperona apresentou o menor $\Delta \mathrm{Ct}$ e o maior eficiência de amplificação, resultando na sua seleção como normalizador para análise da expressão 
do gene.

\subsection{Análise estatística}

A qPCR foi realizada em três repetições com replica técnica para cada tratamento. A análise estatística foi realizada utilizando o software $R$, versão 3.2.2 Os dados de expressão de genes foram comparados pelo teste $T$ student (teste $t, \alpha=0,05$ ).

\subsection{Peroxidação lipídica e quantificação de peróxido de hidrogênio}

A peroxidação lipídica foi determinada por uma estimativa do teor de ácido tiobarbitúrico como descrito por (KRAMER et al., 1991) Malondialdeído (MDA) foi quantificado através da medição da absorbância a 535 e 600 nM, e a concentração foi calculada utilizando um coeficiente de extinção de $155 \mathrm{mM}^{-1} \mathrm{~cm}^{-1}$.

$\mathrm{O}$ teor de $\mathrm{H}_{2} \mathrm{O}_{2}$ foi determinado de acordo com (ALEXIEVA et al., 2001). As células bacterianas foram homogeneizadas em $0,1 \%(\mathrm{w} / \mathrm{v})$ de ácido tricloroacético. O conteúdo foi centrifugado a $12,100 \mathrm{~g}, 15 \mathrm{~min}, 4{ }^{\circ} \mathrm{C}$, e $200 \mu \mathrm{L}$ do sobrenadante foi adicionado a $200 \mu \mathrm{L}$ de tampão fosfato de potássio $100 \mathrm{mM}(\mathrm{pH} \mathrm{7,0)} \mathrm{e} 800 \mu \mathrm{L}$ de $\mathrm{KI} 1 \mathrm{M}$. A absorbância foi lida a $390 \mathrm{nM}$. Teor de $\mathrm{H}_{2} \mathrm{O}_{2}$ para todas as amostras foi determinado utilizando $\mathrm{H}_{2} \mathrm{O}_{2}$ como um padrão.

\subsection{Extração da Enzima GPx e Western Blot}

A linhagem recombinante $S$. albus 8002 produtora constitutiva da enzima GPx foi crescida durante $48 \mathrm{~h}$, imediatamente o material celular foi macerado com nitrogênio liquido. $200 \mathrm{mg}$ foram homogeneizados em solução tampão para extração da proteína total, utilizando-se $1 \mathrm{~mL}$ de tampão de lise. Após a extração proteica, os tubos foram centrifugados a $14000 \mathrm{rpm}$ durante 10 minutos a $4{ }^{\circ} \mathrm{C}$, e a quantidade de proteína foi determinada usando o método de Bradford (BRADFORD, 1976). 
As amostras foram diluídas e aplicadas às canaletas do gel de poliacrilamida a $15 \%$ para fracionamento. Foram aplicados $5 \mu \mathrm{L}$ de marcador de peso molecular (Kaleidoscope, pré-corado, Bio-Rad, USA). As proteínas foram separadas através de SDS-PAGE aplicando100 volts durante duas horas.

Após a corrida, as proteínas foram transferidas para membrana de nitrocelulose (Bio-Rad) utilizando tampão de transferência gelado durante 1 hora a 100V.

A membrana foi incubada com solução de bloqueio dos sítios não ocupados durante 15 minutos à temperatura ambiente. Após este bloqueio, as membranas foram incubadas com o anticorpo: Anti-Glutathione peroxidase (GPx1) (Cell Signaling Technology, Inc. Massachusetts, USA) diluído em leite Desnatado (3\%) e TBS-T, durante 24 horas à $4{ }^{\circ} \mathrm{C}$ sob agitação constante.

Após a incubação com o anticorpo, a membrana foi lavada duas vezes com TBS-T e uma vez com TBS durante 10 minutos. Apos a lavagem foi incubada com Amersham ECLTM Advance Western Blotting Detection Kit (GE Healthcare, Fairfield, Connecticut, EUA). Após a incubação, foi exposto um filme fotossensível sobre a membrana, utilizando-se $\circ$ cassete radiológico 1 minuto. $O$ filme foi revelado de forma convencional. As imagens foram digitalizadas em scanner para posterior análise quantitativa das bandas obtidas através do programa ImageJ (NIH, USA).

\subsection{Atividade enzimática da Glutationa Peroxidase GPx}

A enzima antioxidante GPx foi extraída segundo o item 3.21 a partir de $S$. olindensis produtor e não produtor de Comomicina $D$, e as linhagens recombinates $\Lambda P K S S$. olindensis deficiente na produção. S. albus 8000 (pEM4A) e S. albus 8002 (pEM4AcosP2) durante estresse com $10 \mathrm{ug} / \mathrm{mL}$ de cosmomicina $D$ e $25 \mu \mathrm{g} / \mathrm{mL}$ de Doxorrubicina. 
A atividade enzimática da Glutationa peroxidase (GPx) foi determinada numa reação acoplada a hidroperóxido de terc-butilo (TBHP) dependente de $\operatorname{NADP}(\mathrm{H})$ oxidação monitorada a $340 \mathrm{~nm}$ (YU et al., 2005). Para determinar a atividade da GPx dentro de uma amostra, tendo em conta que 1 unidade $=1 \mu \mathrm{mol}$ de NADPH oxidado por $\min ^{-1}$.

\subsection{Análise estatística}

A atividade da enzima, MDA e peróxido de hidrogênio foram realizadas em três repetições para cada tratamento. As diferenças foram verificadas por meio de análise de variância $(P<0,05)$ e análise de comparação pelo teste de Duncan. As medias foram comparadas pela diferença mínima significativa $(P<0,05)$. Todas as análises estatísticas foram realizadas utilizando o software $R$, versão 3.2.2 Os dados de expressão de genes foram comparados pelo teste T student (teste $t, \alpha=0,05$ ). 


\section{RESULTADOS}

\subsection{Analise bioinformática e predição da função dos genes de resistência}

A análise da sequência do cluster de cosmomicina D; mostrou quatro genes com função hipotética de resistência (Tabela 6): cos/ com uma similaridade de 94\% com uma proteína transportadora do tipo ABC / ATP binding de S. zinciresistens, cosJ com similaridade de $91 \%$ com uma proteína de membrana do transportador ABC de $S$. zinciresistens, cosP com uma similaridade de $99 \%$ com a enzima Glutationa peroxidase e $\cos U$ com uma similaridade de $88 \%$ com uma proteína do tipo "UvrA-like"

Neste estudo foi realizada uma reanotação dos genes com o objetivo de analisar as possíveis diferenças dos sistemas de resistência com outros genes reportados nas bases de dados. Para isso, foram utilizadas as ferramentas DELTA BLAST do NCBI, HMMER (http://hmmer.janelia.org/), Phyre 2 para análise de aminoácidos (http://www.sbg.bio.ic.ac.uk/phyre2/html/page.cgi?id=index) e o servidor TMHMM (http://www.cbs.dtu.dk/services/TMHMM) para proteínas transmembrana.

Foram elucidados quatro genes $\cos l, \cos J, \cos P$, e $\cos U \operatorname{com}$ os seguintes resultados: 
Tabela 6- Predição da função dos genes de resistência

\begin{tabular}{|c|c|c|c|c|}
\hline Gene & $\begin{array}{l}\text { Função } \\
\text { hipotética }\end{array}$ & $\begin{array}{c}\# \\
\text { a.a }\end{array}$ & $\begin{array}{c}\% \text { identidade (DELTA } \\
\text { BLAST) }\end{array}$ & Valor E- (HMMER) \\
\hline cosl & $\begin{array}{c}\text { Proteína de } \\
\text { ligação à ATP do } \\
\text { transportador ABC }\end{array}$ & 329 & $\begin{array}{c}\text { ABC transporter ATPase } \\
\text { [Streptomyces sp. NRRL } \\
\text { WC-3641] 100\% }\end{array}$ & $\begin{array}{c}\text { ATPase do trasportador } \\
\text { ABC Streptomyces } \\
\text { venezuelae } 1,5 \text { e- } 169\end{array}$ \\
\hline $\cos J$ & $\begin{array}{c}\text { Proteína de } \\
\text { membrana do } \\
\text { transportador ABC }\end{array}$ & 276 & $\begin{array}{c}\text { Permease ABC } \\
\text { transporter [Streptomyces } \\
\text { sp. NRRL WC-3641] } 99 \%\end{array}$ & $\begin{array}{c}\text { Permease ABC } \\
\text { Streptomyces } \\
\text { zinciresistens K42 2,1 e- } \\
163 /\end{array}$ \\
\hline $\cos P$ & $\begin{array}{l}\text { Glutationa } \\
\text { peroxidase }\end{array}$ & 163 & $\begin{array}{c}\text { Glutationa peroxidase } \\
\text { [Streptomyces sp. NRRL } \\
\text { WC-3641] 99\% }\end{array}$ & $\begin{array}{l}\text { Glutationa peroxidase } \\
\text { Streptomyces } \\
\text { zinciresistens K42 5,6 e- } \\
74\end{array}$ \\
\hline $\cos U$ & $\begin{array}{l}\text { Proteína tipo } \\
\text { "UvrA-like" }\end{array}$ & 761 & $\begin{array}{l}\text { Proteína de Resistência } \\
\text { Daunorubicina } d r r C \\
\text { [Streptomyces sp. NRRL } \\
\text { WC-3641] } 100 \%\end{array}$ & $\begin{array}{l}\text { Transportador ABC do } \\
\text { tipo "like protein" } \\
\text { Streptomyces } \\
\text { zinciresistens K42 0,0 } \\
\text { e+00 }\end{array}$ \\
\hline
\end{tabular}

\subsubsection{Mecanismo de efluxo codificado pelos genes cosl e cosJ}

Os genes cosl e cosJ fazem parte da superfamília de proteínas de transporte (Tipo ABC dependentes de ATP). O primeiro gene cos/ codifica para uma ATPase (Figura 19) (Nucleotide binding domine- NBD) e apresenta uma identidade de $99 \%$ com uma proteína de ligação à ATP do transportador ABC de Streptomyces sp. NRRL WC-3641 e um e- valor de 1,5 e-169 de Streptomyces venezuelae.

A proteína é uma ATPase com uma organização que incluem os motivos Walker $\mathrm{A} e$ Walker $B$, indicando a presença de um sítio de ligação e o motivo assinatura único nas proteínas $A B C$, localizado upstream do motivo Walker B. A distancia de aminoácidos entre a lisina $(K)$ conservada do domínio walker $A$ e o acido aspártico $(D)$ do domínio walker $B$ é um ponto de referencia importante na classificação de transportadores $A B C$ que na proteína codificada por cosl é de 117 (Figura 19b). 
Figura 19- Delta Blast do gene cosl

A

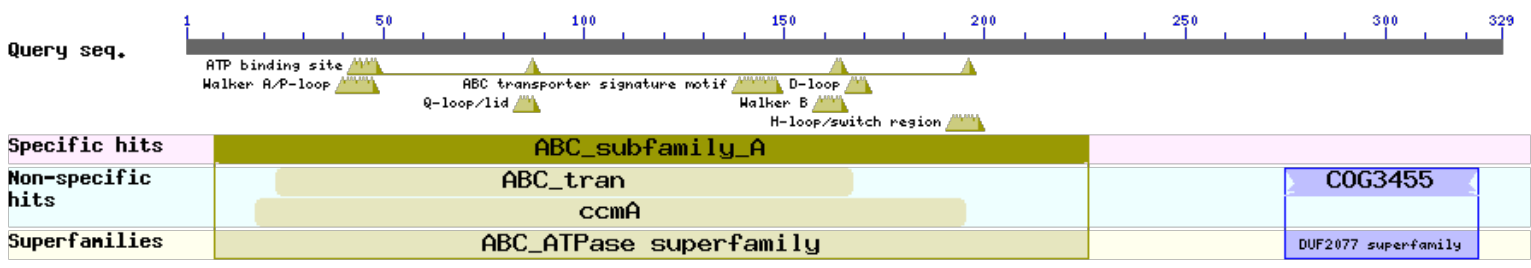

B

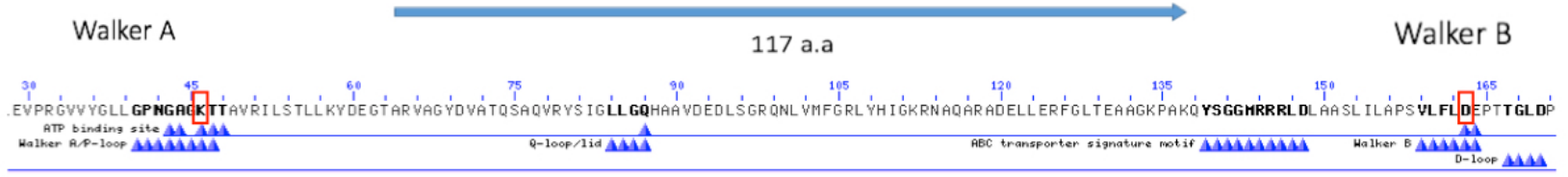

Análise do Mapa da sequência de aminoácidos do gene $\cos$ / B) distancia de referencia entre o motivo Walker A e B gerada com o uso da ferramenta Delta-Blast (Domain Enhanced Lookup Time Accelerated $B L A S T)$ do NCBI.

(http://blast.ncbi.nlm.nih.gov/Blast.cgi?PAGE_TYPE=BlastSearch\&PROGRAM=blastp\&BLAST_PROGRA MS=deltaBlast).

A análise do segundo gene cosJ (TMD) (Figura 20) demostrou que forma parte do complexo transportador $A B C$ pois apresenta uma identidade de $99 \%$ com uma proteína permease do transportador ABC de Streptomyces sp. NRRL WC-3641, e um evalor de 2,1 e- 163 com Streptomyces zinciresistens K42. Este componente está associado à membrana e é o responsável pela formação do poro pelo qual a substância é transportada (TM ou permease). Este tipo de proteínas é em geral formado por duas proteínas hidrofóbicas com uma grande abertura na face extracelular da membrana (HIGGINS, 2001). 
Figura 20- Delta Blast gene cosJ

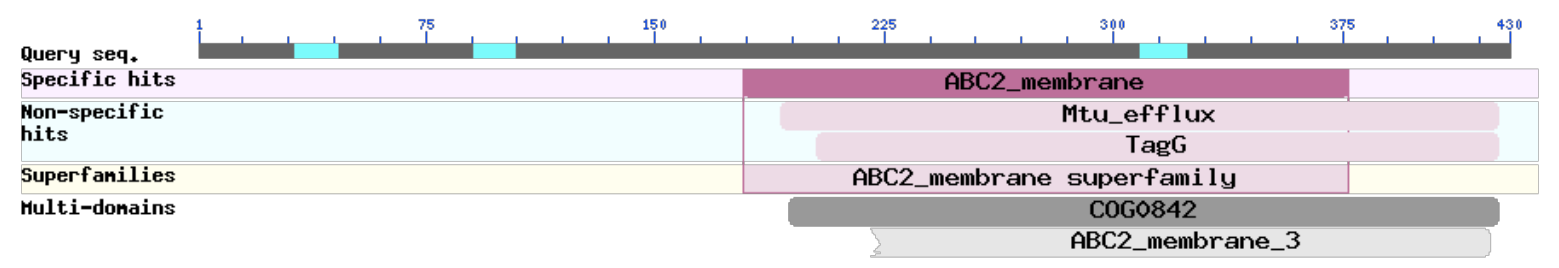

Mapa da sequência de aminoácidos do gene $\cos \mathrm{J}$ com o uso da ferramenta Delta-Blast (Domain Enhanced Lookup Time Accelerated BLAST) do NCBI (http://blast.ncbi.nlm.nih.gov/Blast.cgi?PAGE TYPE=BlastSearch\&PROGRAM=blastp\&BLAST_PROGRA MS=deltaBlast).

Através da análise feita pelo recurso DELTA BLAST (Figura 20) conclui-se que a proteína pertence à superfamília das proteínas $A B C$ associadas à membrana, porém foi realizada uma análise da sequência de aminoácidos para estabelecer como a estrutura está distribuída na membrana celular; a base de dados Phyre demostra que a sequência da região $\mathrm{N}$ terminal, até a parte $\mathrm{C}$ terminal, tem 6 hélices transmembranares (Figura 21). A probabilidade e predição das hélices foi conferida com a base de dados TMHMM confirmando seis regiões transmembranares da sequência com valor perto de 1 (Figura 22). Podemos inferir que a proteína transmembrana codificada pelo gene cosJ em $S$. olindensis concorda com a típica formação que apresentam as proteínas transmembranares (TM), de quatro a oito estruturas, em forma de hélices-alfa (usualmente seis) como neste caso (Figura 3-4), que se organizam como homodímeros (HOLLAND, 2011). 
Figura 21- Distribuição das hélices transmembranares

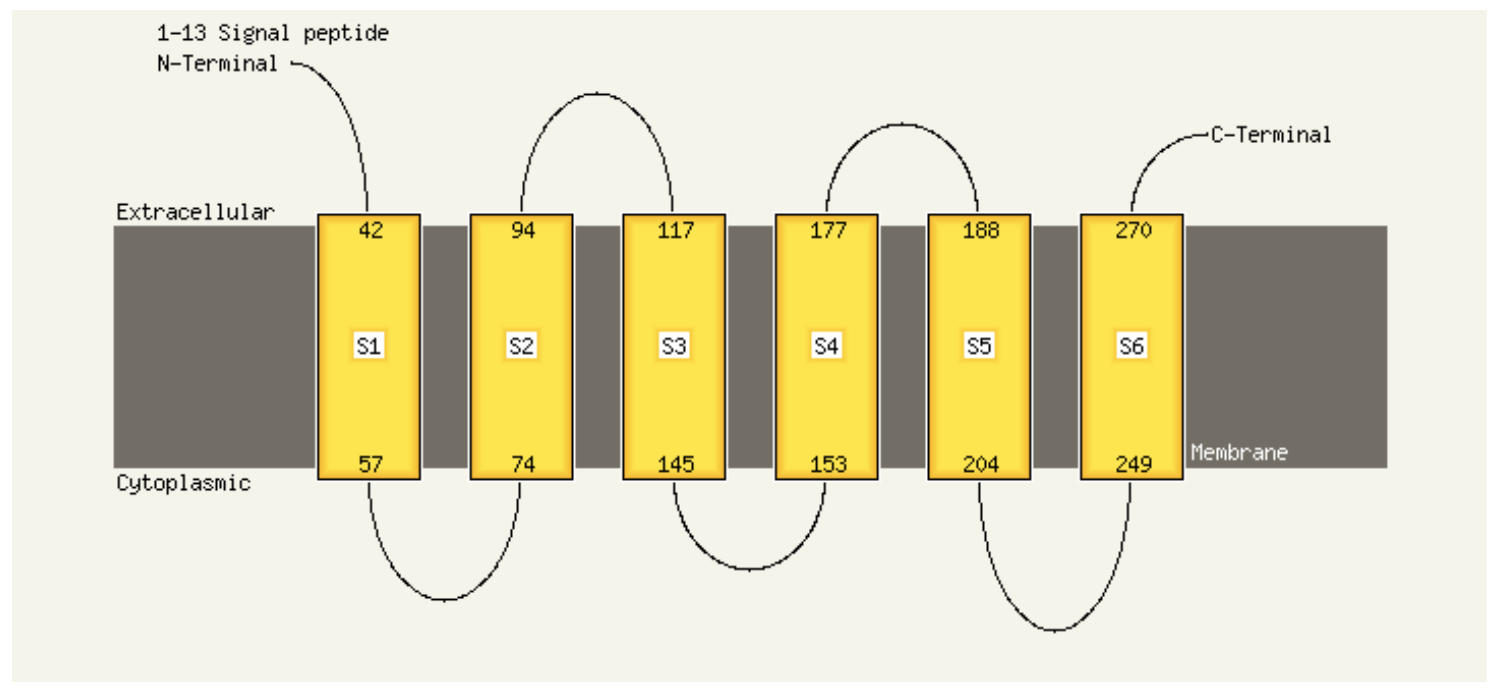

Predição e topologia das hélices transmembrana com uso do servidor Phyre 2 (http://www.sbg.bio.ic.ac.uk/phyre2/html/page.cgi?id=index).

Figura 22- Probabilidade de hélices transmembranares

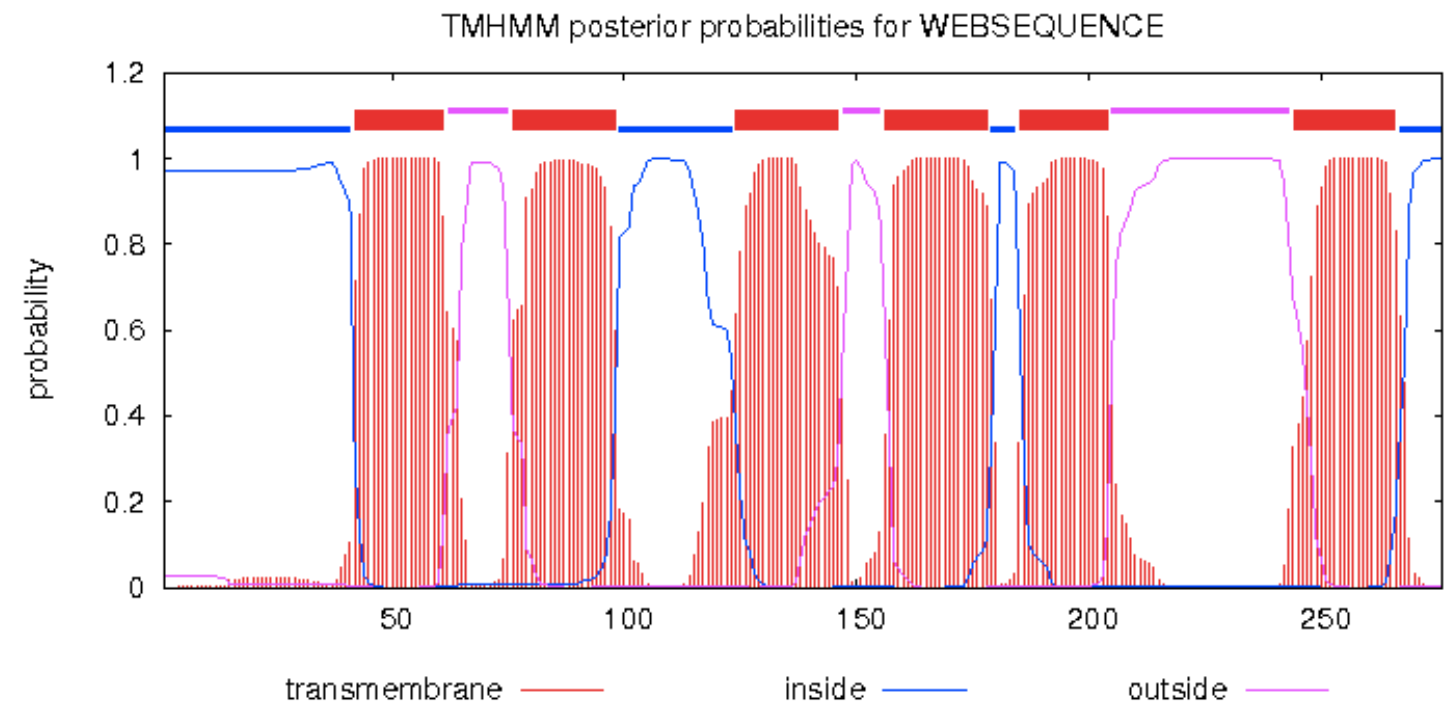

Gráfico de probabilidade e aminoácidos que atravessam a membrana com o uso do servidor TMHMM (http://www.cbs.dtu.dk/services/TMHMM-2.0). 


\subsubsection{Novo mecanismo hipotético com função peroxidase codificado pelo gene $\cos P$}

$\mathrm{Na}$ análise do cluster foi encontrado junto aos genes do complexo transportador $A B C$, um gene com função peroxidase (Figura 23) que provavelmente está envolvido na função de detoxificação contra radicais livres e peroxidação como produto do efeito das antraciclinas. É importante ressaltar que não existem referências que descrevam as peroxidases como essenciais nos mecanismos de resistência nos cluster codificantes de metabólitos secundários em Streptomyces.

Este gene, apresenta uma identidade de 99\% com Glutationa peroxidase [Streptomyces sp. NRRL WC-3641] e um e- valor de 5,6 e-74 com Streptomyces zinciresistens K42.

Figura 23- Delta Blast gene $\cos P$

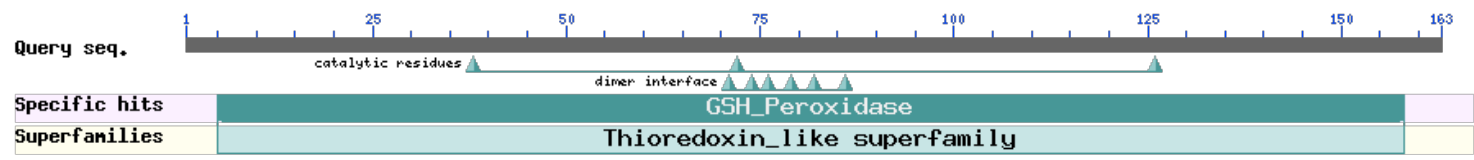

Análise da seqüência de aminoácidos do gene cos $P$ com o uso da ferramenta Delta-Blast (Domain $\begin{array}{lllll}\text { Enhanced } \quad \text { Lookup } & \text { Bccelerated } & \text { BST } & \text { do }\end{array}$ (http://blast.ncbi.nlm.nih.gov/Blast.cgi?PAGE_TYPE=BlastSearch\&PROGRAM=blastp\&BLAST PROGRA MS=deltaBlast).

5.1.3 Mecanismo de reparo de DNA pela proteína do tipo UvrA like codificada pelo gene $\cos U$

Este gene apresenta uma alta similaridade como o gene $d r r C$ de $S$ peucetius, que faz parte de um grupo de proteínas associado ao reparo do DNA. Com a análise da sequência (Figura 24) foi possível verificar uma deleção no domínio de ligação UvrB, de forma similar a proteínas do tipo UvrA like presentes em diferentes espécies de Actinobacteria , Firmicutes , Bacteroidetes e Proteobacteria (MARSZAŁKOWSKA et al., 2013). 
Figura 24- Delta Blast gene $\cos U$

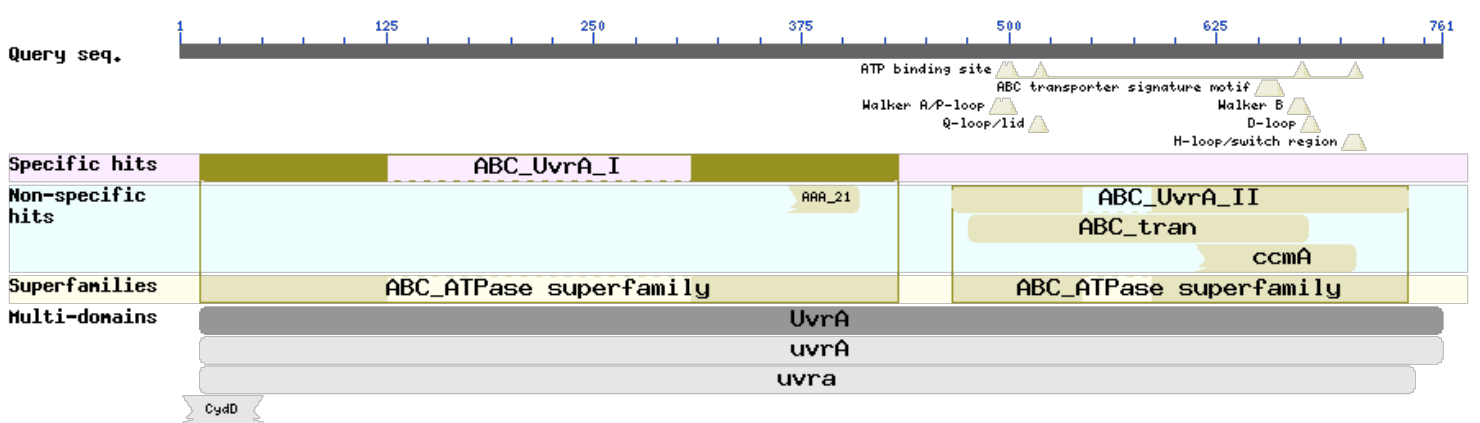

Análise da sequência de aminoácidos do gene $\operatorname{Cos} U$ com o uso da ferramenta Delta-Blast (Domain Enhanced Lookup Time Accelerated BLAST) do NCBI (http://blast.ncbi.nlm.nih.gov/Blast.cgi?PAGE TYPE=BlastSearch\&PROGRAM=blastp\&BLAST PROGRA MS=deltaBlast).

\subsection{Amplificação e clonagem dos genes $\cos I J, \cos P, \cos U$ e $\cos I J P U$ no vetor PEM4A}

Foram desenhados iniciadores complementares as regiões gênicas com possível função de resistência. Os iniciadores incluem uma região complementar as enzimas Xbal e EcoRI (Tabela 4) com o fim de facilitar o sentido e a inserção no vetor PEM4A (Figura 27). Os fragmentos gênicos com os tamanhos e funções esperadas formam amplificados nas reações de PCR com os iniciadores mencionados na tabela 4 usando como molde DNA de S. olindensis.

Figura 25- Mapa físico dos genes de resistência e posição dos iniciadores desenhados

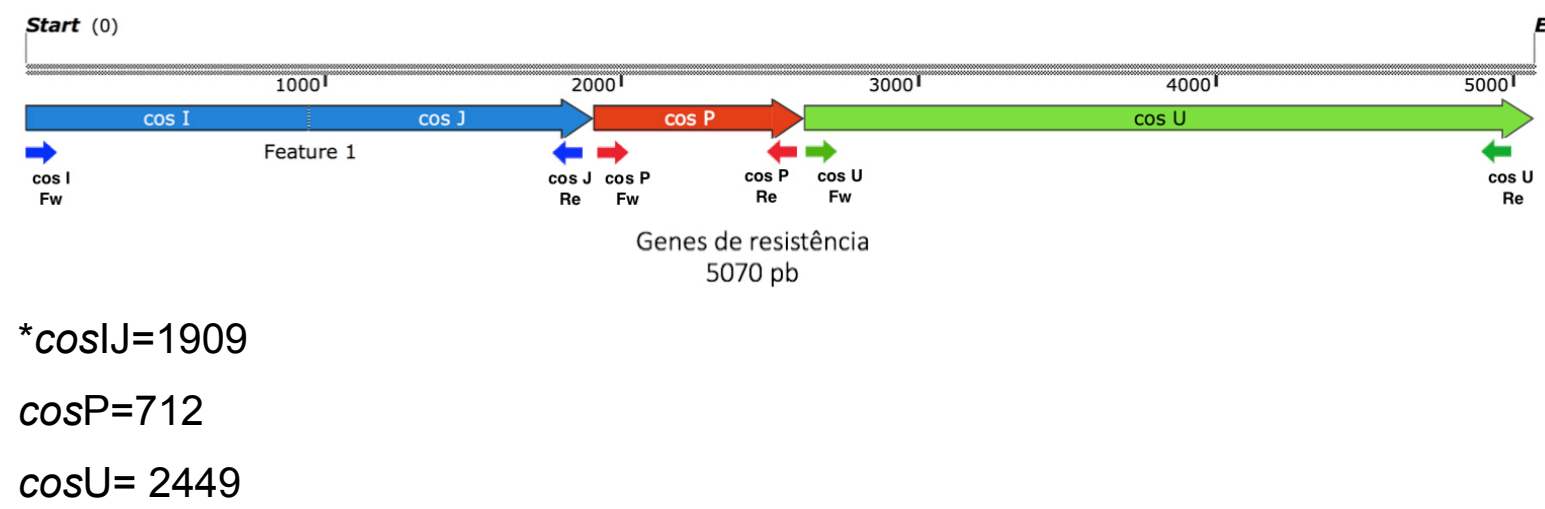


Uma vez padronizadas as condições de PCR, foi realizada a verificação por meio de eletroforese em gel de agarose, e sequenciados seus produtos de PCR (Figura 26).

Figura 26- Amplificação por PCR dos genes $\cos / J, \cos P, \cos U, \cos / J P U$

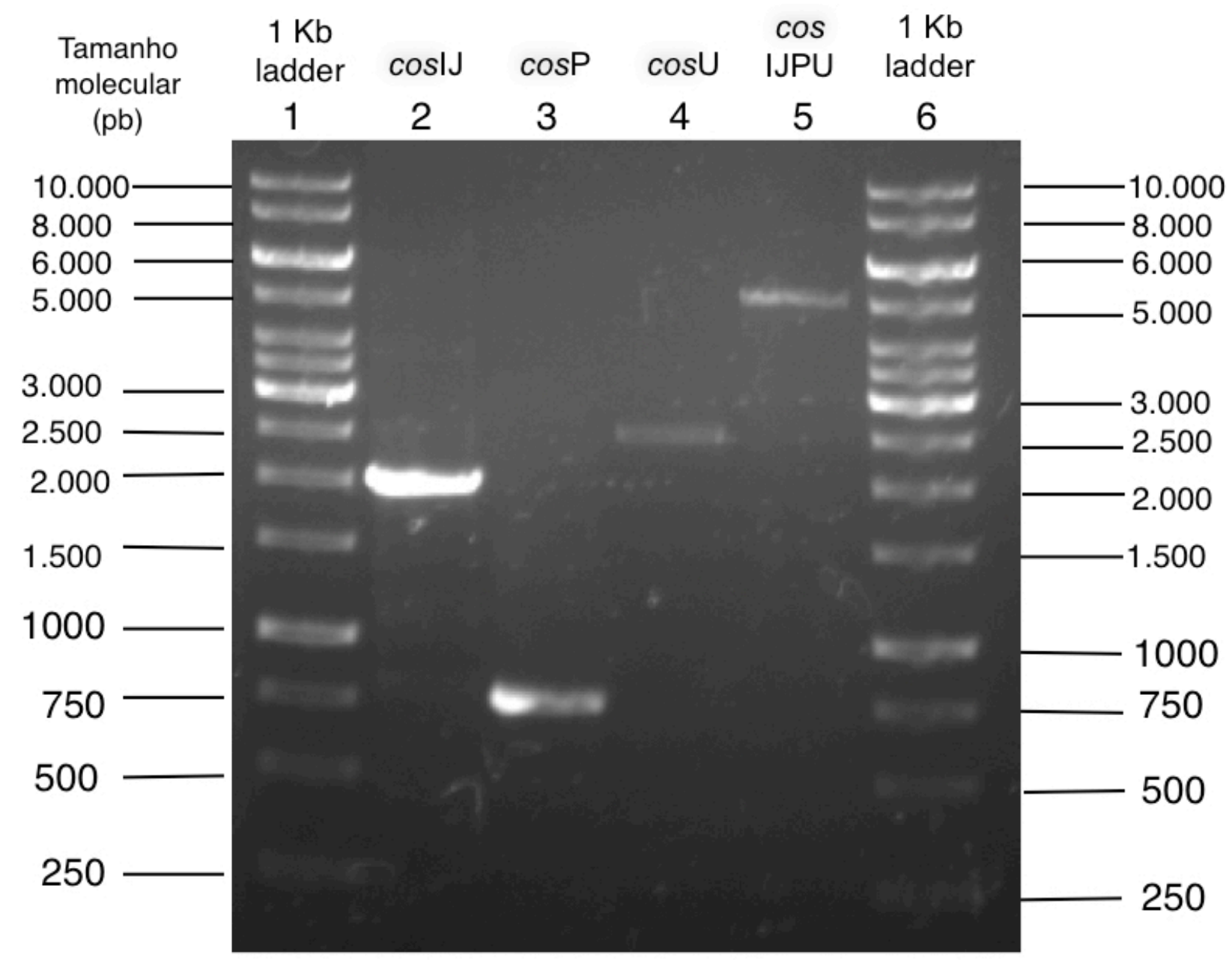

1. $1 \mathrm{~Kb}$ (Thermo scientific), 2. $\cos / J, 3 . \cos P, 4 . \cos U, 5 . \cos / J P U$ 6. $1 \mathrm{~Kb}$ (Thermo scientific).

Os genes $\cos / J, \cos P$ e $\cos U$ e seu conjunto $\cos / J P U$ após a reação de PCR, foram digeridos com as enzimas de restrição Xbal e EcoRI e clonados diretamente no vetor PEM4A.

O vetor pEM4A (Figura 8) tem um promotor constitutivo $e^{2} E^{*}$ da eritromicina o 
que permite a expressão eficiente de genes em microrganismos do gênero Streptomyces spp. (BLANCO et al., 2001).

Figura 27- Mapa físico do plasmídeo PEM4A utilizado para realizar as construções contendo os genes de resistência.

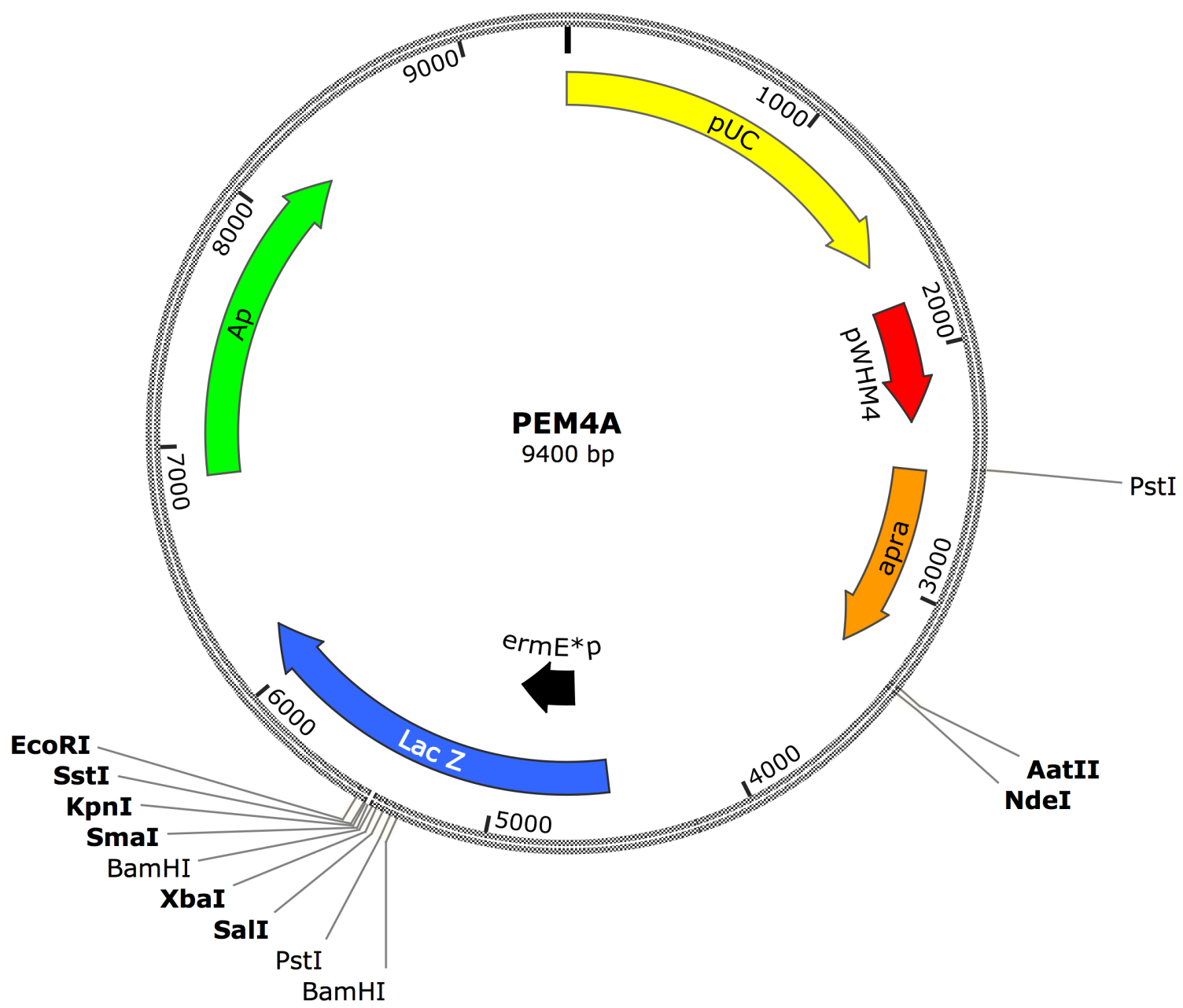

$\operatorname{Apr}^{R}$ (Resistência a apramicina). LacZ (gene repórter de $\beta$ Galactosidase e sitio múltiplo de clonagem). ermE* $^{*}$ (promotor constitutivo). Tamanho aproximado de 9,4Kb. 
Células eletrocompetentes de E. coli $\mathrm{DH} 10 \mathrm{~B}$ foram usadas para a transformação com a mistura de ligação e a obtenção dos plasmídeos recombinantes. As construções foram confirmadas por análise de restrição (Figura 28). A clivagem liberou dois fragmentos referentes ao vetor vazio $(9,4 \mathrm{~Kb})$ e os insertos contendo os genes (cos/J, $\cos P, \cos U \cos (J P U)$ (Figura 25). Os plasmídeos resultantes foram denominados pRD8001, pRD8002, pRD8003 e pRD8004 (Anexo 1). Os plasmídeos recombinantes foram usados para o sequenciamento dos insertos, sendo que todos apresentaram o gene correto.

Figura 28- Restrição dos plasmídeos recombinantes pRD8001,8002, 8003, 8004 (Hindlll e EcoRI).

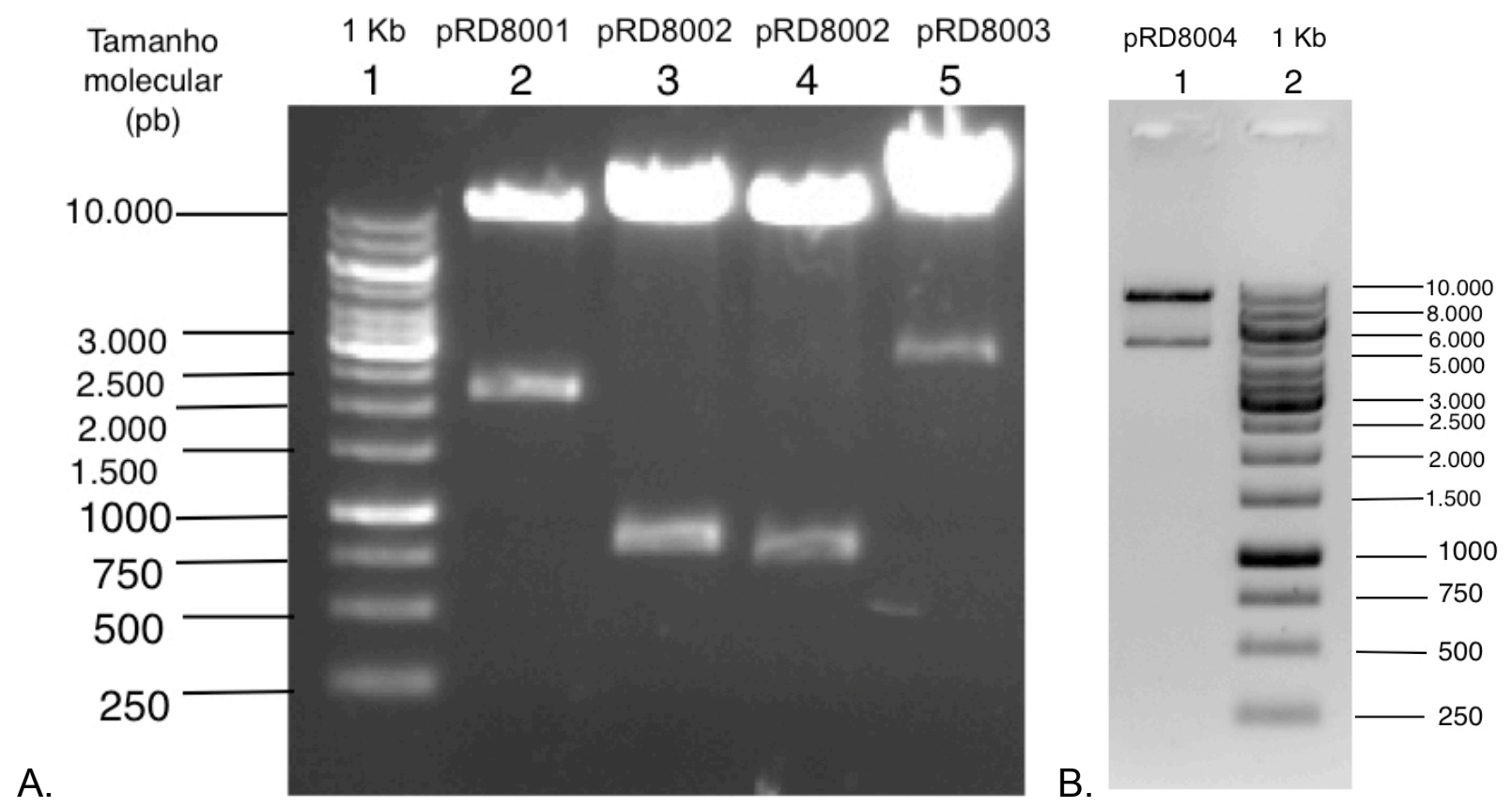

A. 1. $1 \mathrm{~Kb}$ (Thermo scientific), 2. pRD8001, 3. pRD8002, 4. pRD8002, 5. pRD8003. B. 1. pRD8004, 2. 1Kb (Thermo scientific). 
O gênero Streptomyces possui um sistema de restrição de metilo-dependente que reduz significativamente a eficiência de transformação quando o DNA é metilado (GONZÁLEZ-CERÓN; MIRANDA-OLIVARES; SERVÍN-GONZÁLEZ, 2009). Após a confirmação dos plasmídeos recombinantes provenientes da linhagem E. coli DH10B, estes foram transformados em células eletrocompetentes de E. coli ET12567, obtendo DNA plasmidial não metilado, para o posterior uso em a linhagem Streptomyces albus $\mathrm{J} 1074$.

\subsection{Análise de resistência em transformantes de $S$. albus $(\cos / J, \cos P, \cos U$, $\cos (J P U)$}

Foram inoculados $10^{7}$ esporos $/ \mathrm{mL}$ das linhagens de Streptomyces selvagens e recombinantes durante 24 e 48 h no meio R2YE contendo Doxorubicina e extrato bruto de cosmomicina $D$ entre 0 e $200 \mu \mathrm{g} / \mathrm{mL}$. A concentração de $150 \mu \mathrm{g} / \mathrm{mL}$ é classificada como resistente e $200 \mu \mathrm{g} / \mathrm{mL}$ altamente resistente em Streptomyces para o antibiótico Doxorubicina (WESTMAN et al., 2012). Foi evidente que a super-expressão dos genes de resistência nas linhagens recombinantes $S$. albus 8001, 8002, 8003, 8004 confere uma vantagem com relação ao $S$. albus 8000 contendo unicamente o plasmídeo fechado. As linhagens recombinantes contendo os genes $\cos I \mathrm{~J}, \cos U, \cos I J P U$ apresentaram MIC entre 150 e $200 \mu \mathrm{g} / \mathrm{mL}$, cosP de $100 \mu \mathrm{g} / \mathrm{mL}$ e a linhagem selvagem de $25 \mu \mathrm{g} / \mathrm{mL}$. A linhagem S. olindendis apresentou MIC $>200 \mu \mathrm{g} / \mathrm{mL}$ sendo classificado como altamente resistente para doxorubicina (Tabela 7). Para cosmomicina os MICs foram menores comparados com doxorubicina, no entanto continuam tendo a vantagem com respeito à linhagem controle $S$. albus 8000 . É importante ressaltar que este resultado indica e confirma a hipótese de que a cosmomicina é mais toxica que a antraciclina de referência DOX. (Figura 29). 
Tabela 7- Concentração mínima inibitória (MIC). Susceptibilidade à doxorubicina e cosmomicina D.

\begin{tabular}{llcc}
\hline Linhagem & Genótipo & \multicolumn{2}{c}{ MIC $(\boldsymbol{\mu g} / \mathbf{m L})$} \\
& & Doxorubicina & Cosmomicina D \\
\hline S. olindensis & Wild-type & $>200$ & $>250$ \\
S. albus 8000 & pEM4A & 25 & 10 \\
S. albus 8001 & pRD8001 & 150 & 75 \\
S. albus 8002 & pRD8002 & 50 & 25 \\
S. albus 8003 & pRD8003 & 150 & 50 \\
S. albus 8004 & pRD8004 & 200 & 75 \\
\hline
\end{tabular}

Figura 29- Concentração mínima inibitória de Doxorubicina em Streptomyces albus selvagem (WT)

A.

S. olindensis

S. albus 8000
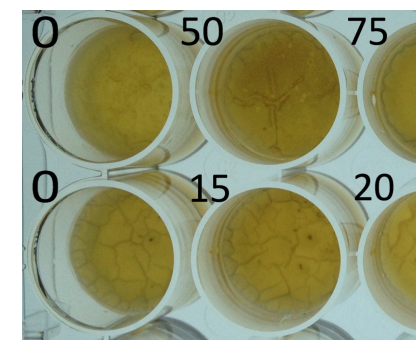

$25 *$
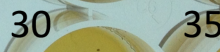

S. albus 8001

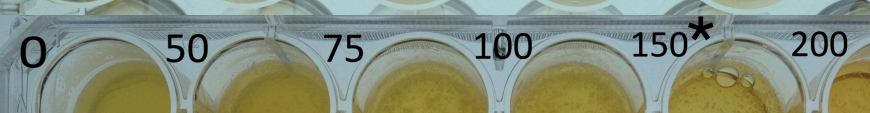

S. albus 8002
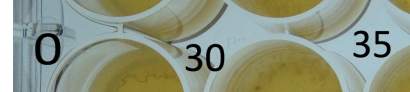

40

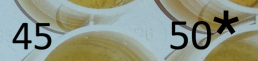

S. albus 8003

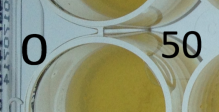

75

100

$150 *$

200

S. albus 8004

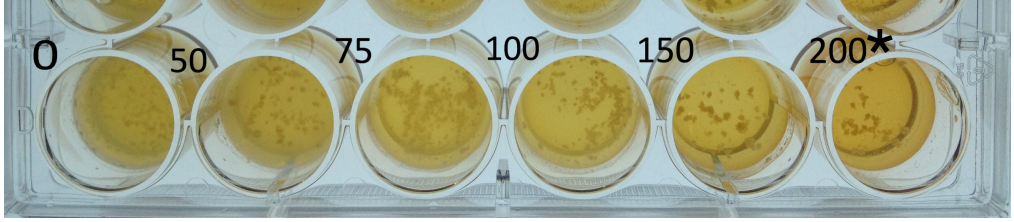


B.

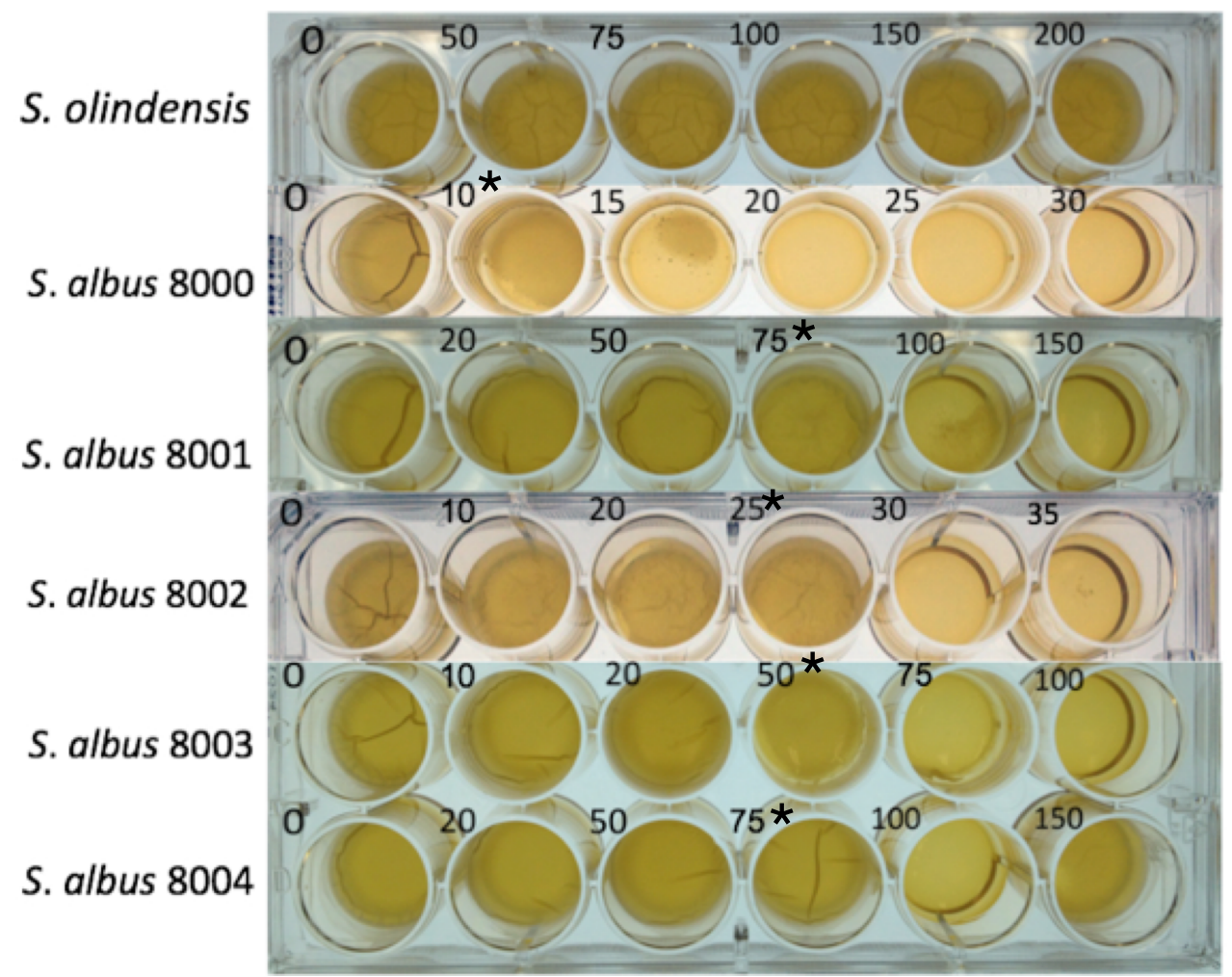

(Painel A 1-6) S. olindensis (wt), S. albus 8000 (pEM4A), S. albus 8001 (pRD8001), S. albus 8002 (pRD8002), S. albus 8003 (pRD8003), S. albus 8004 (pRD8004) contendo Doxorubicina com uma concentração de 0 - $200 \mu \mathrm{g} / \mathrm{mL}$. (Panel B 1-6) S. olindensis (wt), S. albus 8000 (pEM4A), S. albus 8001 (pRD8001), S. albus 8002 (pRD8002), S. albus 8003 (pRD8003), S. albus 8004 (pRD8004) contendo cosmomicina D com uma concentração de 0- $200 \mu \mathrm{g} / \mathrm{mL}$. *Ponto de inibição 


\subsection{Níveis de expressão dos genes de resistência em $S$. albus $8001,8002,8003,8004$ por qPCR.}

As linhagens recombinantes de $S$. albus que contém os genes de resistência, podem ter diferentes níveis de expressão, quando comparadas a S. olindensis. Isto pode estar relacionado ao fato destes genes serem regulados pelo promotor ermE* $p$ (promotor constitutivo) e apresentarem diferenças significativas que não foram perceptíveis na análise de concentração mínima inibitória (MIC); o tamanho do inserto no plasmídeo pode influir nos níveis de expressão quando é controlado pelo promotor ermE* $p$. Verificou-se que os genes envolvidos na resistência da cosmomicina apresentam diferenças de expressão quando submetidos a um promotor diferente do promotor natural e durante a produção do antibiótico. Para esta análise, foi extraído RNA das linhagens de $S$. albus recombinantes e foi sintetizado seu correspondente cDNA. A expressão dos genes foi determinada por qPCR (Figura 30). De igual maneira, foram desenhados iniciadores específicos para o gene endógeno controle dnaJ de $S$. olindensis e S. albus J1074.

Figura 30- PCR quantitativa- real time dos genes $\cos \mathrm{J}, \cos \mathrm{P}$ e $\cos \mathrm{U}$.

$\cos J$

25

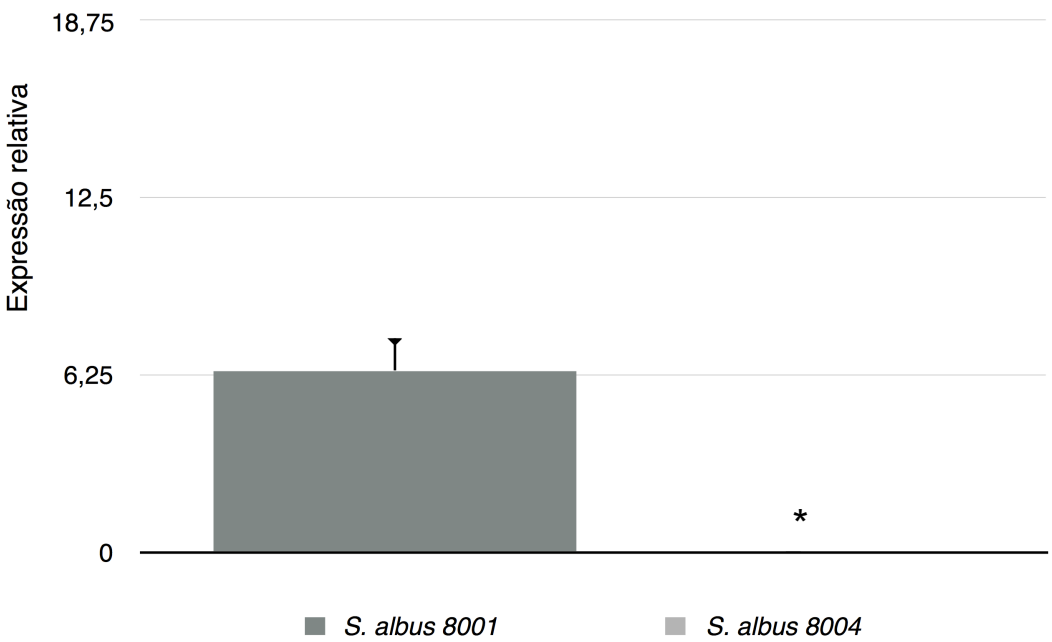


$\cos P$

25

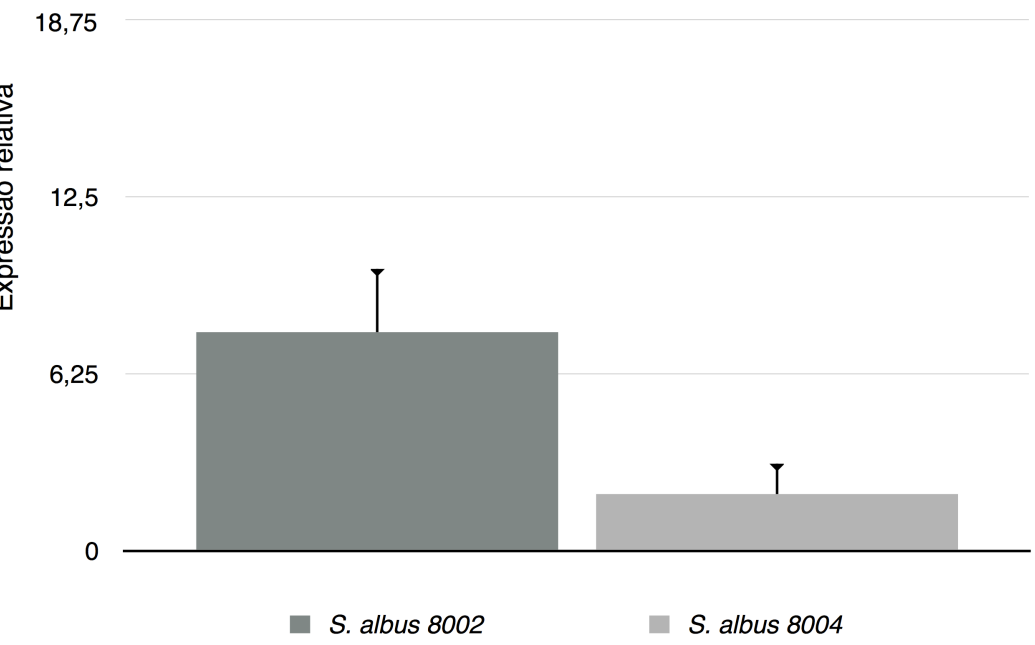

$\cos U$

25

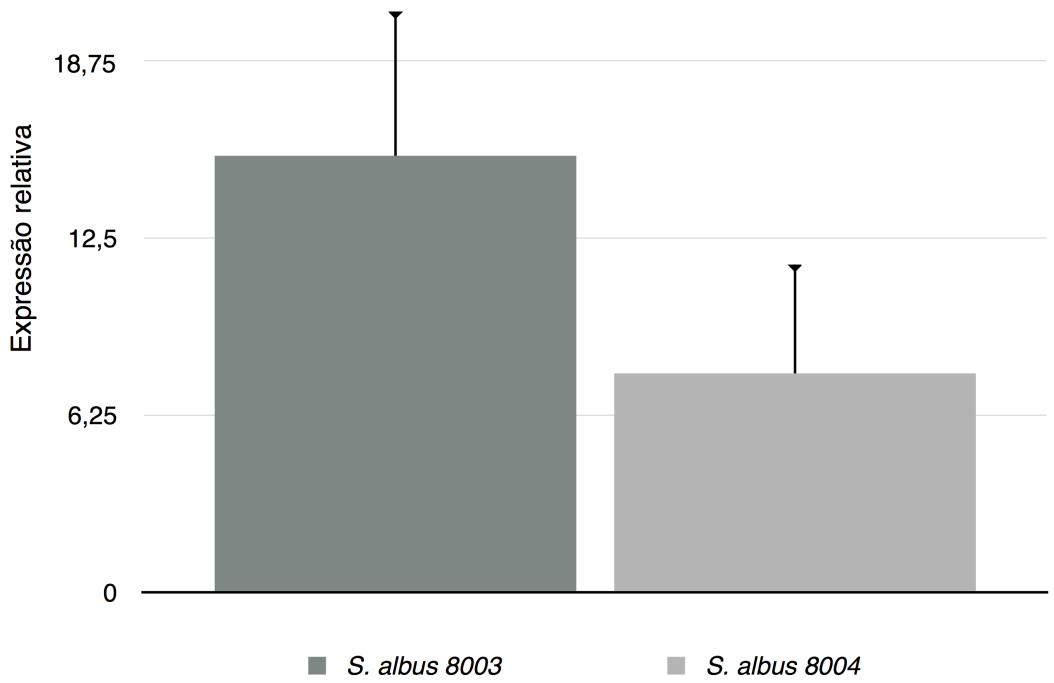

Determinação dos níveis relativos de expressão apos $48 \mathrm{~h}$ de crescimento nas linhagens recombinantes de $S$. albus $8001,8002,8003$ comparadas com S. albus 8004 usando o gene DNAJ como endógeno Os valores são a média de determinações em triplicata \pm desvio padrão (SD) *Diferença significativa T test. 
5.5 Resposta da enzima Glutationa peroxidase à peroxidação lipídica causada por estresse com cosmomicina $D$.

Foram avaliados o estresse causado pelo antibiótico através da peroxidação lipídica e quantificação de $\mathrm{H}_{2} \mathrm{O}_{2}$ durante o crescimento de $S$. olindensis WT, $S$. olindensis APKS mutante bloqueado para a síntese do antibiótico, e S. albus 8002 abrigando o gene da glutationa peroxidase ( $\operatorname{cosP})$, estressado com concentrações subinibitórias de cosmomicina D (Figura 31).

Figura 31- Peroxidação lipídica (A e B) e quantificação de $\mathrm{H}_{2} \mathrm{O}_{2}$ (C e D).

A.

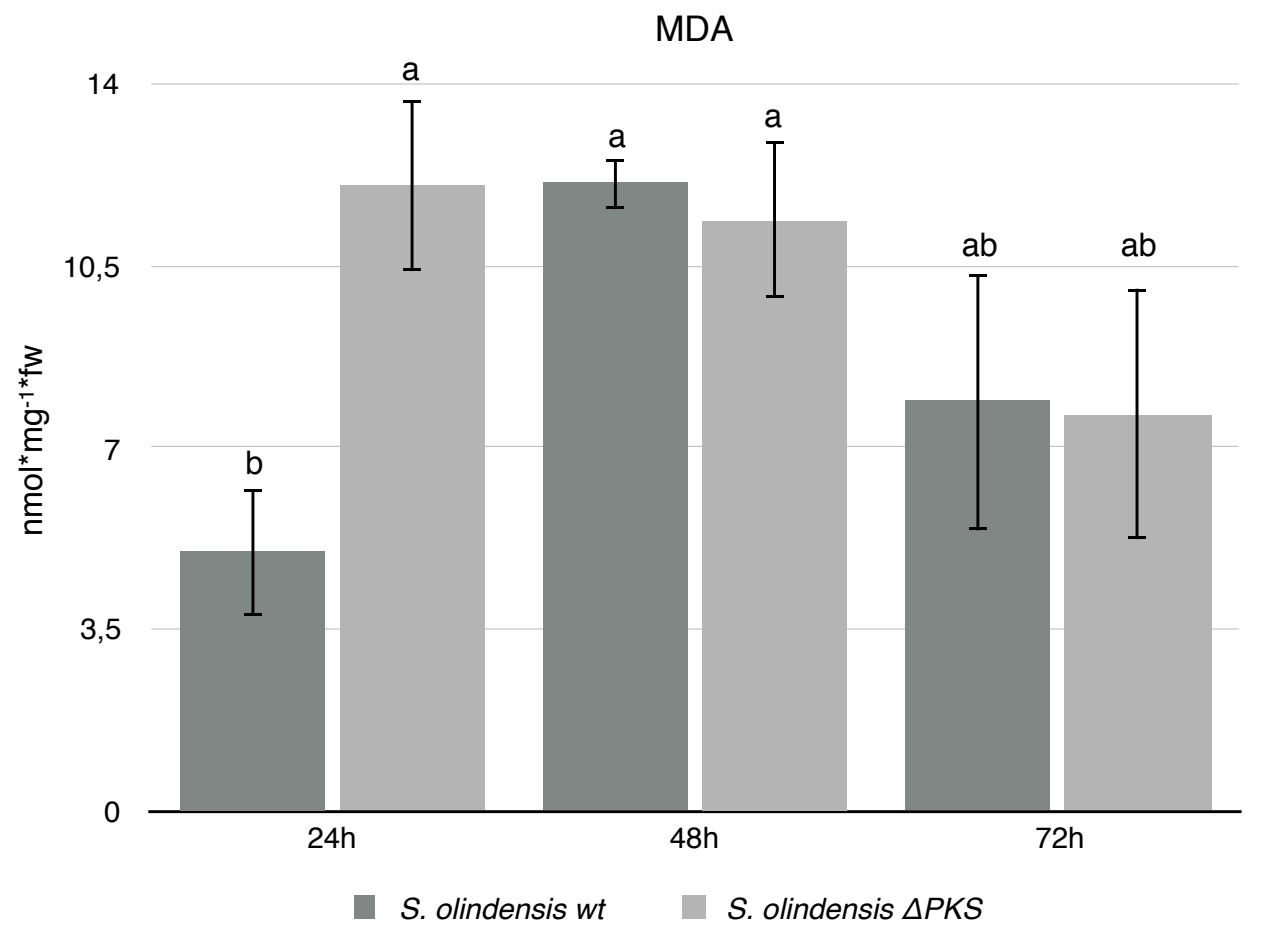

B. 
MDA

14

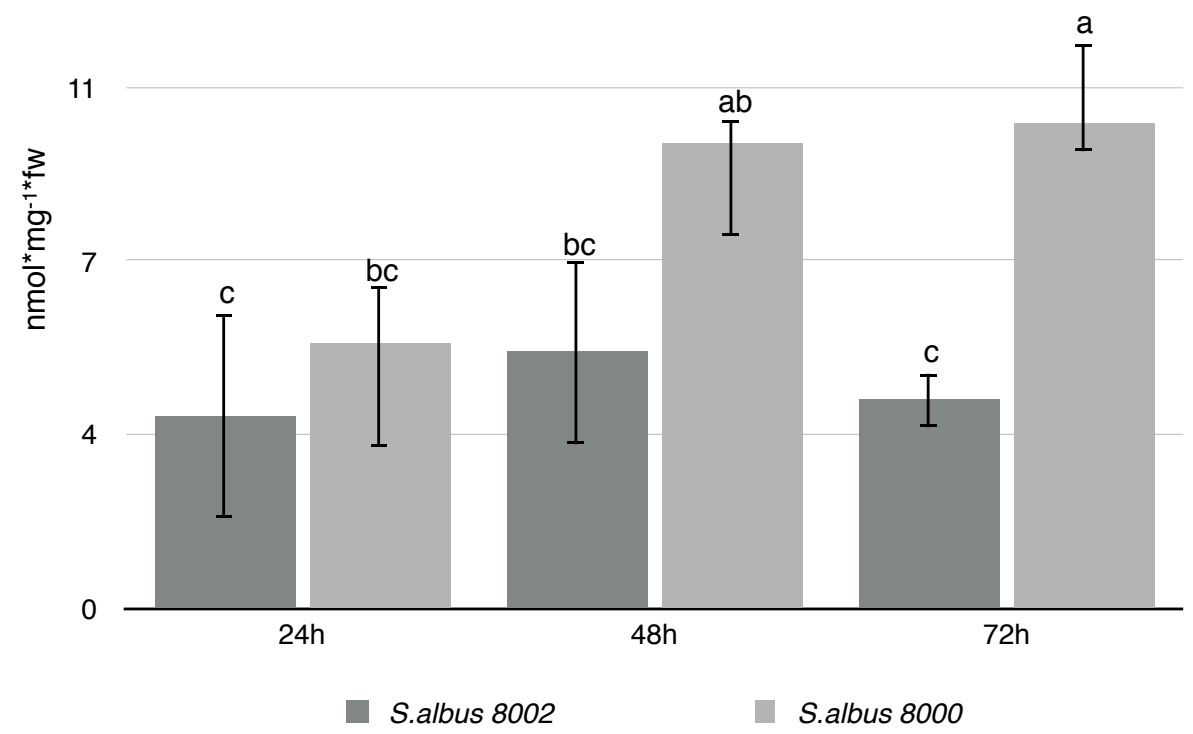

C.

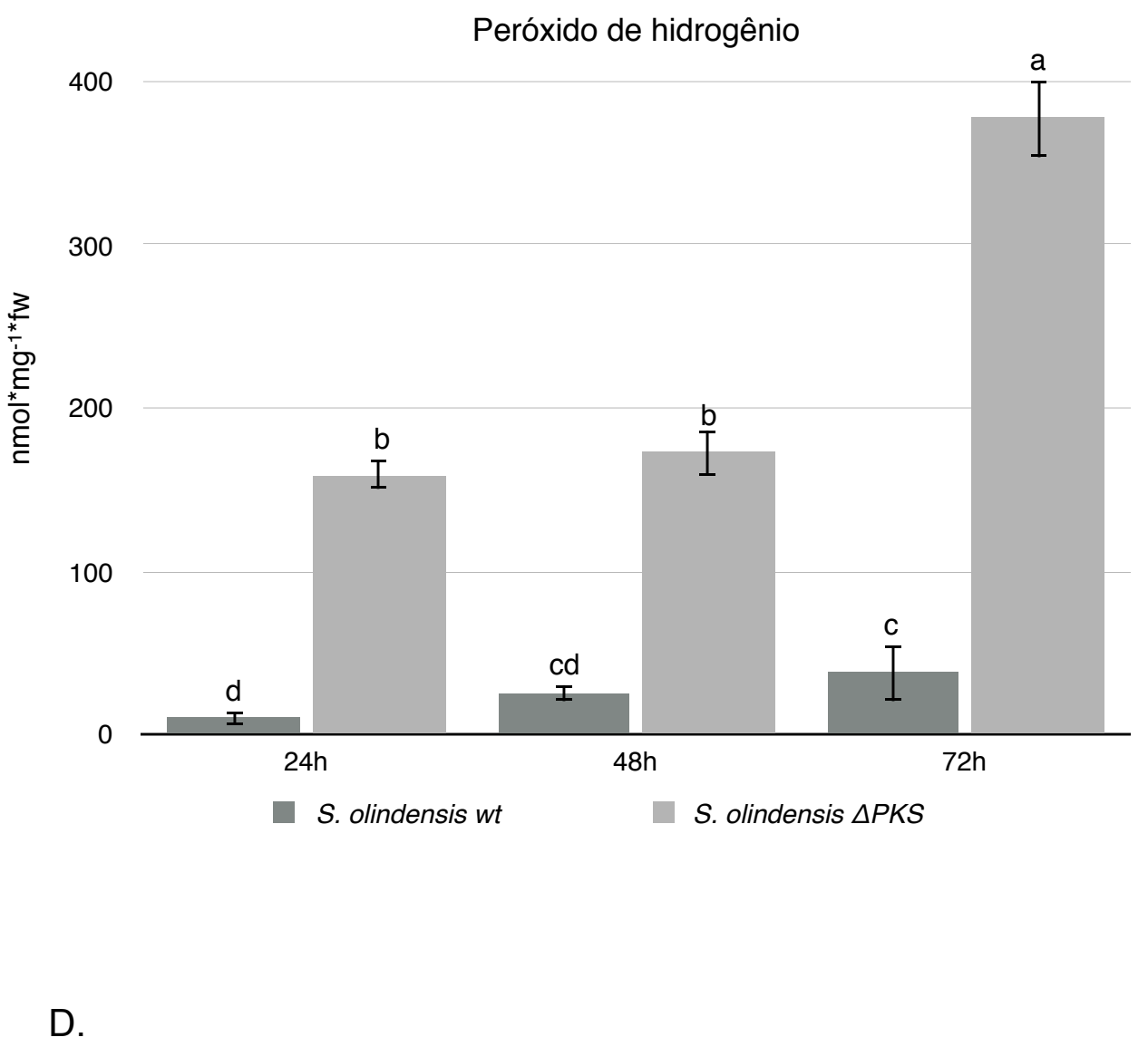


Peróxido de hidrogênio

400
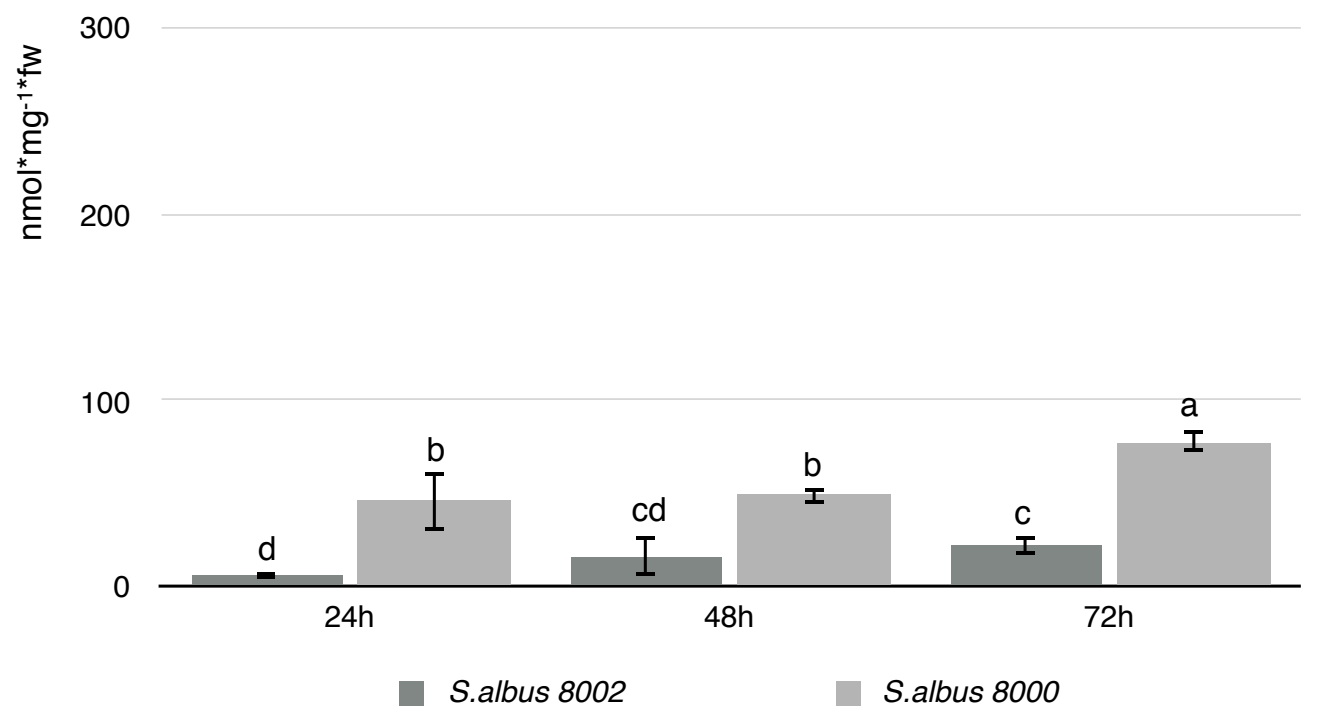

* S. olindensis produtor de cosmomicina D, S. olindensis $\Lambda \mathrm{PKS}$ bloqueado para a produção do

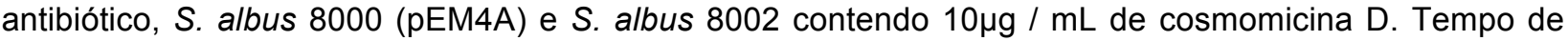
crescimento foi de $72 \mathrm{~h}$. Os valores são a média de determinações em triplicata \pm desvio padrão (SD), análise de variância (ANOVA) $<0,05$. Análise de comparação pelo teste de Duncan.

Aumentos transitórios na peroxidação lipídica foram observados com o ácido tiobarbitúrico nas linhagens de S. olindensis APKS e S. albus J1074, e em menor quantidade de malondialdeído (MDA) em S. olindensis WT e na linhagem recombinante S. albus 8002 durante $72 \mathrm{~h}$ de crescimento. As linhagens que contêm glutationa peroxidase ( $\cos \mathrm{P})$ mostraram uma diminuição significativa na produção de $\mathrm{H}_{2} \mathrm{O}_{2}$, com respeito ao controle $S$. albus 8002 (Figura 31D). No entanto, a linhagem mutante $S$. olindensis PPKS apresentou níveis maiores de peroxidação, o que pode estar relacionado com a repressão do gene cosP quando não há produção do antibiótico (Figura 31C). 


\subsection{Níveis de expressão dos genes de resistência por RT-PCR e qPCR em $S$. olindensis}

Durante a análise de peroxidação lipídica, a linhagem $S$. olindensis $\Lambda P K S$ apresentou níveis entre 159 e $376 \mathrm{~nm}^{*} \mathrm{mg}^{-1} \mathrm{fw}_{\mathrm{w}}$ em relação à linhagem selvagem, que apresentou um nível máximo de $38,04 \mathrm{~nm}^{*} \mathrm{mg}^{-1} \mathrm{fw}$. Verificou-se que se os genes envolvidos na resistência da cosmomicina são expressos quando o microrganismo está produzindo o antibiótico.

Foram realizadas análises da expressão gênica, dos genes $\cos J$ e $\cos U$, e do gene com função peroxidase, $\cos P$. Assim, foi extraído RNA (Figura 32) e posteriormente sintetizado o correspondente cDNA. A expressão destes genes foi determinada por RTPCR, denotando que os genes associados à resistência se encontravam induzidos na condição de produção de antibiótico. De igual maneira, foram desenhados iniciadores específicos (Tabela 4) para o gene endógeno dnaJ (ATPase envolvida no enovelamento protéico) de $S$. olindensis para comparar sua expressão como controle nas condições de produção e não produção do antibiótico (Figura 33). 
Figura 32- O RNA total extraído durante $48 \mathrm{~h}$ de crescimento das linhagens $\mathrm{S}$. olindensis WT e S. olindensis $\Lambda$ PKS (antes do tratamento com DNAse)

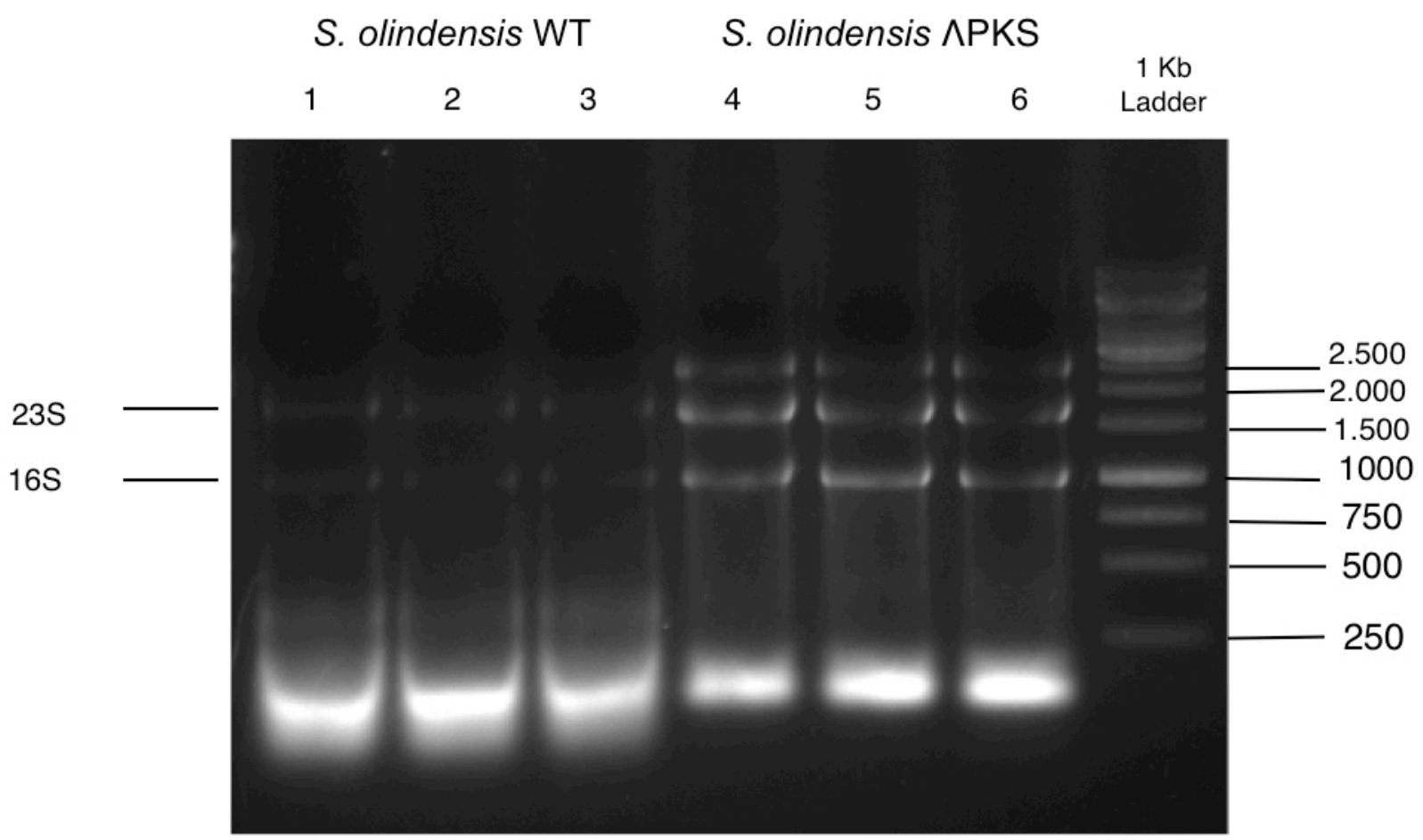

1-3. (S. olindensis wild type), 4-6. (S. olindensis $\triangle \mathrm{PKS})$, 7. (1 Kb ladder Thermo scientific).

Os resultados de RT-PCR, durante a produção do antibiótico cosmomicina $D$, mostraram que os genes cosJ, $\cos P$, e $\cos U$ estão sendo expressos, quando o microrganismo começa a produção da cosmomicina aproximadamente as $48 \mathrm{~h}$ de crescimento. O gene endógeno de referência foi o gene dnaJ (Figura 33). 
Figura 33- Eletroforese RT-PCR

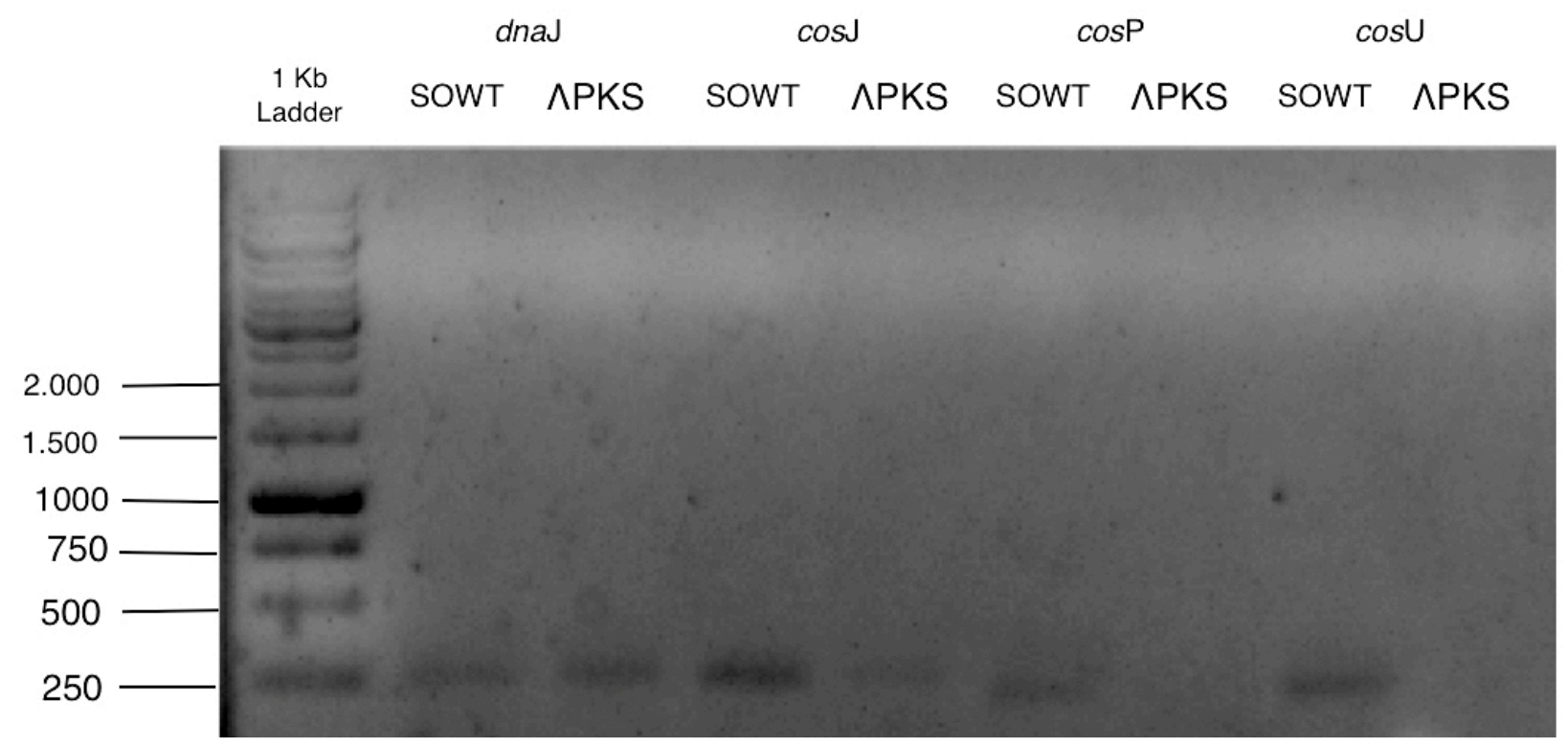

$1 \mathrm{~Kb}$ ladder Thermo scientific; 2. S. olindensis WT gene DNAJ; 3. S. olindensis $\triangle \mathrm{PKS}$ gene DNAJ 4. S. olindensis WT gene cosJ; 5. S. olindensis $\triangle \mathrm{PKS}$ gene cosJ 6. S. olindensis WT gene cosP; 7. S. olindensis $\triangle \mathrm{PKS}$ gene cosP 8. S. olindensis WT gene cosU; 9. S. olindensis $\triangle \mathrm{PKS}$ gene cosU.

Figura 34- PCR quantitativa- real time dos genes cosJ, cosP e cosU durante a produção e não produção do antibiótico na linhagem selvagem S. olindensis

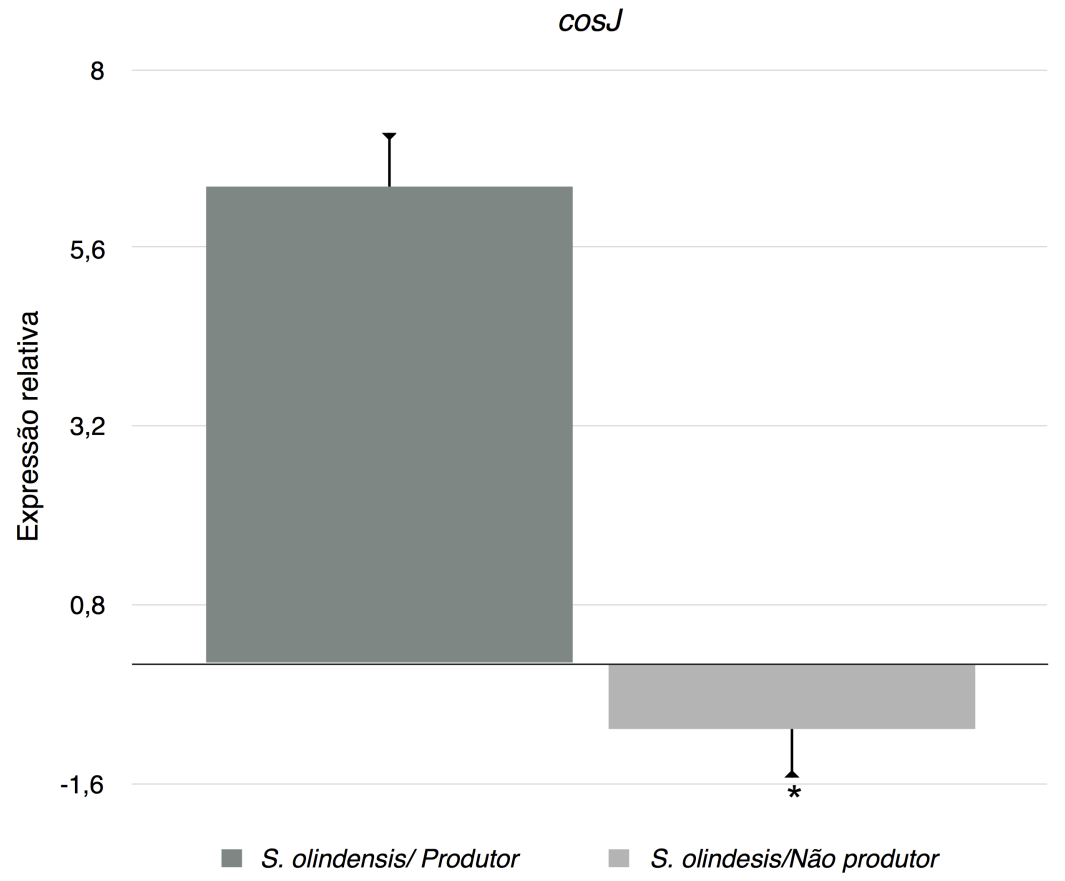


$\cos P$

8

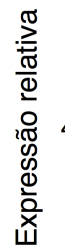

2

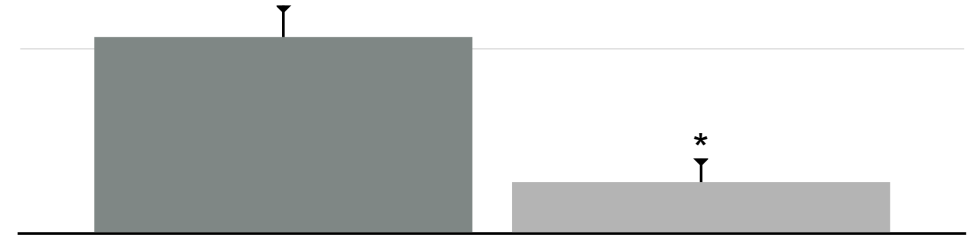

S. olindensis/Produtor

S. olindensis/Não produtor

$\cos U$

8

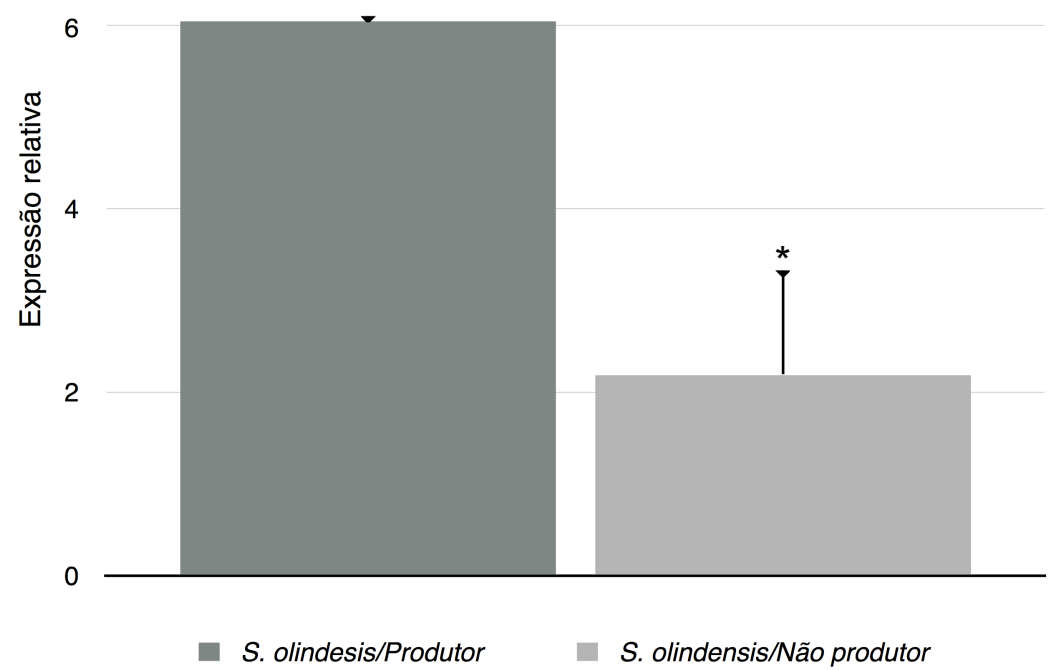

Determinação dos níveis relativos de expressão dos genes de resistência apos $48 \mathrm{~h}$ de crescimento da linhagem selvagem $S$. olindenis durante a produção e não produção do antibiótico usando o gene DNAJ como endógeno Os valores são a média de determinações em triplicata \pm desvio padrão (SD) *Diferença significativa $\mathrm{T}$ test. 


\subsection{Western Blotting da linhagem recombinante S. albus 8002}

Durante a análise de expressão foi possível concluir que os genes de resistência são expressos durante a produção do antibiótico na linhagem selvagem de $S$. olindensis. No entanto os níveis de expressão da enzima GPx da linhagem recombinante podem variar devido a que o gene cosP encontrasse baixo o controle do promotor constitutivo ermEp*. Verificou-se então a quantidade enzimática produzida da linhagem recombinante e sobre concentrações subinibitorias das antraciclinas (Figura 35).

Figura 35- Western Blot e quantificação da enzima Glutationa peroxidase com o anticorpo GPx1 na linhagem recombinante S. albus 8000 e 8002

A)

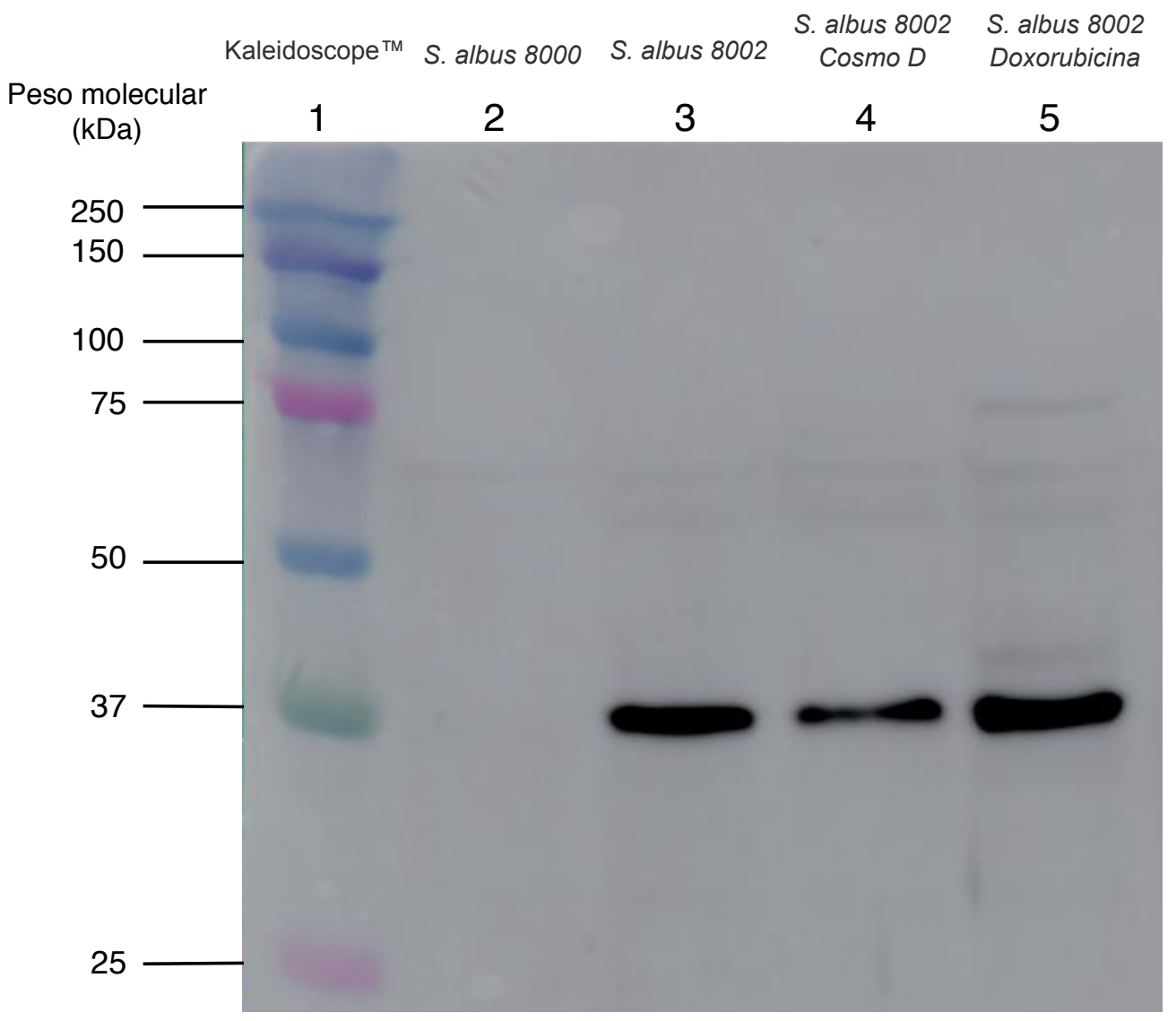


B)

\section{GPx-1}

20

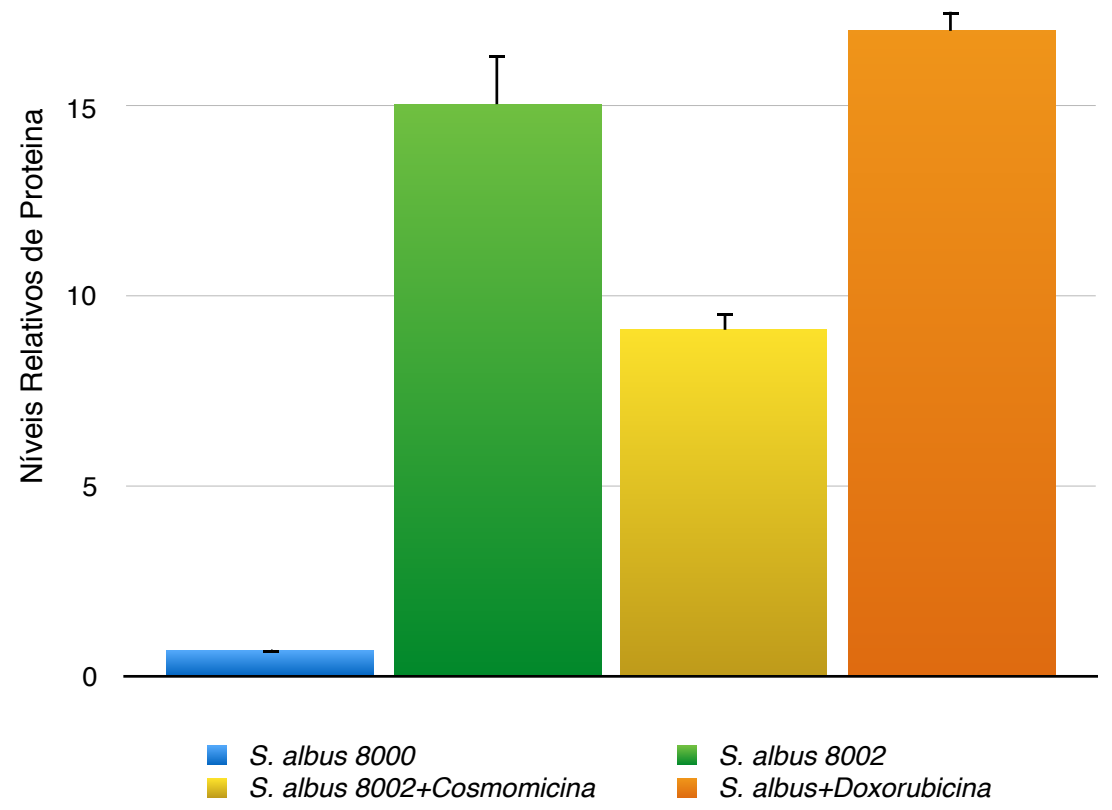

A) 1. Marcador Kaleidoscope ${ }^{\mathrm{TM}}$ (Bio-Rad Inc), 2. S. albus 8000, 3. S. albus 8002, 4. S. albus $8000+$ Cosmomicina D 5. S. albus $8000+$ Doxorubicina. B) Gráfico de barras para a comparação quantitativa entre os níveis de expressão de proteína GPx 1.

\subsection{Atividade enzimática da Glutationa peroxidase como resposta ao estresse por Doxorubicina e Cosmomicina D.}

A atividade da enzima GPx esta diretamente relacionada com a presença do antibiótico e é significativamente diferente nas linhagens que não apresentam expressão do gene $\cos P$ (Figura 35). 
Figura 36- Atividade da enzima Glutationa peroxidase

\section{Atividade de GPx}

220

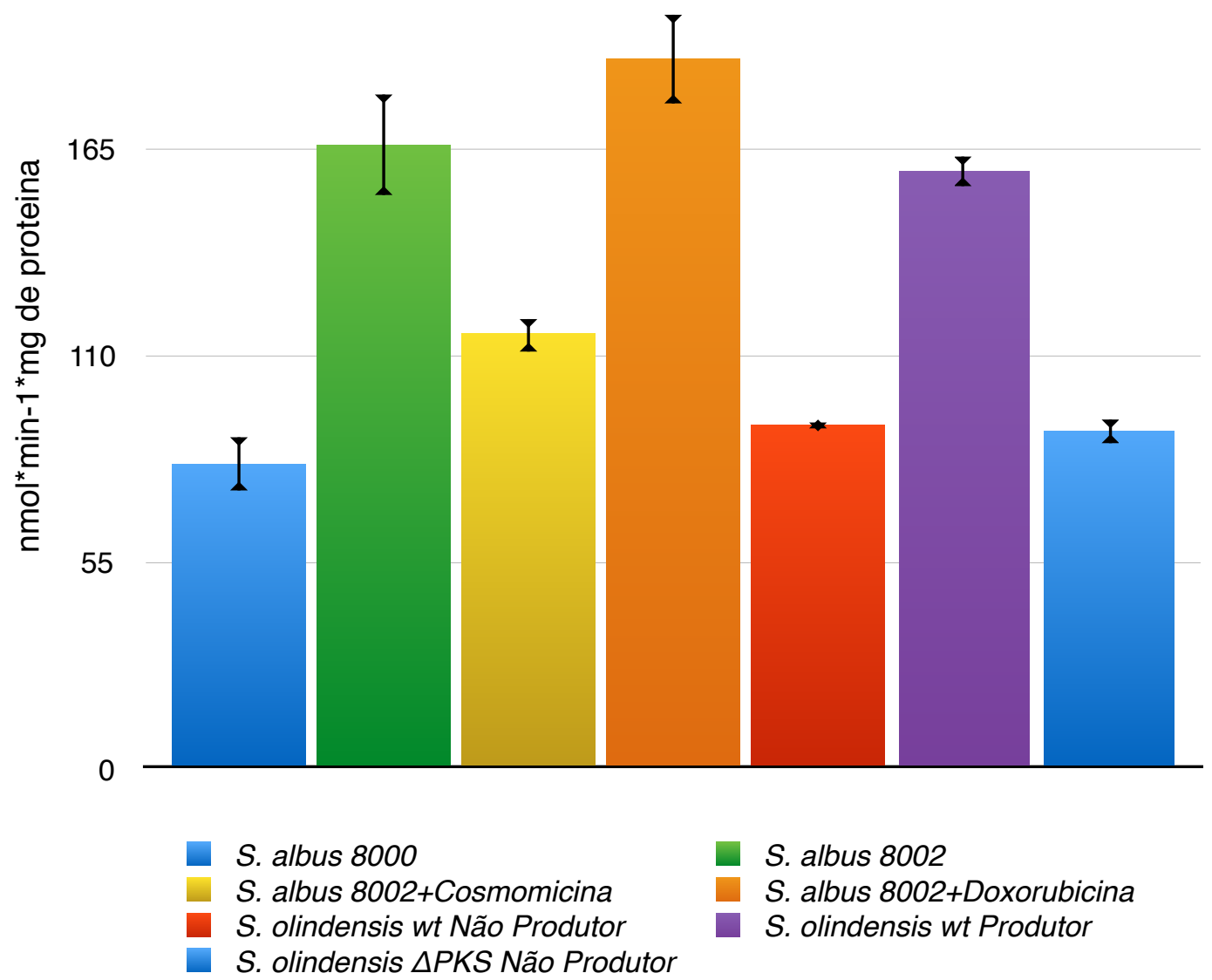

* S. olindensis wt produtor e não produtor de cosmomicina D. S. olindensis $\Lambda$ PKS bloqueado para a produção do antibiótico, S. albus 8000 (pEM4A) e S. albus 8002 contendo $10 \mu \mathrm{g} / \mathrm{mL}$ de cosmomicina D e $25 \mu \mathrm{g} / \mathrm{mL}$ de Doxorubicina. Tempo de crescimento foi de $48 \mathrm{~h}$. Os valores são a média de determinações em triplicata \pm desvio padrão (SD), análise de variância (ANOVA) $<0,05$. 


\section{DISCUSSÃO}

\subsection{Mecanismo de efluxo do antibiótico}

O sistema $A B C$ transportador, é um dos maiores grupos de proteínas na natureza (BOUIGE et al., 2002). No caso dos procariontes, as proteínas ABC estão presentes na membrana citoplasmática (interior) e podem ser importadores ou exportadores. As proteínas $A B C$ são transportadoras ativas, bombeando seus substratos com o uso de energia (hidrólise do ATP) (SHAROM, 2008). Estas proteínas estão associadas à face interna da membrana citoplasmática, com o domínio de ligação de nucleotídeos (NBD ou ATPase), responsáveis pela ligação e hidrólise do ATP, o que permite a passagem do substrato (HOLLAND, 2011).

Após análise da sequência de aminoácidos codificada pelo gene cosl com o uso da ferramenta DELTA BLAST, constatou-se que a proteína é uma ATPase com uma organização que incluem os motivos Walker A e Walker B (Figura 19), indicando a presença de um sítio de ligação e o motivo assinatura único nas proteínas $A B C$, localizado upstream do motivo Walker B (HUNKE, 1998; SCHNEIDER).

O motivo Walker A de ligação ao ATP (também conhecido como P-loop ou de ligação de fosfato) é um dos motivos mais comuns e altamente conservados encontrados em genomas e é considerado um motivo fundamental e antigo em sistemas biológicos (KOONIN; TATUSOV; RUDD, 1995). O motivo Walker A interage com o fosfato $\beta$, e consequentemente oferece uma orientação definida. O motivo Walker B interage principalmente com fosfato $\mathrm{y}$ do nucleotídeo. Assim, o ATP é segurado entre os dois monômeros do NBD e atua na ligação do mesmo (PONTESUCRE, 2007).

Até o momento, foram descritos três tipos de transportadores $A B C$, designados como tipo I, II e III. Esta classificação baseia-se no número, e organização dos domínios de ligação ao ATP (MÉNDEZ; SALAS, 2001). No caso das antraciclinas como daunorubicina (antibiótico produzido por Streptomyces peucetius) é descrito o sistema transportador tipo I, e sua confirmação funcional foi feita por clonagem dos genes ( $d r r A$ e $d r r B)$, avaliando a capacidade de resistência à daunorrubicina/doxorrubicina 
(GUILFOILE; HUTCHINSON, 1991). É interessante ressaltar que alguns dos metabólitos que são classificados neste grupo são agentes antitumorais como (daunorubicina e mitramicina), mas também outras moléculas como poliéteres (tetronasina e macrotetrolide), dois inibidores da síntese de proteínas (oleandomicina e kasugamicina) e um composto imunossupressor (rapamicina) fazem parte do grupo I. Os transportadores foram inicialmente identificados por clonagem e seleção para resistência ao antibiótico (MÉNDEZ; SALAS, 2001).

A análise de qPCR e RT-PCR constatou que a linhagem selvagem de $S$ olindensis apresenta diferenças significativas durante a produção do antibiótico (Figura 33); o gene coslJ é superexpresso, em quanto os mesmos genes são reprimidos quando o microrganismo não produz o metabolito (Figura 33-34), o que significa que a montagem do transportador unicamente ocorre quando o efluxo é necessário.

No caso das linhagens recombinantes S. albus 8001 e 8004 apresentaram diferenças significativas na expressão dos genes coslJ. A linhagem 8004 (Figura 30) apresento níveis menores de expressão o que foi evidente nos valores de MIC (Figura 29), onde o nível de resistência não foi representativamente maior que as linhagens contendo os mecanismos individuais. A resposta a este resultado provavelmente está relacionada com as diferenças de expressão que o promotor ermEp* pode apresentar, quando o tamanho do inserto é maior (BLANCO et al., 2001; WANG et al., 2013). No entanto não afeta o análise funcional e a vantagem por ganho de função é evidente.

De acordo com as análises do complexo transportador $A B C$ de $S$. olindensis podemos inferir:

- É codificado por dois genes: cosl (NBD) e cosJ (TMD).

- O sistema de transporte é formado por duas proteínas codificadas por genes independentes: uma proteína de ligação do ATP, com um único domínio de ligação de nucleotídeos (um motivo Walker A e B). 
- Possui uma proteína de membrana hidrofóbica (TM) contendo seis hélices transmembranares.

- A distância entre os aminoácidos da lisina conservada do motivo Walker A e o motivo Walker B é de 117 (Figura 19B).

- A sobreexpressão dos genes coslJ é unicamente ativada na síntese da Cosmomicina D.

O complexo de $S$. olindensis pode ser agrupado na categoria I e corrobora com as características de classificação segundo Méndez; Salas, 1998 para alguns actinomicetos produtores de antibióticos.

\subsection{Mecanismo de detoxificação de espécies reativas de oxigênio (ROS) causadas por antraciclinas}

Sabe-se que as antraciclinas produzem radicais livres pela associação com compostos férricos gerando estrese oxidativo (RUGGIERO et al., 2008). O estresse oxidativo depende das espécies reativas de oxigênio (ROS), que são geradas pela ação de xenobióticos e como consequência de processos metabólicos (FINDLAY; TAPIERO; TOWNSEND, 2005). O poder oxidante do $\mathrm{O}_{2}$ e $\mathrm{H}_{2} \mathrm{O}_{2}$ é perigoso para as células. Estas espécies podem inativar importantes enzimas metabólicas, alterando sua atividade catalítica. Por exemplo, $\mathrm{H}_{2} \mathrm{O}_{2}$ pode atravessar a membrana celular e iniciar a oxidação lipídica pela desprotonação de ácidos graxos (GECHEV et al., 2006).

A glutationa peroxidase é uma enzima que reduz $\mathrm{H}_{2} \mathrm{O}_{2}$ ou hidroperóxidos orgânicos para água ou o álcool correspondente, usando a glutationa reduzida (HERBETTE; ROECKEL-DREVET; DREVET, 2007). Como proposto por Moscow e colaboradores (1994), o mecanismo catalítico da glutationa peroxidase envolve a reação desta enzima no estado reduzido [selenolato (Ez-Se ${ }^{-}$com o hidroperóxido, resultando em um álcool (Ez-SeOH). Em seguida, em uma reação de duas etapas com glutationa (GSH) e selenossulfeto (Ez-SeSG), o selenol reduzido é regenerado. Desta maneira, ocorre inibição da formação de espécies reativas de oxigênio, tais como peróxido de 
hidrogênio e peroxinitrito (MOSCOW et al., 1994).

Diversos sistema de oxido-redução passam um eléctron para o grupo semi-quinona convertendo ele em radical semiquinona. Para gerar a molécula original se reduz o oxigênio molecular para pegar outro elétron que regenere a quinona, deixando o oxigênio em forma de superóxido; o que quer dizer que o átomo de oxigênio contem no seu ultimo orbital um elétron não pareado. A conversão em semiquinona confere a molécula da antraciclina capacidades oxidantes, formando a sua vez moléculas que oxidam diversas biomoléculas das estruturas celulares próximas, especialmente a membrana celular (Figura 37). Uma primeira linha de enzimas antioxidantes, como a superóxido dismutase (SOD) converte o superóxido em peroxido de hidrogênio, que a sua vez continua sento um composto oxidante. No entanto uma segunda linha de enzimas antioxidantes como a catalase e a glutationa peroxidase (GPx), podem converter finalmente o peroxido de hidrogênio em agua e oxigênio molecular (MISITI et al., 2003).

Figura 37. Geração de espécies reativas de oxigênio (ROS), por antraciclinas

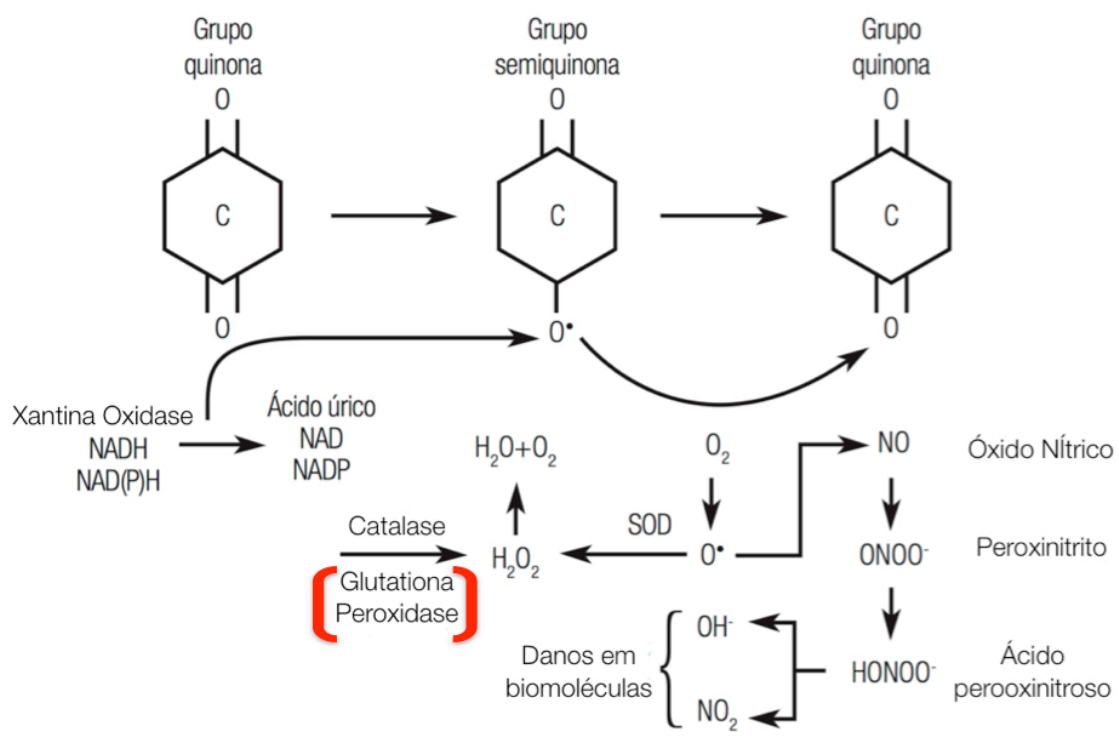

NADH Dinucleótido de nicotinamida e adenina $\operatorname{NADP}(\mathrm{H})$ Fosfato de dinucleótido de nicotinamida e adenina SOD, superoxido dismutase; ONOO-, peroxinitrito; $\mathrm{HONOO}$, ácido peroxinitroso; $\mathrm{OH}^{-}$, radical oxidrilo; NO, dióxido de nitrogênio .

Adaptado e modificado de: (MISITI et al., 2003). 
No caso das linhagens recombinantes S. albus 8002 e 8004 não apresentaram diferenças significativas na expressão do gene cosP. Este resultado constatou que a linhagem selvagem recombinantes S. albus 8002 (Figura 29) apresenta uma vantagem de resistência quando comparada com o controle $S$. albus 8000 , no entanto os valores de resistência foram mais baixos que as linhagens recombinates 8001 e 8003 na análise de resistência MIC. Esta diferencia provavelmente esta relacionada com que o mecanismo transportador (cosIJ) e o mecanismo proteico do tipo UvrA "like" (cosU), podem ter uma atividade essencial na resistência para a célula. E no caso do mecanismo com função peroxidase (GPx) existe a possibilidade que seja um mecanismo auxiliar para antraciclinas ou moléculas com um toxicidade maior.

A análise de expressão em $S$ olindensis apresenta diferenças significativas durante a produção do antibiótico (Figura 33). O gene cosP é expresso quatro vezes a mais quando comparado com o microrganismo que não produz o metabolito (Figura 33-34), no entanto, apresenta uma expressão basal, que foi verificada com o análise de MDA, quantificação de $\mathrm{H}_{2} \mathrm{O}_{2}$ (Figura 31), Western blot e atividade enzimática (Figura 35-36). A hipótese da expressão basal provavelmente está relacionada com a necessidade de mecanismos de detoxificação de ROS durante a biossíntese da molécula, já que as quinonas ou intermediários tem atividade oxidante antes da terminação da molécula.

Os principais produtos primários da peroxidação lipídica são hidroperóxidos lipídicos $(\mathrm{LOOH})$. Entre os muitos aldeídos diferentes que podem ser formados como produtos secundários durante a peroxidação lipídica, o mais intensamente estudado é o malonaldeído (MDA). O teste de TBA produz um produto vermelho fluorescente que pode ser detectado por espectrofotometria e permitir gerar hipóteses a partir do estresse oxidativo de um composto (AYALA; MUÑOZ; ARGÜELLES, 2014; CABISCOL; TAMARIT; ROS, 2000; ESTERBAUER; CHEESEMAN, 1990; MINOTTI et al., 2004; YOON et al., 2002). 
O presente estudo demonstra claramente que não só a doxorubicina tem efeito de peroxidação lipídica. Os resultados com cosmomicina $D$, concordam com estudos anteriores que relataram que as espécies reativas de oxigênio geradas durante o ciclo de oxidação-redução das antraciclinas podem oxidar Glutationa intracelular e fornecer estimulação para detoxificação (HENDERSON et al., 1978). Os resultados de MDA e $\mathrm{H}_{2} \mathrm{O}_{2}$ permitiram inferir como as enzimas antioxidantes agem em resposta as antraciclinas como a cosmomicina $\mathrm{D}$.

Interessantemente o estudo de Weisman e colaboradores (2012) discute a atividade biológica de 7-Deoxydoxorubicinolone em bactérias e tecido. $\mathrm{O}$ resultado mostra que as células bacterianas apresentam níveis mais elevados de catalase, superóxido dismutase e glutationa peroxidase em relação ao tecido cardíaco humano, o que pode explicar as diferentes respostas para o mesmo composto entre células cardíacas e células bacterianas. Eles concluem que as células bacterianas são muito mais competentes para lidar com os resultados do ciclo oxidativo das antraciclinas e as espécies reativas de oxigênio (ROS) e particularmente o gênero Streptomyces é geralmente bem equipado para lidar com o estresse oxidativo. É importante ressaltar que as moléculas derivadas da aglicona podem se acumular nas membranas, devido à sua hidrofobicidade. O rápido crescimento e divisão celular bacteriana em relação ao tecido cardíaco eucariótico, pode também explicar o efeito diferencial das antraciclina em células procariotas e eucariotas (WESTMAN et al., 2012).

Durante a análise proteica (Figura 35a) das linhagens recombinantes foi comparada a quantidade enzimática GPx a partir de proteína total, em condições de estresse com doxorubicina e cosmomicina $\mathrm{D}$. Interessantemente, o tratamento com cosmomicina (Figura 35b) apresenta uma quantidade menor de GPx quando comparada com DOX, este resultado foi visualizado na análise de atividade, e é provável que esteja relacionado com a saturação da enzima e concorda com as observações de (SPLITTGERBER; TAPPEL, 1979), onde a enzima GPx, em concentração constante e aumento da quantidade de hidroperoxidos, mostrou que a taxa de atividade enzimática é menor apos a saturação, o que está relacionado com a toxicidade e geração de ROS maior da cosmomicina com relação a DOX. 
Com base nos resultados deste estudo, podemos supor que as antraciclinas, tais como a cosmomicina $D$ e derivados das antraciclinas, induzem enzimas antioxidantes como a Glutationa peroxidase, que neste caso é codificada pelo cluster biossintético em S. olindensis, e pode, progressivamente, ser expressa e alterar o estado redox da célula durante a produção e exposição ao metabolito, e finalmente desempenham um papel importante nos mecanismos de resistência responsáveis pela toxicidade celular induzida por antibióticos como a cosmomicina D.

\subsection{Mecanismo de reparo ao DNA}

As proteínas diméricas do grupo UvrA são capazes de reconhecer várias lesões estruturais ou químicas do DNA, usando um mecanismo de leitura indireta. (SANCAR; RUPP, 1983). As proteínas UvrA bacterianas, geralmente estão relacionadas com outras proteínas conhecidas como UvrB, UvrC, e UvrD, e conformam o sistema de reparo por excisão de nucleotídeos (NER) que é essencial para a sobrevivência de quase todas as bactérias ( JACIUK et al., 2011; TRUGLIO et al., 2006). A proteína codificada pelo gene cosU tem uma alta similaridade com proteínas UvrA, no entanto contém a deleção do domínio de ligação às proteínas UvrB. Por essa razão, a função da proteína não está envolvida em NER e é classificada com UvrA tipo Ila.

No caso das linhagens recombinantes S. albus 8003 e 8004 não apresentaram diferenças significativas na expressão do gene cosU. Constatou-se que, a linhagem selvagem recombinante de S. albus 8003 (Figura 29), apresenta uma vantagem de resistência quando comparada com o controle S. albus 8000; o valor de resistência da linhagem recombinante 8003 é classificada como indicativo de um mecanismo importante junto com o mecanismo transportador (coslJ), e formam um complexo de defesa essencial para a célula. A análise de expressão em $S$ olindensis apresenta diferenças significativas durante a produção do antibiótico (Figura 33); o gene cosU é expresso três vezes a mais quando comparado com o microrganismo que não produz o 
metabolito (Figura 33-34), e concorda com a sobre-expressão dos genes unicamente na produção do antibiótico.

As proteínas UvrA tipo lla têm sido descritas como dependentes de ATP e com função de ligação ao ATP nos microrganismos produtores de antibióticos como $S$. peucetius (daunorubicina) (FURUYA; HUTCHINSON, 1998; LOMOVSKAYA et al., 1996), em Streptomyces nogalater produtor de nogalamicina (TORKKELL et al., 2001), a cromomicina em S. griseus subsp. griseus (MENÉNDEZ et al., 2007) ,e na resistência a mitramicina em S. argillaceus (GARCIA-BERNARDO et al., 2000). Nogalamicina, daunorubicina, cromomicina e mitramicina e cosmomicina $D$ são fármacos que se intercalam no DNA, sugerindo que a função de UvrA tipo lla está associada com a remoção de agentes de ligação não covalente do DNA. 


\section{CONCLUSÃO}

Neste trabalho é proposto o modelo para a resistência (self-resistance) de $S$. olindensis DAUFPE 5622 durante a biossíntese de cosmomicina D (Figura 38). Este composto é reconhecido pelo transportador $A B C$ codificado pelos genes coslJ, em seguida, a enzima glutationa peroxidase ( $\operatorname{cosP}$ ) participa na proteção contra ROS e peroxidação lipídica causada por derivados da quinona. Finalmente, a proteína UvrA tipo lla é importante para reduzir a interação entre o DNA e o antibiótico. Isto representa uma vantagem para este microrganismo sobreviver durante a biossíntese do antibiótico e evita a interação do composto com seus possíveis alvo intracelulares antes de ser secretado.

A evolução do gênero Streptomyces desenvolveu diferentes estratégias de resistência e isso depende da forma de ação do composto bioativo. A compreensão desses mecanismos nos microrganismos produtores é muito importante e significativa, porque permite compreender melhor os processos de transferência horizontal dos genes resistência a linhagens patogénicas, o que pode gerar novas alternativas terapêuticas. Além disso, permite a construção de linhagens recombinantes para superexpressão de mecanismos de resistência, para eventualmente, melhorar a produção de antibióticos usando biossíntese combinatória de clusters. 
Figura 1. Modelo proposto para resistência (self-resistance) à Cosmomicina D em Streptomyces olindensis

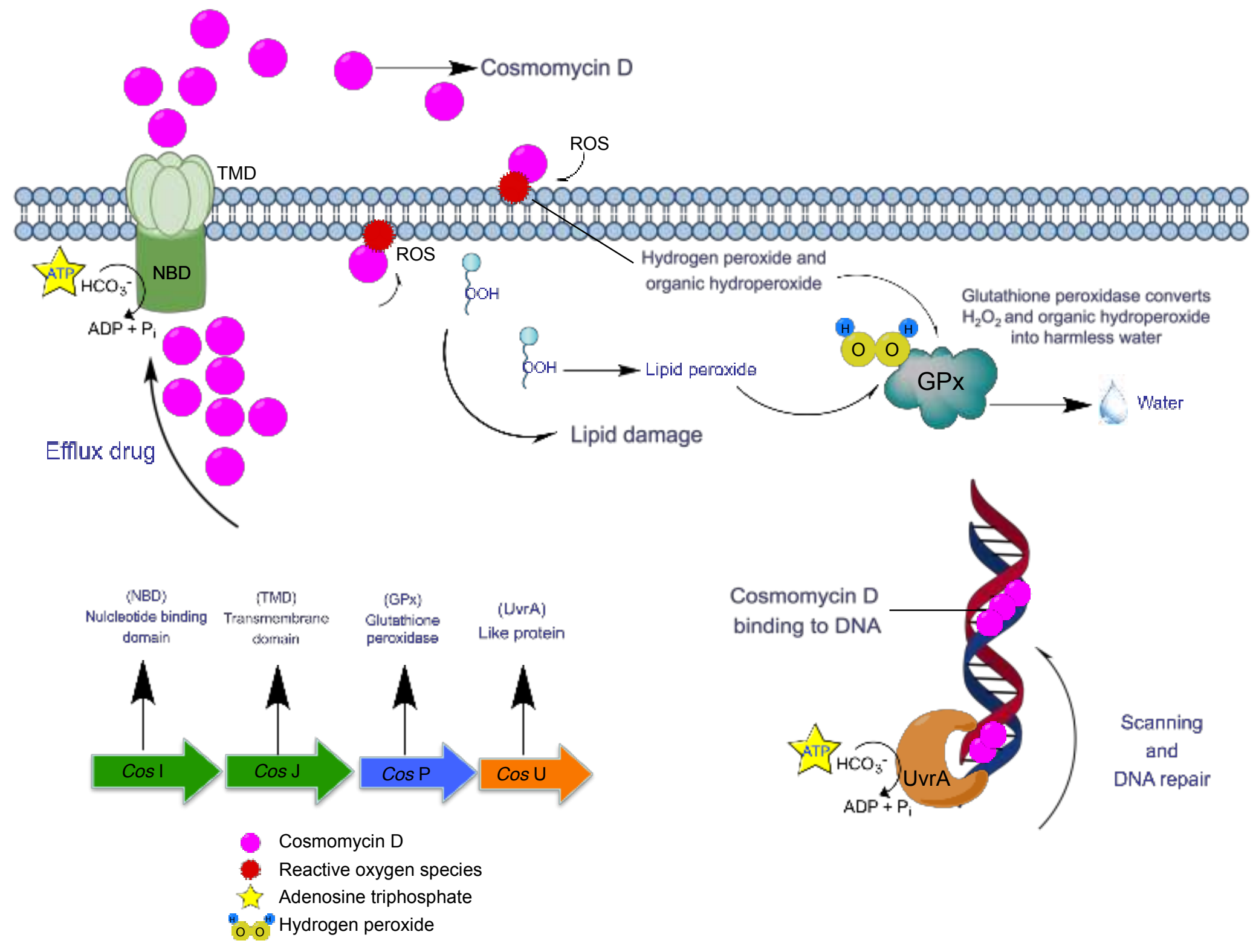




\section{REFERÊNCIAS*}

ALBERTS, D. S.; MUGGIA, F. M.; CARMICHAEL, J.; WINER, E. P.; JAHANZEB, M.; VENOOK, A. P.; SKUBITZ, K. M.; RIVERA, E.; SPARANO, J. A.; DIBELLA, N. J.; STEWART, S. J.; KAVANAGH, J. J.; GABIZON, A. A. Efficacy and safety of liposomal anthracyclines in phase $1 / / l$ clinical trials. Seminars in oncology, v. 31, p. 53-90, 2004.

ALEXIEVA, V.; SERGIEV, I.; MAPELLI, S.; KARANOV, E. The effect of drought and ultraviolet radiation on growth and stress markers in pea and wheat. Plant, Cell and Environment, v. 24, n. 12, p. 1337-1344, 2001.

AUSTIN, M. B.; NOEL, J. P. The chalcone synthase superfamily of type III polyketide synthases. Natural Product Reports, v. 20, n. 1, p. 79-110, 2003. Disponível em: <http://xlink.rsc.org/?DOI=b100917f>.

AYALA, A.; MUÑOZ, M. F.; ARGÜELLES, S. Lipid peroxidation: Production, metabolism, and signaling mechanisms of malondialdehyde and 4hydroxy-2-nonenalOxidative Medicine and Cellular Longevity, v 2014, p 31 , 2014.

BENVENISTE, R.; DAVIES, J. Aminoglycoside antibiotic-inactivating enzymes in actinomycetes similar to those present in clinical isolates of antibioticresistant bacteria. Proceedings of the National Academy of Sciences of the United States of America, v. 70, p. 2276-2280, 1973.

BINASCHI, M.; BIGIONI, M.; CIPOLLONE, A.; ROSSI, C.; GOSO, C.; MAGGI, C. A.; CAPRANICO, G.; ANIMATI, F. Anthracyclines: selected new developments. Current medicinal chemistry. Anti-cancer agents, v. 1, p. 113-130, 2001.

BINASCHI, M.; CAPRANICO, G.; DAL BO, L.; ZUNINO, F. Relationship between lethal effects and topoisomerase II-mediated double-stranded DNA breaks produced by anthracyclines with different sequence specificity. Molecular pharmacology, v. 51, p. 1053-1059, 1997.

BLANCO, G.; PATALLO, E. P.; BRAA, A. F.; TREFZER, A.; BECHTHOLD, A.; ROHR, J.; MÉNDEZ, C.; SALAS, J. A. Identification of a sugar flexible glycosyltransferase from Streptomyces olivaceus, the producer of the antitumor polyketide elloramycin. Chemistry and Biology, v. 8, p. 253-263, 2001.

* De acordo com:

ASSOCIAÇÃO BRASILEIRA DE NORMAS TÉCNICAS. NBR 6023: Informação e documentação: referências: elaboração. Rio de Janeiro, 2002. 
BOUIGE, P.; LAURENT, D.; PILOYAN, L.; DASSA, E. Phylogenetic and functional classification of ATP-binding cassette (ABC) systems. Current protein \& peptide science, v. 3, p. 541-559, 2002.

BRADFORD, M. M. A rapid and sensitive method for the quantitation of microgram quantities of protein utilizing the principle of protein-dye binding. Analytical biochemistry, v. 72, p. 248-254, 1976.

CABISCOL, E.; TAMARIT, J.; ROS, J. Oxidative stress in bacteria and protein damage by reactive oxygen species. International Microbiology, v. 3, n. 1, p. 3-8, 2000.

CARVALHO, H.; GARRIDO, L. M.; FURLAN, R. L. A.; PADILLA, G.; AGNOLETTO, M.; GUECHEVA, T.; HENRIQUES, J. A. P.; SAFFI, J.; MENCK, C. F. M. DNA damage induced by the anthracycline cosmomycin D in DNA repair-deficient cells. Cancer chemotherapy and pharmacology, v. 65, p. 989-994, 2010.

CONTRERAS, C. Caracterização de Genes Biossintéticos do Antitumoral Cosmomicina D. 2013 [Tese mestrado] Instituto de Ciências biomédicas, Universidade de São Paulo.

CUNDLIFFE, E.; DEMAIN, A. L. Avoidance of suicide in antibiotic-producing microbes. Journal of industrial microbiology \& biotechnology, v. 37, p. 643-672, 2010.

DEMAIN, A. L. Microbial secondary metabolism: a new theoretical frontier for academia, a new opportunity for industry. Ciba Foundation Symposium, v. 171, n. March, p. 3-16; discussion 16-23, 1992. Disponível em: <http://www.ncbi.nlm.nih.gov/pubmed/21498065>.

ESTERBAUER, H.; CHEESEMAN, K. H. Determination of aldehydic lipid peroxidation products: Malonaldehyde and 4-hydroxynonenal. Methods in Enzymology, v. 186, p. 407-421, 1990.

FERNÁNDEZ-MORENO, M. A.; VALLÍN, C.; MALPARTIDA, F. Streptothricin biosynthesis is catalyzed by enzymes related to nonribosomal peptide bond formation. Journal of bacteriology, v. 179, p. 6929-6936, 1997.

FINDLAY, V. J.; TAPIERO, H.; TOWNSEND, D. M. Sulfiredoxin: a potential therapeutic agent? Biomedicine \& pharmacotherapy = Biomédecine \& pharmacothérapie, v. 59, p. 374-379, 2005.

FRELET, A.; KLEIN, M. Insight in eukaryotic $A B C$ transporter function by mutation analysis. FEBS letters, v. 580, p. 1064-1084, 2006.

FURLAN, R. L. A.; WATT, S. J.; GARRIDO, L. M.; AMARANTE-MENDES, G. 
P.; NUR-E-ALAM, M.; ROHR, J.; BRAÑA, A.; MENDEZ, C.; SALAS, J. A.; SHEIL, M. M.; BECK, J. L.; PADILLA, G. DNA-binding properties of cosmomycin $D$, an anthracycline with two trisaccharide chains. The Journal of antibiotics, v. 57, p. 647-654, 2004.

FURUYA, K.; HUTCHINSON, C. R. The DrrC protein of Streptomyces peucetius, a UvrA-like protein, is a DNA-binding protein whose gene is induced by daunorubicin. FEMS microbiology letters, v. 168, p. 243-249, 1998.

GANDLUR, S. M.; WEI, L.; LEVINE, J.; RUSSELL, J.; KAUR, P. Membrane topology of the DrrB protein of the doxorubicin transporter of Streptomyces peucetius. The Journal of biological chemistry, v. 279 , n. 26 , p. 27799-806, 25 jun. 2004. Disponível em: <http://www.ncbi.nlm.nih.gov/pubmed/15090538>. Acesso em: 5 fev. 2014.

GARCIA-BERNARDO, J.; BRAÑA, A. F.; MÉNDEZ, C.; SALAS, J. A. Insertional inactivation of $\mathrm{mtr} X$ and $\mathrm{mtr} Y$ genes from the mithramycin gene cluster affects production and growth of the producer organism Streptomyces argillaceus. FEMS microbiology letters, v. 186, p. 61-65, 2000.

GARRIDO, L. M.; LOMBÓ, F.; BAIG, I.; NUR-E-ALAM, M.; FURLAN, R. L. A.; BORDA, C. C.; BRAÑA, A.; MÉNDEZ, C.; SALAS, J. A.; ROHR, J.; PADILLA, $G$. Insights in the glycosylation steps during biosynthesis of the antitumor anthracycline cosmomycin: characterization of two glycosyltransferase genes. Applied microbiology and biotechnology, v. 73, p. 122-131, 2006.

GECHEV, T. S.; VAN BREUSEGEM, F.; STONE, J. M.; DENEV, I.; LALOI, C. Reactive oxygen species as signals that modulate plant stress responses and programmed cell death. BioEssays : news and reviews in molecular, cellular and developmental biology, v. 28, p. 1091-1101, 2006.

GEWIRTZ, D. A. A critical evaluation of the mechanisms of action proposed for the antitumor effects of the anthracycline antibiotics adriamycin and daunorubicin. Biochemical pharmacology, v. 57, p. 727-741, 1999.

GILLESPIE, D. E.; BRADY, S. F.; BETTERMANN, A. D.; CIANCIOTTO, N. P.; LILES, M. R.; RONDON, M. R.; CLARDY, J.; GOODMAN, R. M.; HANDELSMAN, J.; LYNCH, B. A.; MACNEIL, I. A.; OSBURNE, M. S.; CLARDY, J.; HANDELSMAN, J.; GOODMAN, R. M.; ICROBIOL, A. P. P. L. E. N. M. Isolation of Antibiotics Turbomycin A and B from a Metagenomic Library of Soil Microbial DNA. Society, v. 68, n. 9, p. 4301-4306, 2002. Disponível em: <http://www.ncbi.nlm.nih.gov/pubmed/12200279>.

GONZÁLEZ-CERÓN, G.; MIRANDA-OLIVARES, O. J.; SERVÍN-GONZÁLEZ, L. Characterization of the methyl-specific restriction system of Streptomyces coelicolor A3(2) and of the role played by laterally acquired nucleases. FEMS Microbiology Letters, v. 301, p. 35-43, 2009. 
GOOSEN, N.; MOOLENAAR, G. F. Repair of UV damage in bacteriaDNA Repair, v. 7, p. 353-379, 2008.

GUILFOILE, P. G.; HUTCHINSON, C. R. A bacterial analog of the mdr gene of mammalian tumor cells is present in Streptomyces peucetius, the producer of daunorubicin and doxorubicin. Proceedings of the National Academy of Sciences of the United States of America, v. 88, n. 19, p. 8553-7, 1 out. 1991.

em: $<$ http://www.pubmedcentral.nih.gov/articlerender.fcgi?artid=52547\&tool=pmcent rez\&rendertype $=$ abstract $>$.

HANEKOP, N.; ZAITSEVA, J.; JENEWEIN, S.; HOLLAND, I. B.; SCHMITT, L. Molecular insights into the mechanism of ATP-hydrolysis by the NBD of the ABC-transporter HlyB. FEBS letters, v. 580, p. 1036-1041, 2006.

HE, M.; SHELDON, P. J.; SHERMAN, D. H. Characterization of a quinone reductase activity for the mitomycin $C$ binding protein (MRD): Functional switching from a drug-activating enzyme to a drug-binding protein. Proceedings of the National Academy of Sciences of the United States of America, v. 98, n. 3, p. 926-931, 2001.

HENDERSON, C. A.; METZ, E. N.; BALCERZAK, S. P.; SAGONE, A. L. Adriamycin and daunomycin generate reactive oxygen compounds in erythrocytes. Blood, v. 52, n. 5, p. 878-885, 1978.

HERBETTE, S.; ROECKEL-DREVET, P.; DREVET, J. R. Seleno-independent glutathione peroxidases: More than simple antioxidant scavengers FEBS Journal, v. 274, p. 2163-2180, 2007.

HERTWECK, C. The biosynthetic logic of polyketide diversity. Angewandte Chemie (International ed. in English), v. 48, n. 26, p. 4688-716, jan. 2009. Disponivel em: <http://www.ncbi.nlm.nih.gov/pubmed/19514004>. Acesso em: 27 fev. 2013.

HERTWECK, C.; LUZHETSKYY, A.; REBETS, Y.; BECHTHOLD, A. Type II polyketide synthases: gaining a deeper insight into enzymatic teamwork. Natural Product Reports, v. 24, n. 1, p. 162-190, 2007. Disponível em: <http://www.ncbi.nlm.nih.gov/pubmed/17268612>.

HIGGINS, C. F. ABC transporters: physiology, structure and mechanism--an overview. Research in microbiology, v. 152, n. 3-4, p. 205-10, 2001. Disponível em: <http://www.ncbi.nlm.nih.gov/pubmed/11421269>.

HOLLAND, I. B. ABC transporters, mechanisms and biology: an overview. Essays in biochemistry, v. 50, p. 1-17, 2011. Disponível em: <http://www.ncbi.nlm.nih.gov/pubmed/21967049>.

HOLLENSTEIN, K.; DAWSON, R. J. P.; LOCHER, K. P. Structure and 
mechanism of $A B C$ transporter proteins. Current opinion in structural biology, v. 17, n. 4, p. 412-8, ago. 2007. Disponível em: <http://www.ncbi.nlm.nih.gov/pubmed/17723295>. Acesso em: 22 jan. 2014.

HOPWOOD, D. A. Genetic engineering of Streptomyces to create hybrid antibiotics. Current opinion in biotechnology, v. 4, p. 531-537, 1993.

HOPWOOD, D. A. Cracking the Polyketide Code. PLoS Biology, v. 2, n. 2, p. E35, $2004 . \quad$ Disponível em: <http://www.pubmedcentral.nih.gov/articlerender.fcgi?artid=340943\&tool=pmce ntrez\&rendertype $=$ abstract $>$.

HOPWOOD, D. A. How do antibiotic-producing bacteria ensure their selfresistance before antibiotic biosynthesis incapacitates them? Molecular microbiology, v. 63, p. 937-940, 2007.

HUTCHINSON, C. R. Combinatorial biosynthesis for new drug discovery. Current opinion in microbiology, v. 1, p. 319-329, 1998.

HUTCHINSON, C. R.; FUJII, I. Polyketide synthase gene manipulation: a structure-function approach in engineering novel antibiotics. Annual Review of Microbiology, v. 49, p. 201-238, 1995. Disponível em: <http://www.ncbi.nlm.nih.gov/pubmed/8561459>.

HWANG, C. K. Y. U.; KIM, H. S. U. B.; HONG, Y.; KIM, Y. H. O. Expression of Streptomyces peucetius genes for doxorubicin resistance and aklavinone 11hydroxylase in Streptomyces galilaeus ATCC 31133 and production of a hybrid aclacinomycin . Expression of Streptomyces peucetius Genes for Doxorubicin Resistance and A. v 39, n. 7, p. 1616-1620, 1995.

JACIUK, M.; NOWAK, E.; SKOWRONEK, K.; TAŃSKA, A.; NOWOTNY, M. Structure of UvrA nucleotide excision repair protein in complex with modified DNA. Nature structural \& molecular biology, v. 18, n. 2, p. 191-197, 2011.

KAUR, P. Biochemical Coupling between the DrrA and DrrB Proteins of the Doxorubicin Efflux Pump of Streptomyces peucetius. Journal of Biological Chemistry, v. 273, n. 28, p. 17933-17939, 10 jul. 1998. Disponível em: <http://www.jbc.org/cgi/doi/10.1074/jbc.273.28.17933>. Acesso em: 5 fev. 2014.

KEATINGE-CLAY, A. T.; MALTBY, D. A.; MEDZIHRADSZKY, K. F.; KHOSLA, C.; STROUD, R. M. An antibiotic factory caught in action. Nature Structural \& Molecular Biology, v. 11, n. 9, p. 888-893, 2004. Disponível em: $<$ http://www.ncbi.nlm.nih.gov/pubmed/15286722>.

KHOSLA, C.; ZAWADA, R. J. Generation of polyketide libraries via combinatorial biosynthesis. Trends in biotechnology, v. 14, n. 9, p. 335-341, 1996. 
KIESER, T.; BIBB, M. J.; BUTTNER, M. J.; CHATER, K. F.; HOPWOOD, D. A. Practical Streptomyces Genetics. United Kindom: John Innes Centre Ltd., 2000. p. 529.

KIM, H. S.; HONG, Y. S.; KIM, Y. H.; YOO, O. J.; LEE, J. J. New anthracycline metabolites produced by the aklavinone 11-hydroxylase gene in Streptomyces galilaeus ATCC 31133. The Journal of antibiotics, v. 49, p. 355-360, 1996.

KIM, J.; LEE, Y.-J.; SHIN, D.-S.; JEON, S.-H.; SON, K.-H.; HAN, D. C.; JUNG, S.-N.; OH, T.-K.; KWON, B.-M. Cosmomycin C inhibits signal transducer and activator of transcription 3 (STAT3) pathways in MDA-MB-468 breast cancer cell. Bioorganic \& medicinal chemistry, v. 19, n. 24, p. 7582-9, 15 dez. 2011. Disponível em: <http://www.ncbi.nlm.nih.gov/pubmed/22071520>. Acesso em: 5 fev. 2014.

KLEINKAUF, H.; VON DÖHREN, H. A nonribosomal system of peptide biosynthesis. European journal of biochemistry / FEBS, v. 236, p. 335-351, 1996.

KOONIN, E. V; TATUSOV, R. L.; RUDD, K. E. Sequence similarity analysis of Escherichia coli proteins: functional and evolutionary implications. Proceedings of the National Academy of Sciences of the United States of America, v. 92, p. 11921-11925, 1995.

KRAMER, G. F.; NORMAN, H. a.; KRIZEK, D. T.; MIRECKI, R. M. influence of UV-B radiation on polyamines, lipid peroxidation and membrane lipids in cucumber. Phytochemistry, v. 30, p. 2101-2108, 1991.

KÜMMERER, K. Resistance in the environment. The Journal of antimicrobial chemotherapy, v. 54, p. 311-320, 2004.

LAGE, H.; HELMBACH, H.; DIETEL, M.; SCHADENDORF, D. Modulation of DNA topoisomerase II activity and expression in melanoma cells with acquired drug resistance. British journal of cancer, v. 82, p. 488-491, 2000.

LEWIS, K. Multidrug tolerance of biofilms and persister cells. Current topics in microbiology and immunology, v. 322, p. 107-131, 2008.

LIMA, O. G.; LYRA, F. D. A.; ALBUQUERQUE, M. M. F.; MACIEL, G. M.; COELHO, J. S. B. Primeiras observações sobre o complexo antibiótico e antitumoral retamicina produzido pelo Streptomyces olindensis nov. sp. IAUFPe. Revista do Instituto de Antibióticos, v. 9, n. 1-2, p. 27-37, 1969.

LINTON, K. J.; COOPER, H. N.; HUNTER, I. S.; LEADLAY, P. F. An ABCtransporter from Streptomyces longisporoflavus confers resistance to the polyether-ionophore antibiotic tetronasin. Molecular microbiology, v. 11, p. 777-785, 1994. 
LOCHER, K. P. Structure and mechanism of $A B C$ transporters. Current opinion in structural biology, v. 14, n. 4, p. 426-31, ago. 2004. Disponível em: <http://www.ncbi.nlm.nih.gov/pubmed/15313236>. Acesso em: 2 fev. 2014.

LOMOVSKAYA, N.; HONG, S. K.; KIM, S. U.; FONSTEIN, L.; FURUYA, K.; HUTCHINSON, R. C. The Streptomyces peucetius drrC gene encodes a UvrAlike protein involved in daunorubicin resistance and production. Journal of bacteriology, v. 178, p. 3238-3245, 1996.

LORUSSO, V.; MANZIONE, L.; SILVESTRIS, N. Role of liposomal anthracyclines in breast cancer. Annals of Oncology, v.18 Supl. 6, 2007.

MALLA, S.; NIRAULA, N. P.; LIOU, K.; SOHNG, J. K. Self-resistance mechanism in Streptomyces peucetius: overexpression of drrA, drrB and drrC for doxorubicin enhancement. Microbiological research, v. 165, n. 4, p. 25967, 302010.2 maio 20 em: <http://www.ncbi.nlm.nih.gov/pubmed/19651502>. Acesso em: 5 fev. 2014.

MALPARTIDA, F.; HOPWOOD, D. A. Physical and genetic characterisation of the gene cluster for the antibiotic actinorhodin in Streptomyces coelicolor A3(2). Molecular \& general genetics : MGG, v. 205, p. 66-73, 1986.

MARSZAŁKOWSKA, M.; BIL, M.; KREFT, Ł.; OLSZEWSKI, M. A new division of bacterial UvrA homologues. Biotechnologia, v. 94, n. 1, p. 54-56, 2013.

MARTIN, T. W.; DAUTER, Z.; DEVEDJIEV, Y.; SHEFFIELD, P.; JELEN, F.; HE, M.; SHERMAN, D. H.; OTLEWSKI, J.; DEREWENDA, Z. S.; DEREWENDA, U. Molecular basis of mitomycin $C$ resistance in Streptomyces: Structure and function of the MRD protein. Structure, v. 10, n. 7, p. 933-942, 2002.

MASANORI, S.; THOMPSON, C. J.; TAKANORI, K.; KATSUYUKI, S.; ROLF, D.; RAIMUNDO, V.; JULIAN, D. Characterisation by molecular cloning of two genes from Streptomyces verticillus encoding resistance to bleomycin. Gene, v. 151, n. 1-2, p. 11-16, 30 dez. 1994. Disponível em: <http://www.sciencedirect.com/science/article/pii/0378111994906262>.

MASSINI, K. C. Bioprospecção de genes biossintéticos de policetídeos em dna metagenômico de solo de mata atlântica de solo de mata atlântica. 2009. $112 \mathrm{f}$ [Tese Doutorado] Instituto de Ciências biomédicas, Universidade de São Paulo, São Paulo, 2009.

MCDANIEL, R.; EBERT-KHOSLA, S.; HOPWOOD, D. A.; KHOSLA, C. Rational design of aromatic polyketide natural products by recombinant assembly of enzymatic subunits. Nature, v. 375, p. 549-554, 1995.

MÉNDEZ, C.; SALAS, J. a. The role of ABC transporters in antibiotic-producing organisms: drug secretion and resistance mechanisms. Research in microbiology, v. $152, \quad$ n. $3-4, \quad$ p. $341-50,2001$. Disponível em: 
<http://www.ncbi.nlm.nih.gov/pubmed/11421281>.

MÉNDEZ, C.; SALAS, J. A. ABC transporters in antibiotic-producing actinomycetes. FEMS microbiology letters, v. 158, p. 1-8, 1998.

MENÉNDEZ, N.; BRAÑA, A. F.; SALAS, J. A.; MÉNDEZ, C. Involvement of a chromomycin $A B C$ transporter system in secretion of a deacetylated precursor during chromomycin biosynthesis. Microbiology, v. 153, n. 9, p. 3061-3070, 2007.

METSÄ-KETELÄ, M.; SALO, V.; HALO, L.; HAUTALA, A.; HAKALA, J.; MÄNTSÄLÄ, P.; YLIHONKO, K. An efficient approach for screening minimal PKS genes from Streptomyces. FEMS Microbiology Letters, v. 180, n. 1, p. 16, 1999. Disponível em: <http://www.ncbi.nlm.nih.gov/pubmed/10547437>.

MINOTTI, G.; MENNA, P.; SALVATORELLI, E.; CAIRO, G.; GIANNI, L. Anthracyclines: Molecular Advances and Pharmacologic Developments in Antitumor Activity and Cardiotoxicity. v. 56, n. 2, p. 185-229, 2004.

MISITI, F.; GIARDINA, B.; MORDENTE, A.; CLEMENTI, M. E. The secondary alcohol and aglycone metabolites of doxurubicin alter metabolism of human erythrocytes. Brazilian Journal of Medical and Biological Research, v. 36, n. 12, p. 1643-1651, 2003.

MIYAMOTO, Y.; JOHDO, O.; NAGAMATSU, Y.; YOSHIMOTO, A. Cloning and characterization of a glycosyltransferase gene involved in the biosynthesis of anthracycline antibiotic $\beta$-rhodomycin from Streptomyces violaceus. FEMS Microbiology Letters, v. 206, n. 2, p. 163-168, 1 jan. 2002. Disponível em: <http://femsle.oxfordjournals.org/content/206/2/163.abstract>.

MOSCOW, J. A.; SCHMIDT, L.; INGRAM, D. T.; GNARRA, J.; JOHNSON, B.; COWAN, K. H. Loss of heterozygosity of the human cytosolic glutathione peroxidase I gene in lung cancer. Carcinogenesis, v. 15, p. 2769-2773, 1994.

MURRAY, R. G. E.; HOLT, J. G. The History of Bergey 's Manual. Archives, v. 19, p. 1-13, 1989. Disponível em: <http://www.ncbi.nlm.nih.gov/pubmed/19467612>.

OAKES, S. R.; VAILLANT, F.; LIM, E.; LEE, L.; BRESLIN, K.; FELEPPA, F.; DEB, S.; RITCHIE, M. E.; TAKANO, E.; WARD, T.; FOX, S. B.; GENERALI, D.; SMYTH, G. K.; STRASSER, A.; HUANG, D. C. S.; VISVADER, J. E.; LINDEMAN, G. J. Sensitization of BCL-2-expressing breast tumors to chemotherapy by the BH3 mimetic ABT-737Proceedings of the National Academy of Sciences, v. 109 p. 2766-2771, 2012.

ODA, K.; MATOBA, Y.; NODA, M.; KUMAGAI, T.; SUGIYAMA, M. Catalytic mechanism of bleomycin $\mathrm{N}$-acetyltransferase proposed on the basis of its crystal structure. Journal of Biological Chemistry, v. 285, n. 2, p. 1446-1456, 
2010.

OLANO, C.; GARCÍA, I.; GONZÁLEZ, A.; RODRIGUEZ, M.; ROZAS, D.; RUBIO, J.; SÁNCHEZ-HIDALGO, M.; BRAÑA, A. F.; MÉNDEZ, C.; SALAS, J. A. Activation and identification of five clusters for secondary metabolites in Streptomyces albusJ1074. Microbial Biotechnology, v. 7, p. 242-256, 2014.

OMURA, S.; IKEDA, H.; MALPARTIDA, F.; KIESER, H. M.; HOPWOOD, D. A. Production of new hybrid antibiotics, mederrhodins $A$ and $B$, by a genetically engineered strain. Antimicrobial agents and chemotherapy, v. 29, p. 13-19, 1986.

PEREGO, P.; CORNA, E.; DE CESARE, M.; GATTI, L.; POLIZZI, D.; PRATESI, G.; SUPINO, R.; ZUNINO, F. Role of apoptosis and apoptosis-related genes in cellular response and antitumor efficacy of anthracyclines. Current medicinal chemistry, v. 8, p. 31-37, 2001.

PÉREZ, C.; AGUSTÍ, M. a A.; TORNOS, P. [Late-onset anthracycline-induced cardiotoxicity]. Medicina clínica, v. 133, n. 8, p. 311-3, 5 set. 2009. Disponível em: <http://www.ncbi.nlm.nih.gov/pubmed/19501849>. Acesso em: 5 fev. 2014.

PETERSON, R. M.; HUANG, T.; RUDOLF, J. D.; SMANSKI, M. J.; SHEN, B. Mechanisms of self-resistance in the Platensimycin- and platencin-producing streptomyces platensis MA7327 and MA7339 strains. Chemistry and Biology, v. $21, \quad$ n. 3 , p. 389-397, 2014. Disponível em: <http://dx.doi.org/10.1016/j.chembiol.2014.01.005>.

PONTE-SUCRE, A. Availability and applications of ATP-binding cassette (ABC) transporter blockers. Applied Microbiology and Biotechnology, v. 76, p. 279-286, 2007.

POPE, C. F.; O'SULLIVAN, D. M.; MCHUGH, T. D.; GILLESPIE, S. H. A practical guide to measuring mutation rates in antibiotic resistance. Antimicrobial agents and chemotherapy, v. 52, p. 1209-1214, 2008.

REEVES, C. D. The enzymology of combinatorial biosynthesis. Critical Reviews in Biotechnology, v. 23, n. 2, p. 95-147, 2003. Disponível em: <http://www.ncbi.nlm.nih.gov/pubmed/12889743>.

ROJAS, J. D.; STARCEVIC, A.; BARANAŠIĆ, D.; FERREIRA-TORRES, M. A.; CONTRERAS, C. A.; GARRIDO, L. M.; ARAÚJO, W. L.; DE SOUZA, R. F.; ZUCKO, J.; HRANUELI, D.; LONG, P. F.; CULLUM, J.; PADILLA, G. Genome Sequence of Streptomyces olindensis DAUFPE 5622, Producer of the Antitumoral Anthracycline Cosmomycin D. Genome announcements, v. 2, n. 3 , 2014. Disponível em: $<$ http://www.pubmedcentral.nih.gov/articlerender.fcgi?artid=4073108\&tool=pmc entrez\&rendertype $=$ abstract $>$. 
RUGGIERO, A.; RIDOLA, V.; PUMA, N.; MOLINARI, F.; COCCIA, P.; DE ROSA, G.; RICCARDI, R. Anthracycline cardiotoxicity in childhood. Pediatric hematology and oncology, v. 25, p. 261-281, 2008.

SAMBROOK, J.; FRITSCH, E. F.; MANIATIS, T. Molecular cloning: a laboratory manual. cold spring harbor laboratory press. New York: Cold Spring Harbor, 1989. 3 v.

SANCAR, A.; RUPP, W. D. A novel repair enzyme: UVRABC excision nuclease of Escherichia coli cuts a DNA strand on both sides of the damaged region. Cell, v. 33, p. 249-260, 1983.

SCHNEIDER, E.; HUNKE, S. ATP-binding-cassette (ABC) transport systems: Functional and structural aspects of the ATP-hydrolyzing subunits/domains. FEMS Microbiology Reviews, v. 22, p. 1-20, 1998.

SCHWECKE, T.; APARICIO, J. F.; MOLNÁR, I.; KÖNIG, A.; KHAW, L. E.; HAYDOCK, S. F.; OLIYNYK, M.; CAFFREY, P.; CORTÉS, J.; LESTER, J. B. The biosynthetic gene cluster for the polyketide immunosuppressant rapamycin. Proceedings of the National Academy of Sciences of the United States of America, v. 92, p. 7839-7843, 1995.

SHAROM, F. J. ABC multidrug transporters: structure, function and role in chemoresistance. Pharmacogenomics, v. 9, n. 1, p. 105-27, jan. 2008. Disponivel em: <http://www.ncbi.nlm.nih.gov/pubmed/18154452>.

SHELDON, P. J.; JOHNSON, D. A.; AUGUST, P. R.; LIU, H.; SHERMAN, D. H. Characterization of a Mitomycin-Binding Drug Resistance Mechanism from the Producing Organism , Streptomyces lavendulae. v. 179, n. 5, p. 1796-1804, 1997.

SLONCZEWSKI, J. L.; FOSTER, J. W. Microbiology: an evolving science. [s.I]: [s.c.p.], 2009. v. 1, 1280 p.

SPLITTGERBER, A. G.; TAPPEL, A. L. Inhibition of glutathione peroxidase by cadmium and other metal ions. Archives of Biochemistry and Biophysics, v. 197, n. 2, p. 534-542, 1979. Disponível em: $<$ http://www.ncbi.nlm.nih.gov/pubmed/507828>.

STAUNTON, J.; WEISSMAN, K. J. Polyketide biosynthesis: a millennium review. Natural Product Reports, v. 18, n. 4, p. 380-416, 2001. Disponível em: <http://xlink.rsc.org/?DOl=a909079g>.

STROHL, W. R.; CONNORS, N. C. Significance of anthraquinone formation resulting from the cloning of actinorhodin genes in heterologous streptomycetes. Molecular microbiology, v. 6, p. 147-152, 1992.

SUGIYAMA, M. Structural biological study of self-resistance determinants in 
antibiotic-producing actinomycetes. The Journal of Antibiotics, n. February, p. 1-8, $2015 . \quad$ Disponível em: <http://www.nature.com/doifinder/10.1038/ja.2015.32>.

SUGIYAMA, M.; NIMI, O. Streptomycin: Biosynthesis and Self-Resistance Mechanism in Streptomycin-Producing <1>Streptomyces griseus $</ \mid>$. Actinomycetologica, v. 4, n. 1, p. 15-22, 1990.

SULTANA, A. Mechanistic insights into the biosynthesis of polyketide antibiotics. 2006. Karolinska Institutet, 2006.

TORKKELL, S.; KUNNARI, T.; PALMU, K.; MÄNTSÄLÄ, P.; HAKALA, J.; YLIHONKO, K. The entire nogalamycin biosynthetic gene cluster of Streptomyces nogalater: Characterization of a 20-kb DNA region and generation of hybrid structures. Molecular Genetics and Genomics, v. 266, p. 276-288, 2001.

TRUGLIO, J. J.; CROTEAU, D. L.; VAN HOUTEN, B.; KISKER, C. Prokaryotic nucleotide excision repair: The UvrABC system. Chemical Reviews, v. 106, n. 2, p. 233-252, 2006.

VASANTHAKUMAR, A.; KATTUSAMY, K.; PRASAD, R. Regulation of daunorubicin biosynthesis in Streptomyces peucetius - feed forward and feedback transcriptional control. Journal of basic microbiology, p. 1-9, 2013. Disponível em: <http://www.ncbi.nlm.nih.gov/pubmed/23417448>.

WANG, J.; KODALI, S.; LEE, S. H.; GALGOCI, A.; PAINTER, R.; DORSO, K.; RACINE, F.; MOTYL, M.; HERNANDEZ, L.; TINNEY, E.; COLLETTI, S. L.; HERATH, K.; CUMMINGS, R.; SALAZAR, O.; GONZÁLEZ, I.; BASILIO, A.; VICENTE, F.; GENILLOUD, O.; PELAEZ, F.; JAYASURIYA, H.; YOUNG, K.; CULLY, D. F.; SINGH, S. B. Discovery of platencin, a dual FabF and FabH inhibitor with in vivo antibiotic properties. Proceedings of the National Academy of Sciences of the United States of America, v. 104, n. 18, p. 7612-7616, 2007.

WANG, J.; SOISSON, S. M.; YOUNG, K.; SHOOP, W.; KODALI, S.; GALGOCI, A.; PAINTER, R.; PARTHASARATHY, G.; TANG, Y. S.; CUMMINGS, R.; HA, S.; DORSO, K.; MOTYL, M.; JAYASURIYA, H.; ONDEYKA, J.; HERATH, K.; ZHANG, C.; HERNANDEZ, L.; ALLOCCO, J.; BASILIO, A.; TORMO, J. R.; GENILLOUD, O.; VICENTE, F.; PELAEZ, F.; COLWELL, L.; LEE, S. H.; MICHAEL, B.; FELCETTO, T.; GILL, C.; SILVER, L. L.; HERMES, J. D.; BARTIZAL, K.; BARRETT, J.; SCHMATZ, D.; BECKER, J. W.; CULLY, D.; $\mathrm{SINGH}, \mathrm{S}$. B. Platensimycin is a selective FabF inhibitor with potent antibiotic properties. Nature, v. 441, n. 7091, p. 358-361, 2006.

WANG, W.; LI, X.; WANG, J.; XIANG, S.; FENG, X.; YANG, K. An engineered strong promoter for streptomycetes. Applied and Environmental 
Microbiology, v. 79, n. 14, p. 4484-4492, 2013.

WEISS, R. B. The anthracyclines: will we ever find a better doxorubicin? Seminars in oncology, v. 19, p. 670-686, 1992.

WESTMAN, E. L.; CANOVA, M. J.; RADHI, I. J.; KOTEVA, K.; KIREEVA, I.; WAGLECHNER, N.; WRIGHT, G. D. Bacterial inactivation of the anticancer drug doxorubicin. Chemistry and Biology, v. 19, n. 10, p. 1255-1264, 2012. Disponível em: <http://dx.doi.org/10.1016/j.chembiol.2012.08.011>.

YLIHONKO, K.; HAKALA, J.; KUNNARI, T.; MÄNTSÄLÄ, P. Production of hybrid anthracycline antibiotics by heterologous expression of Streptomyces nogalater nogalamycin biosynthesis genes. Microbiology, v. 142 ( Pt 8, p. 1965-1972, 1996.

YOON, S. J.; PARK, J. E.; YANG, J.-H.; PARK, J.-W. OxyR regulon controls lipid peroxidation-mediated oxidative stress in Escherichia coli. Journal of biochemistry and molecular biology, v. 35, n. 3, p. 297-301, 2002.

YU, H.; LIU, J.; LIU, X.; ZANG, T.; LUO, G.; SHEN, J. Kinetic studies on the glutathione peroxidase activity of selenium-containing glutathione transferase. Comparative biochemistry and physiology. Part B, Biochemistry \& molecular biology, v. 141, n. 3, p. 382-389, 2005.

ZUNINO, F.; PRATESI, G.; PEREGO, P. Role of the sugar moiety in the pharmacological activity of anthracyclines: development of a novel series of disaccharide analogs. Biochemical pharmacology, v. 61, p. 933-938, 2001. 


\section{ANEXO}

A - Mapa físico das construções geradas a partir do plasmídeo PEM4A contendo os genes de resistência.

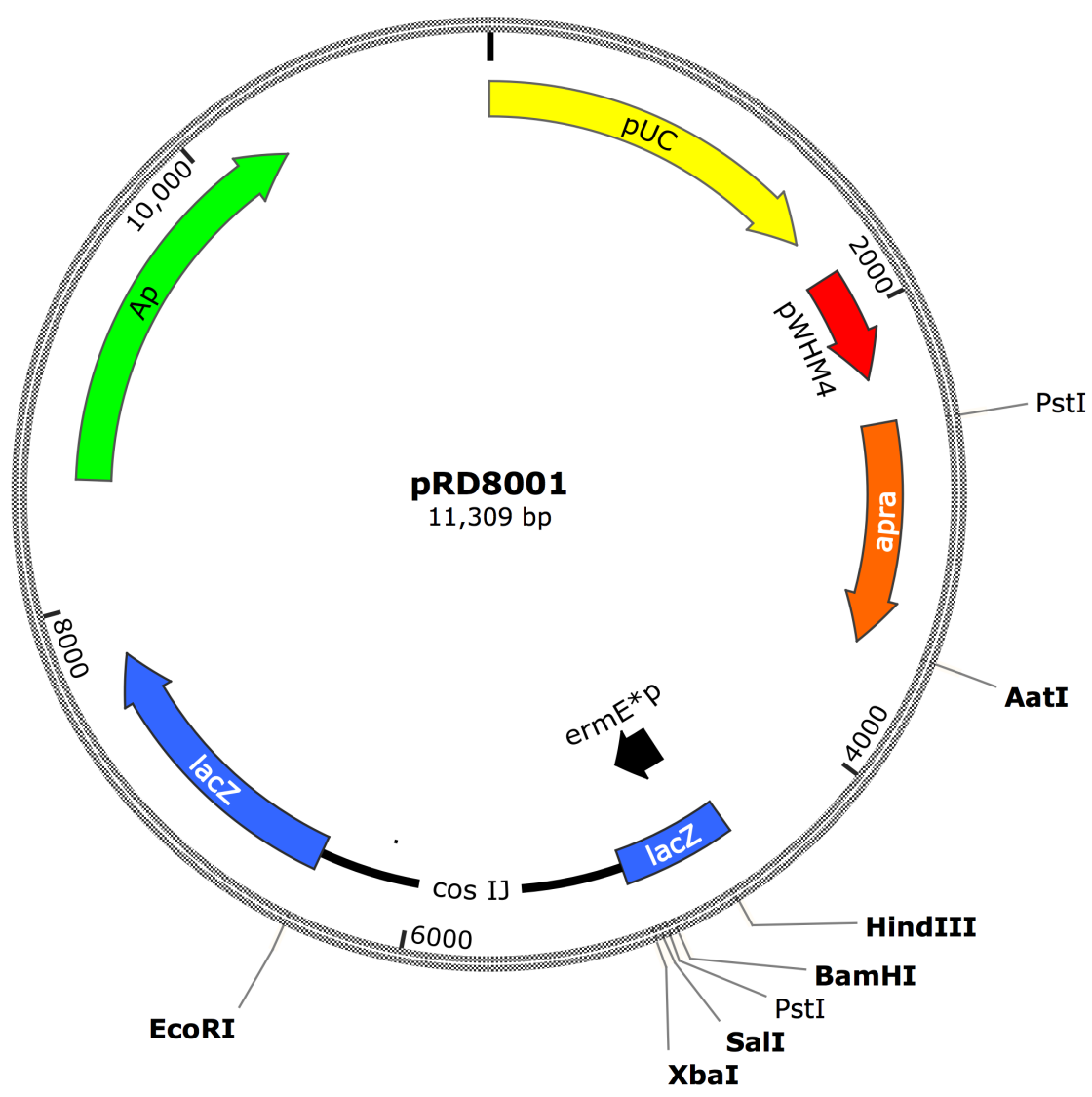




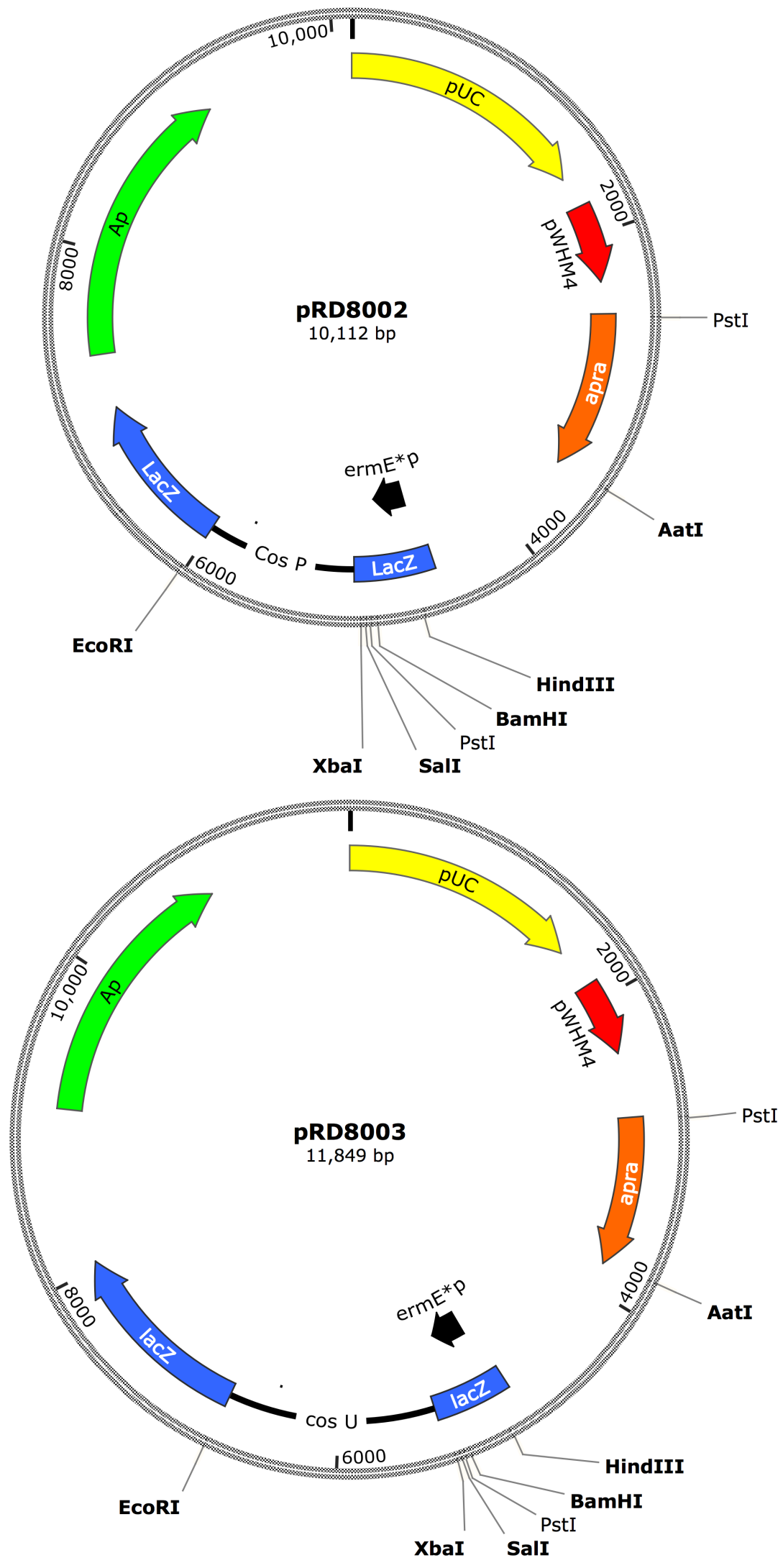




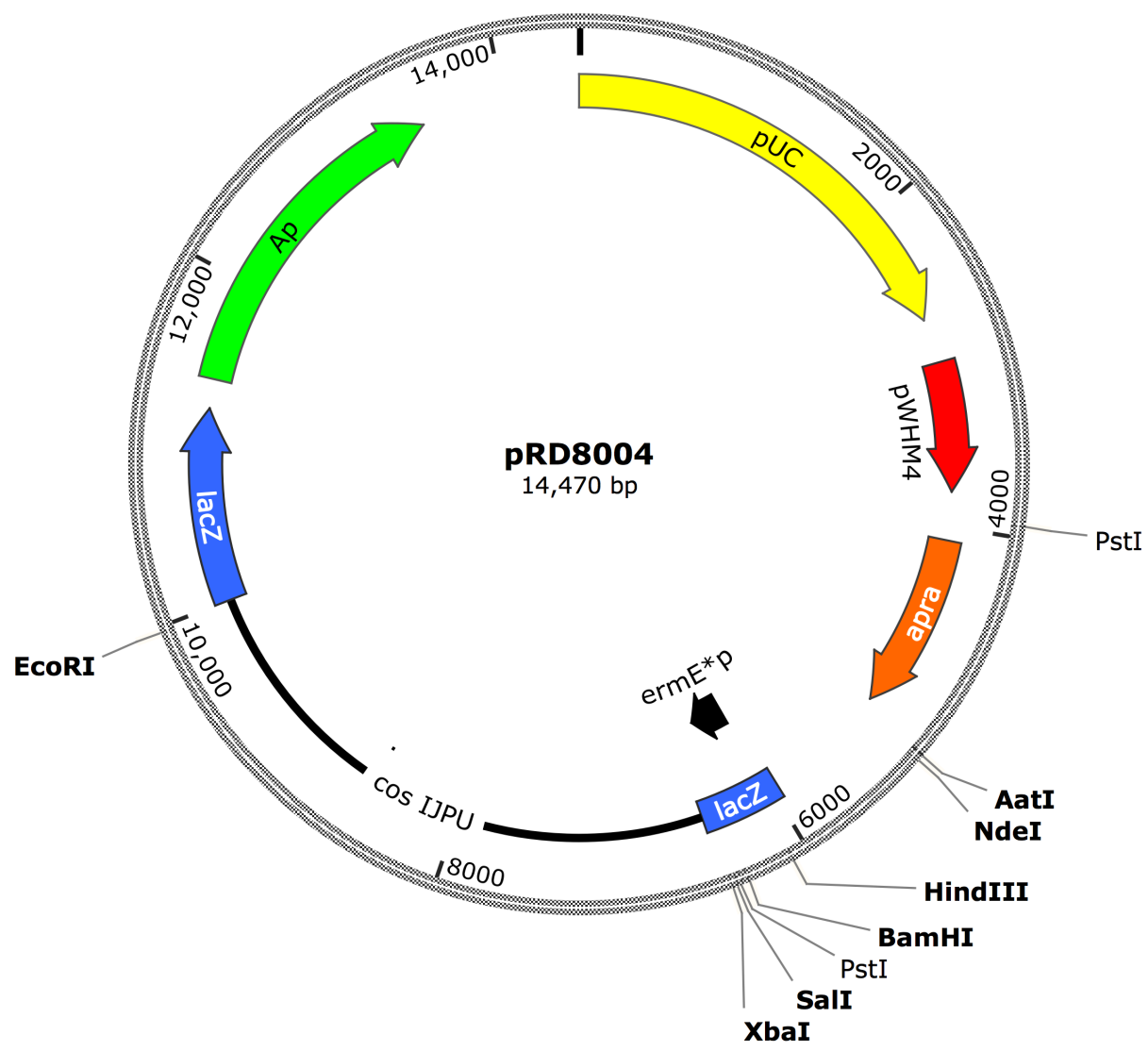

$\mathrm{Apr}^{R}$ (Resistência a apramicina). LacZ (gene repórter de $\beta$ Galactosidase e sitio múltiplo de clonagem contendo os genes cosl, cosJ, $\cos P$, cosU e seu conjunto coslJPU). ermE*p (promotor constitutivo). 